\title{
Encuestas de voluntad de pago para fijar precios de productos y servicios de salud reproductiva: Manual de usuarios
}

Karen G. Fleischman Foreit

James R. Foreit

Population Council

Follow this and additional works at: https://knowledgecommons.popcouncil.org/departments_sbsr-rh

Part of the International Public Health Commons, Obstetrics and Gynecology Commons, Public Health Education and Promotion Commons, Social and Behavioral Sciences Commons, and the Women's Health Commons

How does access to this work benefit you? Let us know!

\section{Recommended Citation}

Foreit, Karen G. Fleischman and James R. Foreit. 2004. "Encuestas de voluntad de pago para fijar precios de productos y servicios de salud reproductiva: Manual de usuarios," FRONTERAS Reporte. Washington, DC: Population Council. 


\title{
ENCUESTAS DE VOLUNTAD DE PAGO PARA FIJAR PRECIOS DE PRODUCTOS Y SERVICIOS DE SALUD REPRODUCTIVA
}

\author{
Manual para usuarios
}

Karen G. Fleischman Foreit

Proyecto POLICY

The Futures Group International

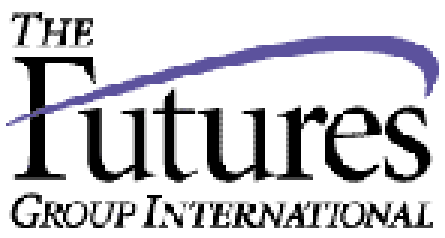

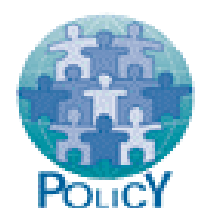

James R. Foreit

FRONTERAS

The Population Council

Population Council FRONTERAS

Esta publicación fue posible gracias al apoyo que proporcionó la AGENCIA DE LOS ESTADOS UNIDOS PARA EL DESARROLLO INTERNACIONAL (USAID) bajo los términos del Acuerdo de Cooperación No. HRN-A-00-98-0012-00, el Programa Fronteras de la Salud Reproductiva de The Population Council (FRONTERAS), y del Contrato No. HRN-C-00-00-00006-00, el Proyecto POLICY de The Futures Group International.

Edición corregida 2004.

(C) 2004 The Population Council. Todos los derechos reservados.

Título original: Willingness to Pay Surveys for Setting Prices for Reproductive Health Products and Services. A User's Manual 


\section{Contenidos}

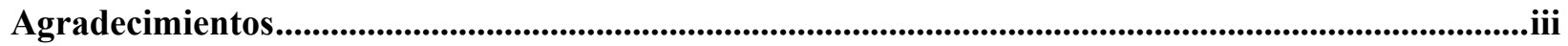

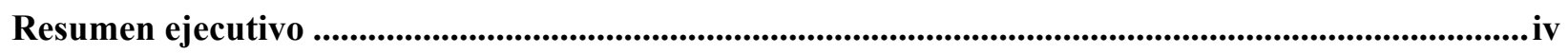

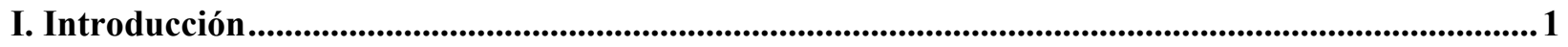

II. Encuestas de voluntad de pago: ¿qué son? .................................................................................................2

III. Encuestas de voluntad de pago: cómo hacerlas ..........................................................................................3

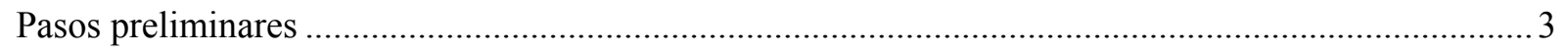

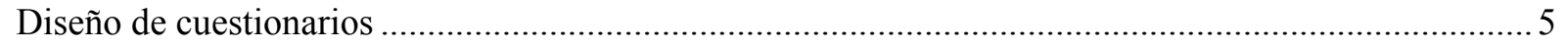

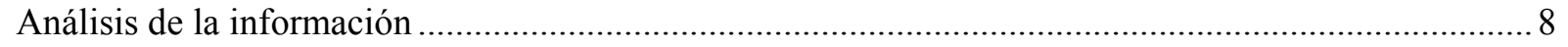

Estimación de la demanda para distintos niveles de precio ................................................................. 10

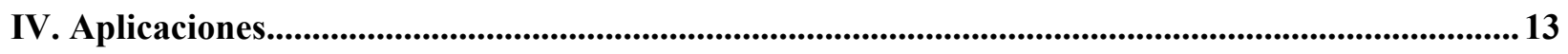

Mali: aumento de precios de los productos en existencia ................................................................ 14

Pakistán: fijar precios para nuevos productos.................................................................................. 19

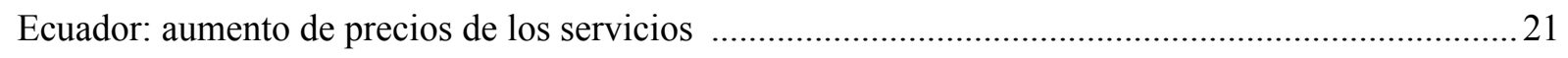

V. Prueba de validez predictiva ......................................................................................................................... 24

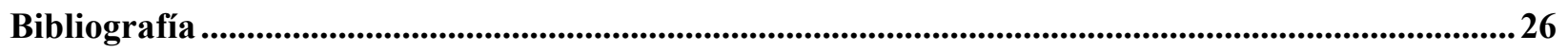

Apéndice I. Modelo de cuestionarios ......................................................................................................................A-1

Apéndice II. Modelo del manual del entrevistador y Modelo del manual de codificación...............A-20 


\section{Agradecimientos}

Los autores quisiéramos reconocer el trabajo de quienes colaboraron con nosotros. Dan Krees de $A b t$ Associates fue el primero que nos mostró la técnica de voluntad de pago (VDP) y dirigió las encuestas de VDP en Ghana y Pakistán. John Bratt de Family Health International tuvo un papel destacado en los estudios de VDP en Ecuador y Guatemala. Varuni Dayaratna de The Futures Group International, Caroline Blair del Population Reference Bureau, Carlos Brambila del Population Council y Bárbara Janowitz de Family Health International trabajaron juntos en los estudios de VDP en Ecuador, Guatemala, Mali, y Filipinas, respectivamente. Le damos un agradecimiento especial a William Winfrey, también de The Futures Group International, por sus consejos durante las encuestas y la elaboración de los borradores de este documento. Las encuestas descritas en este documento se llevaron a cabo gracias al financiamiento de la Oficina de Población, Salud y Nutrición de la Agencia de los Estados Unidos para el Desarrollo Internacional (USAID) recibido bajo distintos contratos y convenios de USAID/Accra y de USAID/Bamako, con excepción de la de Pakistán, que fue financiada por un contrato de DfID con The Futures Group International. Este manual se desarrolló como parte del Programa Fronteras de la Salud Reproductiva (FRONTERAS) y del Proyecto POLICY de The Futures Group International, ambos financiados por USAID. 


\section{Resumen ejecutivo}

Los programas sociales necesitan equilibrar volumen (cobertura) e ingreso (sostenimiento). La ley de la demanda establece que no podemos obtener cobertura y sostenimiento al mismo tiempo, pues al subir los precios, baja la demanda. La pérdida de clientela con el ascenso de precios es inevitable, excepto en los casos en que el precio inicial es tan bajo o la demanda tan alta, que ésta no es sensible a los cambios de precio. Las encuestas de voluntad de pago (VDP) permiten a los administradores de programas simular cambios en la demanda relacionados con el precio, sin cambiar los precios en realidad. Esto les permite tomar decisiones que se basan en información empírica para fijar los precios. Los beneficios de las encuestas de VDP son los siguientes:

- La metodología de las encuestas es sencilla y no obstaculiza la prestación de los servicios, además de que cualquier unidad de investigación puede aplicar las técnicas de estimación directa.

- Las técnicas de VDP pueden utilizarse tanto para productos y servicios que ya existen como para nuevos bienes que aún no están disponibles en el mercado. Dependiendo del contexto del programa y de las decisiones que deban tomarse, la encuesta puede utilizar muestras de la población general o de los usuarios en las unidades y centros donde se brindan los servicios.

- Incluso los clientes sin educación formal pueden responder preguntas hipotéticas acerca de los precios, y sus respuestas por lo general tienen consistencia interna.

- Las estimaciones de las encuestas de VDP son sensibles a las características de los clientes como, por ejemplo, su motivación para usar el producto o servicio, o su condición socioeconómica (CSE).

- Las estimaciones de las encuestas de VDP son conservadoras. Es decir, subestiman el precio máximo que los clientes están dispuestos a pagar y así evitan que los administradores de programas suban excesivamente los precios.

- La información que proporcionan las encuestas de VDP permite predecir con mayor precisión las reacciones frente a los cambios de precios. Aunque las estimaciones no proporcionan predicciones perfectas, los errores no parecen estar relacionados sistemáticamente con las características del programa, tales como el precio inicial o el volumen de los servicios.

Sin embargo, dicho esto, es importante hacer dos advertencias:

1. El rango hipotético de precios debe determinarse en colaboración con la administración de los programas antes de aplicar una encuesta de VDP a gran escala. Los precios objetivo deben basarse en información relevante para el programa como, por ejemplo, los costos del programa para brindar el servicio o producto, las necesidades de ingresos adicionales para enfrentar mayores costos o para subsidiar otras actividades, los precios que ofrecen los competidores por los mismos servicios, etcétera.

2. Es necesario profundizar en el desarrollo de investigaciones para poder validar los resultados de las decisiones que se toman basándose en las encuestas de VDP. Como mínimo, los administradores de programas deberán monitorear la demanda de servicios antes, durante y después de los cambios de precio. Además, se requiere seguir realizando experimentos de campo para valorar la precisión y sensibilidad de las estimaciones de las encuestas sobre los cambios en el uso de los servicios. 


\section{Introducción}

Los administradores de programas sociales enfrentan un dilema al tomar decisiones para fijar precios: equilibrar la necesidad de que un programa sea sostenible con la meta social de crear servicios accesibles para los clientes de bajos ingresos. Subir demasiado los precios impide que los clientes pobres tengan acceso a los servicios. Sin embargo, si los precios se mantienen en un nivel innecesariamente bajo, se perpetúa la dependencia de donantes externos. Hasta hace poco, los administradores se habían visto obligados a tomar decisiones para fijar precios sin contar con una metodología confiable que les permitiera predecir el efecto de los cambios de precio, tanto en el uso de los servicios como en los ingresos del programa. Este documento describe una sencilla técnica de encuesta que permite estimar la voluntad de pago (VDP), es decir, el precio que los clientes están dispuestos a pagar por bienes y servicios, permitiendo así a los administradores tomar decisiones racionales parar fijar precios.

Fijar precios es una decisión clave para cualquier programa proveedor de bienes o servicios. Mientras que los directores comerciales buscan maximizar las ganancias, aumentar su participación en el mercado o desalentar la competencia, los administradores de organizaciones públicas o sin fines de lucro buscan mantenerse al alcance de los medios del comprador, ser sostenibles y tener cobertura. El desafío para los programas sociales es fijar precios suficientemente bajos para que estén al alcance de la clientela objetivo y, al mismo tiempo, lo suficientemente altos para no afectar las marcas y servicios que son autosuficientes y plenamente comerciales. El rango potencial de precios puede ser bastante amplio y, por lo general, no existe un precio óptimo que un programa deba cobrar.

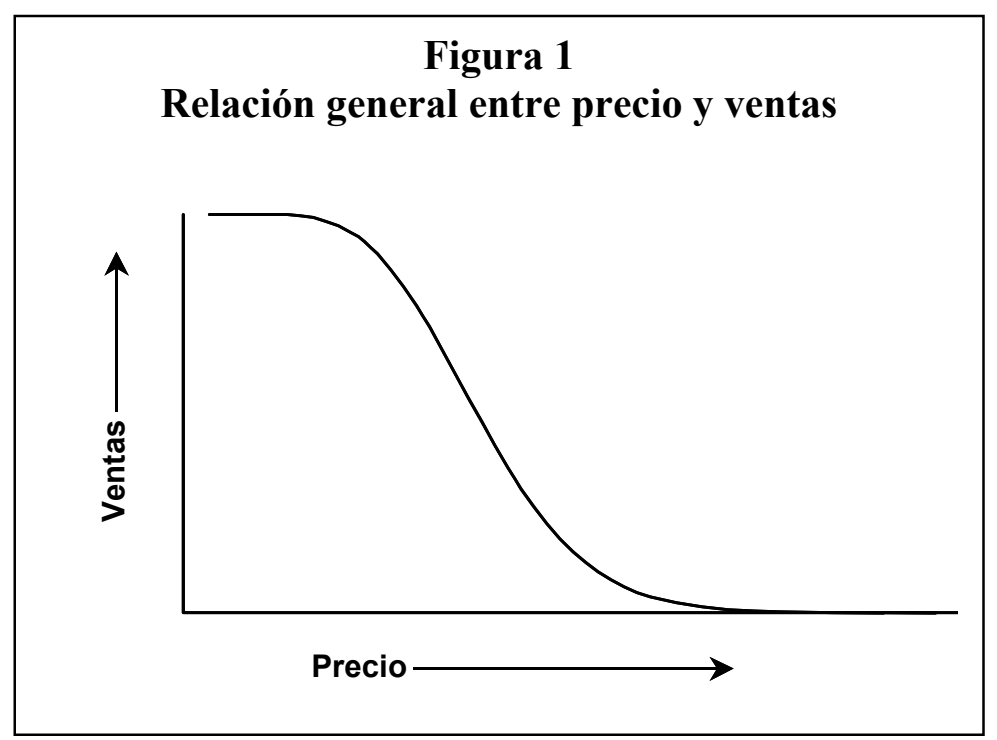

La "ley de la demanda" establece que la demanda es inversamente proporcional al precio. Al subir los precios, las ventas o el uso bajan, y al bajar los precios, las ventas aumentan. Esta relación, sin embargo, puede desvanecerse en los extremos. Un precio mínimo puede reducirse aún más sin por ello representar mayores ventas ${ }^{1}$. De manera similar, los precios pueden llegar a ser tan altos que un aumento mayor no reduzca las ventas. Por lo tanto, podemos esperar que la relación entre el precio y las ventas de un producto o servicio se asemeje a la "curva de demanda" presentada en la Figura $1^{2}$.

\footnotetext{
${ }^{1}$ Olivier (1994) descubrió que reducir a cero el precio de los espermicidas en las instalaciones del Ministerio de Salud de Ghana incrementaba la probabilidad de usar un método anticonceptivo moderno en sólo 5 por ciento, quizá debido a que para empezar los precios ya eran demasiado bajos. Otros investigadores reportaron resultados similares en Tailandia (Akin y Schwarz, 1988), Indonesia (Jensen et al., 1993) y Ecuador (Bratt et al., 1998; León y Cuesta, 1993).

${ }^{2}$ Tradicionalmente, los economistas sitúan el precio en el eje vertical (Y). En este documento situamos las ventas en el eje Y, para respetar la tradición de los científicos del comportamiento de colocar la variable dependiente en este eje. Las ventas son la variable dependiente en la ley de la demanda porque la variable se considera determinada o influenciada por el precio.
} 
La forma de la curva de la demanda para un producto o servicio en particular dependerá de muchos factores, como son los métodos, marcas y fuentes de oferta alternativas, así como los ingresos del cliente y su motivación para usar el producto o servicio. Si existen muchas opciones que compiten en el mercado y los ingresos de los clientes son bajos, las ventas o el uso podrían bajar rápidamente si los precios suben. Por otro lado, si hay pocas alternativas y la motivación de los clientes para usar el producto o servicio es alta, las ventas o el uso se verán menos afectados por los cambios de precio.

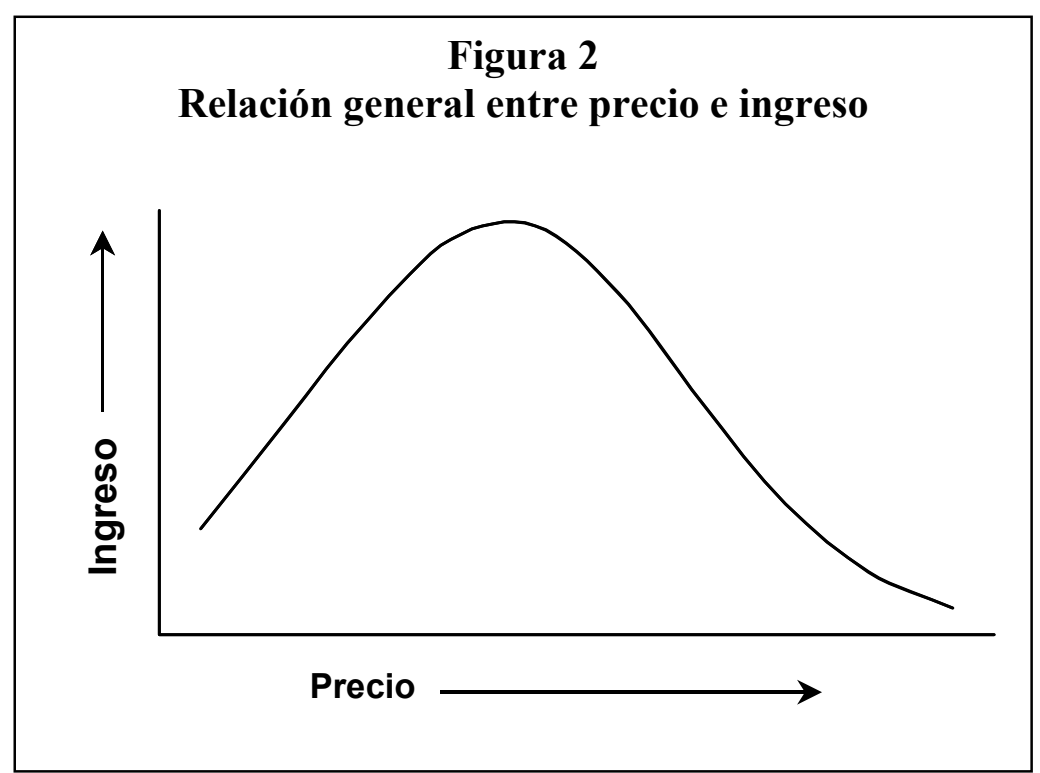

Las expectativas de los ingresos se calculan multiplicando el número esperado de ventas por el precio unitario. Dependiendo de la forma de la curva de la demanda, dentro de ciertos rangos de precio, el descenso de las ventas estará más que compensado por el ingreso adicional que se obtendrá al subir los precios. En otros rangos, pequeños aumentos supondrán un descenso relativamente grande de las ventas, lo cual significará menores ingresos.

Conocer la forma y la altitud de la curva de ingresos permite a los administradores estimar los costos que recuperarán en distintos niveles de precio (Figura 2) ${ }^{3}$.

Muchos programas tienen metas tanto de sostenimiento como de acceso. Poder predecir la respuesta de la clientela a los cambios de precios ayuda a los administradores a estimar el impacto de un aumento tanto sobre los ingresos como sobre el uso de un producto o servicio.

¿Cómo podemos saber cómo será el comportamiento de los consumidores ante distintos precios? Empíricamente, podríamos subir los precios y medir las ventas, continuando el incremento de precios hasta que la demanda caiga a niveles inaceptables o los ingresos comiencen a descender, y luego volver a un precio más bajo. Obviamente, la mayoría de los administradores de programas estaría renuente a experimentar de esta manera con sus clientes e ingresos. Un acercamiento alternativo consiste en preguntar a los clientes activos o potenciales de un producto o servicio cuánto estarían dispuestos a pagar por él ${ }^{4}$.

\section{Encuestas de voluntad de pago: ¿qué son?}

Las encuestas de VDP miden la demanda potencial de productos o servicios preguntando a los consumidores: “¿Compraría usted este producto si se ofreciera a este precio?”. Se utilizan con frecuencia en programas sociales, ambientales y de salud, para fijar precios y hacer análisis de costo-beneficio. Cuando se llevan a cabo algunos análisis sencillos, la información de las encuestas de VDP permite que

\footnotetext{
${ }^{3}$ El ingreso es sólo una parte de la ecuación que determina el sostenimiento. Los costos del programa pueden no mostrar una correspondencia de uno-a-uno con las ventas, por tanto, las ganancias (o pérdidas) netas no necesariamente son reflejo exacto de los ingresos.

${ }^{4}$ Este acercamiento a la VDP también se conoce como "valuación contingente".
} 
los administradores de programas estimen la cantidad de clientes que pagarán un determinado precio, la cantidad de ingreso que se generará a ese precio y, si se incluyen las preguntas adecuadas en el cuestionario, las características de los individuos que pagarán o no ese precio. Cuando se llevan a cabo análisis más complejos, los datos también se pueden usar para estimar el precio de un producto o servicio con el que se obtendrán los máximos ingresos. La encuesta básica de VDP puede llevarse a cabo con rapidez y requiere muestras relativamente pequeñas.

\section{Encuestas de voluntad de pago: cómo hacerlas}

\section{Pasos preliminares}

Las encuestas de voluntad de pago ayudan a responder la pregunta: “¿Cuánto podemos cobrar?”. Pero antes de intentar responder esta pregunta con una encuesta de VDP, debemos obtener la respuesta para: “¿Cuánto deberíamos cobrar?”. Los precios que se ponen a prueba en una encuesta de VDP deben basarse en un objetivo programático. Este objetivo debe ser articulado claramente antes de diseñar la encuesta de voluntad de pago.

Adicionalmente, existen dos preguntas básicas para el administrador del programa: “¿A quién quiere servir?" y "¿Qué planea hacer con el ingreso que se genere al cobrar por los servicios o aumentar los precios?”. Estas preguntas sirven para orientar la investigación hacia la población objetivo y los fines financieros del programa.

Conozca su población objetivo. La mayoría de los proveedores de servicios intentan llegar a tipos específicos de clientes. Los programas sociales, como los de las secretarías o ministerios de salud y las organizaciones no gubernamentales $(\mathrm{ONG})$, con frecuencia definen su mercado objetivo en términos de ingreso, capacidad de pago o falta de acceso a proveedores comerciales. Ya que distintos grupos de clientes pueden reaccionar de manera distinta a los aumentos de precio, especificar cuál va a ser la población objetivo le permite al investigador incluir estas características en la encuesta y enfocar el análisis en los individuos de mayor importancia para el programa.

Conozca sus objetivos financieros. Los motivos más frecuentes para elevar los ingresos son: mantener bajo control los aumentos de costos determinados por la inflación, así como los incrementos en los costos de operación; aumentar la recuperación de costos para disminuir la dependencia de donantes externos (sostenimiento); o generar ingresos suficientes para expandir los servicios o subsidiar otras actividades. Todos estos motivos requieren que los administradores de los programas sepan cuáles son sus costos reales, lo cual implica llevar a cabo una investigación en sí misma. Si la determinación de un nuevo precio tiene como objetivo comprar anticonceptivos, el administrador necesita saber cuánto cuestan. Si el objetivo es generar un exceso de ingresos para subsidiar otro servicio, deben conocerse los costos de ambos servicios. Finalmente, si el objetivo es mejorar el sostenimiento general de la organización, entonces se deben conocer todos los costos del programa. Éstos incluyen los artículos y materiales que se utilizan durante la consulta o que son proporcionados a los clientes (también deben considerarse los precios al mayoreo de los insumos, el valor de los donativos, empaques, transporte, almacenamiento, etc.). Existen varias maneras de clasificar los costos de los programas, entre ellas los costos fijos (como los salarios y las rentas, que se mantienen al mismo nivel sin importar cuántos clientes son atendidos o el número de servicios que se proporcionan) y los costos variables (los cuales tienen que ver con los servicios particulares que se proporcionan y con los artículos y las provisiones utilizadas).

Seleccione un pequeño número de productos o servicios. Los programas de mercadeo generalmente están interesados en la VDP para un producto o servicio o un número pequeño de ellos. Los programas clínicos, 
sin embargo, a menudo están interesados en establecer o aumentar los precios para un número grande de productos o servicios. Aunque se pueda incluir un número relativamente elevado de servicios en una encuesta de VDP, generalmente es mejor enfocarse en no más de tres o cuatro servicios prioritarios. Aquellos servicios que representan un volumen pequeño y que contribuyen poco a los costos o a los ingresos del programa no deben ser incluidos, debido a la dificultad de obtener una muestra lo suficientemente grande como para poder tomar decisiones confiables.

Conozca los precios actuales. Los precios que se cobran en los centros de prestaciones de servicio pueden no ser los mismos que los establecidos por la oficina central de la organización. Los datos de los precios determinados en las oficinas centrales de la organización con frecuencia son incompletos o no están actualizados. Se debe llamar o visitar cada clínica que se incluirá en el estudio para obtener los precios actuales verdaderos para todos los servicios que se cubrirán en la encuesta. En aplicaciones de mercadeo social o comercial, el producto frecuentemente se ofrecerá a precios variables en diversos centros de prestación de servicios. La información confiable sobre el rango de los precios actuales del producto debe obtenerse antes de comenzar la encuesta.

Conozca el volumen actual y pasado de sus servicios. Es esencial contar con estadísticas o registros de ventas precisas para poder interpretar adecuadamente los resultados de las encuestas de VDP. La demanda para muchos productos de salud como, por ejemplo, las sales de rehidratación oral o los mosquiteros para cama, puede fluctuar dependiendo de la temporada del año, y el horario de atención de las clínicas puede interrumpirse durante ciertas festividades religiosas o civiles. Los aumentos de precio pueden tener distintos efectos en contextos nuevos donde la demanda de los clientes está creciendo, en contraste con lo que sucede en ambientes donde la demanda es constante o ha bajado.

Seleccione la estrategia de muestreo. El tipo de muestreo y el tamaño de la muestra que se utiliza en una encuesta de VDP dependerá de la naturaleza del producto o servicio que se estudia y de la precisión requerida para los resultados. La pregunta programática deberá determinar el diseño del estudio. Si el director de una clínica desea conocer el impacto de un aumento de precios sobre su clientela actual, el lugar apropiado para llevar a cabo las entrevistas será la misma clínica. Una encuesta para fijar los precios de productos que serán vendidos en farmacias se puede conducir mediante entrevistas a los clientes que salen de las farmacias (a este tipo de estudio se le conoce como encuestas de "intercepción en farmacias"). La introducción de nuevos servicios o productos o la investigación sobre la VDP entre individuos que no utilizan actualmente los servicios puede ser estudiada apropiadamente con base en muestras probabilísticas de la población en su conjunto o en áreas geográficas o de condición socioeconómica (CSE) específica.

En términos generales, la precisión de las estimaciones aumenta cuando el tamaño de la muestra es mayor, y cuando crece el número de productos, servicios y puntos de entrega que se incluyen en la encuesta, el tamaño de la muestra y los costos se incrementan. Por cuestiones de eficiencia, las encuestas realizadas en clínicas suelen consistir en entrevistas de salida a todos los clientes que obtienen servicios en una muestra de unidades durante un periodo fijo (que por lo general dura de dos a cuatro semanas, dependiendo del volumen de la clientela). Ésta es una opción viable si la clínica tiene un número de clientes relativamente grande; sin embargo, puede ser excesivamente caro obtener un número confiable de observaciones en puntos de entrega de servicios pequeños, como sucede en el caso de centros rurales o cuando las personas que brindan los servicios pertenecen a una pequeña comunidad, y donde normalmente se atiende a no más de uno o dos usuarios por día.

Seleccione una encuesta de VDP independiente o incluya un módulo de VDP en una encuesta más amplia. Se puede ahorrar dinero incluyendo las preguntas básicas de las encuestas de VDP en una encuesta con otros propósitos, por ejemplo, una sobre la satisfacción de los clientes a la salida de una clínica de salud reproductiva. Sin embargo, las oportunidades de colaboración frecuentemente están 
limitadas por las características de la muestra y por el momento en que se lleva a cabo la encuesta más amplia.

\section{Diseño de cuestionarios}

La Administración Nacional Oceánica y Atmosférica (National Oceanic and Atmospheric Administration) de Estados Unidos ha establecido un conjunto de reglas prácticas para superar los principales sesgos asociados con las encuestas de VDP 5 . Esta institución recomienda que las encuestas de VDP: 1) estén basadas en entrevistas personales; 2) usen preguntas cerradas que permitan determinar la VDP de los entrevistados ante un aumento específico en el costo de un servicio que les sea familiar; 3 ) recuerden a los entrevistados que el aumento de precio del servicio reducirá su capacidad de consumo de otros productos o servicios; 4) les recuerden que existen alternativas de sustitución para el servicio en cuestión, y 5) pregunten a los entrevistados acerca de aquellos factores que pueden influir en sus preferencias.

La mayoría de las organizaciones que realizan investigaciones exigen que las personas que serán entrevistadas otorguen su consentimiento informado antes de realizar la entrevista. El consentimiento informado es un proceso de comunicación entre el investigador y el participante potencial; también es un requisito legal en los Estados Unidos. El participante debe estar plenamente informado sobre el propósito del estudio, debe entender la información y debe tener la posibilidad de decidir de manera voluntaria si participará o no en él. El consentimiento informado tiene su origen en investigaciones médicas en las que existen riesgos y beneficios potenciales. Los elementos esenciales del consentimiento informado incluyen:

1. Propósito del estudio.

2. Riesgos para el participante, que incluyan riesgos físicos, sociales y emocionales.

3. Beneficios para el participante, que incluyan, si es necesario, una declaración de que no los hay.

4. Información sobre la confidencialidad, que incluya el uso de elementos identificadores y el acceso a la información personal.

5. Lugar a dónde acudir en caso de dudas o problemas en cualquier momento.

6. Información acerca del abandono del estudio. La persona que participa en el estudio tiene el derecho de dejar de hacerlo en cualquier momento sin ninguna penalización.

7. Garantía de que los servicios están disponibles para el/la participante potencial tanto si acepta participar en el estudio como si no lo hace o si se retira del mismo.

8. Información sobre los procedimientos y la duración del estudio.

Los formularios de consentimiento deben usar frases simples y afirmaciones directas, apropiadas al nivel de educación de las personas que serán entrevistadas. Quien participe en el estudio debe tener la oportunidad de hacer preguntas y haber recibido toda la información antes de firmar el formulario. En el Apéndice 1 se presenta un ejemplo de una declaración de consentimiento informado.

En la práctica, los entrevistados necesitan entender el contexto de las preguntas; es decir, comprender exactamente qué es lo que estarán comprando. Éste es un problema menor cuando a los usuarios activos se les pregunta sobre su disposición para pagar un precio más alto por un producto o servicio, o si a los

\footnotetext{
${ }^{5}$ Después de la fuga de petróleo del Exxon Valdez, el Departamento de Comercio de EU convocó a un panel de expertos para determinar si las estimaciones de pérdidas generadas a través del método de VDP eran lo suficientemente confiables para utilizarse en la medición de daños de un recurso natural. Véase Portnoy (1994) y Phillips et al. (1997). Los lineamientos descritos aquí buscan minimizar los sesgos en las respuestas en caso de que los entrevistados no entiendan las preguntas, no puedan responderlas, no contesten con la verdad o den respuestas para satisfacer al entrevistador, o si la respuesta está pensada "estratégicamente" para influenciar el resultado del estudio a su favor.
} 
no-usuarios se les pregunta sobre un producto o servicio que han utilizado en el pasado. Sin embargo, puede ser difícil preguntarle a los entrevistados sobre algo que nunca han utilizado, como, por ejemplo, un producto nuevo. Al examinar la VDP para nuevos productos, es mejor proporcionar al entrevistado una descripción completa del producto y enseñarle una muestra. Además, cuando se trate de un nousuario, hay que asegurarse primero de que tiene interés en utilizar el producto.

Por otro lado, la manera en que se formulan las preguntas sobre precios puede influir en las respuestas. Hacer a los entrevistados una pregunta directa, única y abierta como “¿Cuánto sería lo más que pagaría por este producto?" no produce respuestas confiables. En cambio, los investigadores coinciden en que es mejor plantear preguntas de precios explícitas y solicitar a los entrevistados que contesten si aceptarían pagar ese precio o no. La encuesta debe incluir suficientes preguntas como para cubrir el rango de precios de interés sin fatigar excesivamente a los entrevistados. Asimismo, el orden de las preguntas debe seleccionarse de tal manera que no induzca a los entrevistados a proporcionar respuestas que indiquen un precio máximo mayor o menor al que realmente quieren decir.

Las preguntas deben comenzar pidiendo a los entrevistados que respondan cuánto pagan actualmente por su método o servicio. A continuación, debe preguntárseles si seguirían comprando el producto o servicio si su precio aumentara en una cantidad determinada. A los entrevistados que contesten que de todos modos comprarían el producto o servicio se les debe preguntar si pagarían un precio aún más alto. A quienes respondan que no o que no están seguros, se les pregunta si pagarían un precio menor, aunque más alto del que pagan actualmente. Nótese que a todos los entrevistados se les hacen exactamente tres preguntas relacionadas con el precio: el precio actual $[\mathrm{P}(0)]$, un precio que representa un aumento mediano $[\mathrm{P}(2)] \mathrm{y}$, en función de su respuesta al aumento de precio mediano, un aumento de precio pequeño $[\mathrm{P}(1)]$ o un aumento de precio alto $[\mathrm{P}(3)]$. A ningún entrevistado se le pregunta sobre los cuatro precios, y los precios que se preguntan a cada uno de ellos varían según la diferencia en los precios que actualmente pagan.

La Figura 3 ilustra el orden de las preguntas que se aplican a los entrevistados que actualmente utilizan el producto o servicio. A los entrevistados que no son usuarios activos se les debe preguntar antes cuál es su interés en utilizar el servicio; se les debe hacer la pregunta 2 de la Figura 3 y plantearse como precios absolutos en lugar de aumentos de precio.

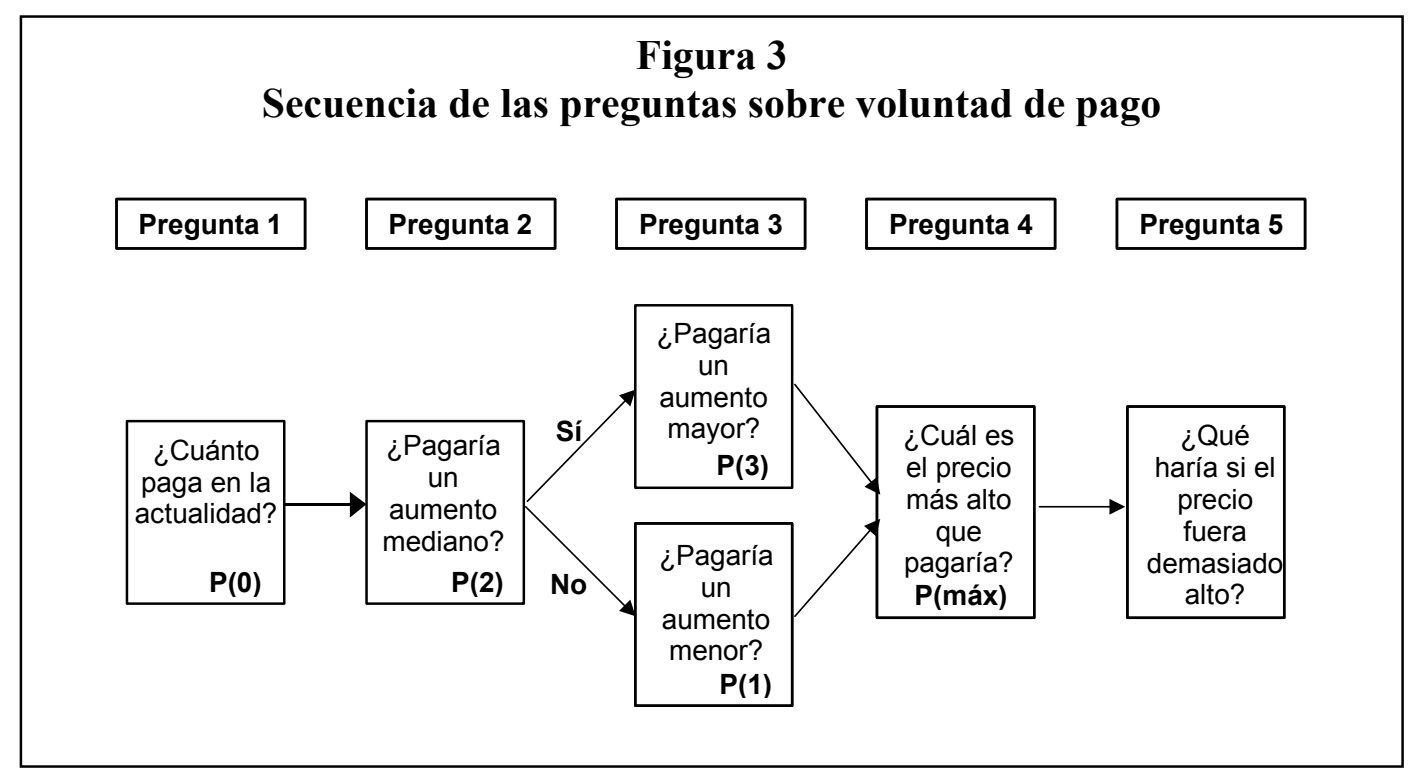


Al desarrollar el cuestionario, el investigador debe poner el precio objetivo ya sea en la pregunta que concierne al aumento de precio bajo o en la del aumento mediano, pero no en la del más alto. La experiencia sugiere que los usuarios y los usuarios potenciales en los países en vías de desarrollo con frecuencia tratan las preguntas sobre la VDP como si fuera una situación de regateo. Se ha observado que están más dispuestos a pagar un precio dado cuando se trata de un aumento bajo que cuando es un aumento mediano (el primer precio preguntado) o el aumento más alto.

Se recomienda ampliamente hacer dos preguntas adicionales relacionadas con el precio. La primera consiste en preguntarle a todos los entrevistados el precio máximo que estarían dispuestos a pagar, independientemente de la respuesta que hayan dado a la pregunta 3. Esto amplía el rango de precios para el servicio o producto en cuestión en el caso de los entrevistados que responden sí al precio más alto preguntado. Por otra parte, en el caso de aquellos que responden no al precio final preguntado, es posible distinguir mejor entre el precio más alto que están dispuestos a pagar y el menor de los precios que no están dispuestos a pagar. La información correspondiente a la pregunta sobre el precio máximo también se puede utilizar para verificar la consistencia interna de las respuestas (idealmente, el número de entrevistados que establece una VDP máxima inferior al precio que pagan actualmente o al aumento de precio aceptado en las preguntas cerradas debería de ser muy pequeño). Por último, se puede preguntar a los entrevistados qué harían si los precios aumentaran más allá del límite que están dispuestos a pagar. Esta pregunta puede ayudar a un programa privado a establecer su nicho de mercado o al director de un programa público que quiera calcular la necesidad de contar con redes de seguridad social.

En las encuestas de VDP siempre deben incluirse preguntas acerca de las características de los clientes. Éstas identifican el perfil de los clientes que pagarán un precio dado y el de aquellos que no lo harán, y con frecuencia se utilizan para establecer la condición económica, el ingreso o la capacidad de pago de los entrevistados. Los indicadores de condición económica más comúnmente utilizados son la educación, el ingreso familiar, la posesión de bienes duraderos, los gastos recientes en otros servicios y productos de salud, y los gastos en artículos no esenciales, como salones de belleza. Las preguntas específicas que será necesario incluir dependerán del país donde se lleva a cabo el estudio. Las Encuestas Demográficas y de Salud son una buena fuente para obtener preguntas sobre educación y sobre la disponibilidad de bienes duraderos. En los cuestionarios modelo para clínicas de servicios también se proporcionan algunos ejemplos (véase el Apéndice I). La educación, el ingreso y la posesión de bienes duraderos son factores que están estrechamente relacionados. Por esta razón, es posible que el investigador desee utilizar únicamente una pregunta (por ejemplo, aquella concerniente a la educación) cuando el tiempo de entrevista deba ser muy corto o en contextos donde las preguntas sobre el ingreso son muy sensibles.

Al entrevistar a usuarios potenciales, también deben agregarse preguntas adicionales que sirvan para conocer su interés o su motivación para usar un producto o servicio. Es poco probable que la información obtenida sobre la VDP de los entrevistados que no tienen intención de comprar el producto o servicio en cuestión sea de utilidad. Por lo tanto, se puede pedir a los entrevistados que califiquen su interés por dicho servicio. Por ejemplo, se les podría preguntar: "¿Le interesa mucho, poco o nada ser esterilizado en los próximos dos años?", o pedirles que contesten sí o no a una pregunta donde se les plantee si están interesados en utilizar un método anticonceptivo o algún otro servicio de salud reproductiva. El investigador probablemente querrá excluir del análisis de VDP a las personas con baja o nula motivación para usar los productos o servicios.

La técnica de las encuestas de VDP recién descrita supone que el único factor que varía es el precio y que los demás factores permanecen constantes. Los investigadores y los administradores quizá quieran saber también si los clientes estarían dispuestos a pagar más si algunos aspectos del servicio mejoraran como, por ejemplo, si se redujeran los tiempos de espera o se instalarán sillas más cómodas, y conocer qué factores podrían derivar en una mayor VDP. La técnica de investigación preferida en esta situación es el análisis conjunto, en el cual se les pide a los entrevistados que escojan entre pares específicos de 
combinaciones de precios y atributos del servicio. Por ejemplo: “¿Preferiría pagar $\$ 5.00$ por su consulta de revisión del DIU, sentarse en sillas de plástico duras y esperar una hora, o pagar $\$ 15.00$, sentarse en una silla tapizada y esperar sólo 10 minutos?”. El número de preguntas que se hagan dependerá del número de precios y de atributos del servicios investigados, pero debe tenerse en cuenta que la evaluación de dos precios y dos atributos requiere de un mínimo de ocho preguntas.

\section{Análisis de la información}

\section{Método de estimación directa para calcular la curva de demanda}

La información tanto de los usuarios activos como de los usuarios potenciales se analiza de la misma manera. Para calcular la curva de demanda, es necesario hacer los siguientes supuestos:

- Los clientes están dispuestos a pagar al menos el precio que pagan actualmente por el producto o servicio.

- El precio máximo para un individuo es el precio más alto que explícitamente ha consentido. Si un entrevistado responde no a $\$ 40$ y si a $\$ 20$, el precio máximo sería \$20.

- La voluntad de pago es transitiva en orden descendente: los clientes que están dispuestos a pagar un precio dado por un producto o servicio también están dispuestos a pagar un precio más bajo por ese producto o servicio.

- La falta de voluntad de pago es transitiva en orden ascendente: los clientes que no están dispuestos a pagar un precio dado por un producto o servicio tampoco están dispuestos a pagar un precio más alto.

Una vez que estos supuestos han sido considerados, se deben seguir los siguientes pasos:

1. Establecer el precio máximo que cada entrevistado está dispuesto a pagar ${ }^{6}$. Si a los entrevistados se les pregunta sobre aumentos de precio, el precio máximo se calcula sumando el aumento más alto que están dispuestos a aceptar más el precio que pagan actualmente. Si a los entrevistados se les pregunta sobre precios absolutos, el precio máximo que se establece es el que mencionan que estarían dispuestos a pagar.

2. Eliminar los casos en que no hay respuesta, así como las respuestas internamente inconsistentes. También deberán eliminarse del análisis a los entrevistados que respondan no sé a todas las preguntas. Sin embargo, un entrevistado que contesta no sé a las preguntas predeterminadas sobre precios pero que proporciona el precio máximo que estaría dispuesto a pagar debe ser incorporado al análisis, al igual que aquellos que responden sí o no a las preguntas de precios pero que no pueden establecer el precio más alto a pagar. En este último caso, el precio máximo será estimado como el precio más alto aceptado o, si no se aceptó ninguno de los aumentos, como el precio actual.

Todas las respuestas sobre el precio máximo que los entrevistados están dispuestos a pagar se deben examinar para ver si son consistentes internamente. El precio máximo deberá ser igual o mayor que el precio más alto aceptado. Se debe eliminar del análisis a los entrevistados que mencionan un precio máximo menor que el precio más alto aceptado en el sondeo o que es inferior al que pagan actualmente.

\footnotetext{
${ }^{6}$ Esta sección asume que todas las entrevistas terminan con la pregunta abierta “¿Cuál es el [aumento de] precio más alto que pagaría?" (pregunta 4 de la Figura 3). Si la pregunta abierta no es respondida por todos los entrevistados, el análisis se vuelve más complicado y se requerirá eliminar a algunos de los entrevistados del análisis a niveles de precios más altos.
} 
Se debe analizar la proporción de entrevistados eliminados porque no proporcionaron respuestas o porque éstas fueron inconsistentes. Si esta proporción es tan grande como para alterar sustancialmente los resultados, la utilidad de la encuesta será cuestionable, y se deberán investigar los motivos por los cuales los entrevistados tuvieron dificultades para responder el cuestionario.

3. Obtener una distribución de frecuencias del precio máximo que los entrevistados están dispuestos a pagar.

4. Establecer la variación en los aumentos de precio, los cuales serán presentados a lo largo del eje X de la curva de demanda, como lo muestra la Figura 1. Graficar el porcentaje de demanda para cada uno de los aumentos de precio, utilizando el complemento de la frecuencia acumulativa de la distribución de frecuencias y las reglas de transitividad descritas anteriormente. Se calcula también el porcentaje de entrevistados que acepta el precio $x$ (100 menos el porcentaje de quienes aceptan un precio máximo menor que $x$ ). El Cuadro 1 ilustra el cálculo correspondiente.

\begin{tabular}{|c|c|c|c|c|c|c|}
\hline \multicolumn{7}{|c|}{ Cuadro 1} \\
\hline \multicolumn{7}{|c|}{ Distribución de frecuencia de máxima voluntad de pago } \\
\hline Q20 & \multicolumn{6}{|c|}{ Precio máximo } \\
\hline \multirow[t]{29}{*}{ Clasificación } & & Valor & Frecuencia & Porcentaje & $\begin{array}{r}\text { Porcentaje } \\
\text { válido }\end{array}$ & $\begin{array}{l}\text { Porcentaje } \\
\text { acumulativo }\end{array}$ \\
\hline & & .00 & 1 & .0 & .2 & .2 \\
\hline & & 100.00 & 52 & 1.9 & 10.3 & 10.5 \\
\hline & & 125.00 & 3 & .1 & .6 & 11.1 \\
\hline & & 150.00 & 27 & 1.0 & 5.4 & 16.5 \\
\hline & & 175.00 & 1 & .0 & .2 & 16.7 \\
\hline & & 200.00 & 40 & 1.4 & 7.9 & 24.6 \\
\hline & & 250.00 & 82 & 2.9 & 16.3 & 40.9 \\
\hline & & 300.00 & 64 & 2.3 & 12.7 & 53.6 \\
\hline & & 350.00 & 4 & .1 & .8 & 54.4 \\
\hline & & 375.00 & 1 & .0 & .2 & 54.6 \\
\hline & & 400.00 & 28 & 1.0 & 5.6 & 60.1 \\
\hline & & 500.00 & 77 & 2.8 & 15.3 & 75.4 \\
\hline & & 600.00 & 15 & .5 & 3.0 & 78.4 \\
\hline & & 700.00 & 7 & .3 & 1.4 & 79.8 \\
\hline & & 750.00 & 22 & .8 & 4.4 & 84.1 \\
\hline & & 800.00 & 2 & .1 & .4 & 84.5 \\
\hline & & 900.00 & 1 & .0 & .2 & 84.7 \\
\hline & & 950.00 & 1 & .0 & .2 & 84.9 \\
\hline & & 1000.00 & 46 & 1.7 & 9.1 & 94.0 \\
\hline & & 1250.00 & 2 & .1 & .4 & 94.4 \\
\hline & & 1300.00 & 1 & .0 & .2 & 94.6 \\
\hline & & 1500.00 & 13 & .5 & 2.6 & 97.2 \\
\hline & & 1550.00 & 1 & .0 & .2 & 97.4 \\
\hline & & 2000.00 & 7 & .3 & 1.4 & 98.8 \\
\hline & & 2500.00 & 1 & .0 & .2 & 99.0 \\
\hline & & 5000.00 & 5 & .2 & 1.0 & 100.0 \\
\hline & & & 2276 & 81.9 & Falta & \\
\hline & & Total & 2780 & 100.0 & 100.0 & \\
\hline Casos válidos & 504 & Casos faltantes & 2276 & & & \\
\hline
\end{tabular}


Supóngase que deseamos graficar la curva de demanda para incrementos de precios de 50 francos a partir de un valor inicial de 50 francos. Un entrevistado (porcentaje acumulado de 0.2 ) señaló un precio máximo de cero; por lo tanto, el porcentaje de entrevistados que está dispuesto a pagar 50 francos es de 100 $0.2=99.8$ por ciento. Puesto que nadie dio un precio máximo entre 0 y 100 francos, el porcentaje dispuesto a pagar 100 francos también es de 99.8 por ciento. Cincuenta y dos entrevistados declararon 100 francos y tres indicaron que 125 francos sería el precio máximo que pagarían; por lo tanto, el porcentaje dispuesto a pagar 150 francos es 100-11.1=88.9. El porcentaje dispuesto a pagar 200 francos es el complemento del porcentaje acumulado que dio un precio más bajo (175 francos): 100-16.7=83.3, y así sucesivamente.

De manera similar, se puede hacer el análisis de la demanda de acuerdo con la condición socioeconómica (CSE) de los entrevistados. Las curvas de demanda resultantes pueden ser comparadas para determinar el impacto de distintos precios sobre el perfil de los clientes activos o de los potenciales.

El procedimiento de análisis directo recién esquematizado tiende a subestimar la VDP máxima porque está basado en un número limitado de sondeos de precio, y muchos entrevistados pueden simplemente repetir el sondeo aceptado más alto como si fuera el precio máximo que estarían dispuestos a pagar. Los economistas de la salud que llevan a cabo análisis de costo-beneficio con frecuencia necesitan estimaciones más finas que las obtenidas a partir del valor máximo de la VDP ${ }^{7} .7$ Por esta razón, tienden a utilizar frecuentemente modelos de regresión múltiple en lugar de recurrir a las estimaciones directas. Sin embargo, la mayoría de los programas sociales no están interesados ni en aumentar los ingresos al máximo ni en realizar análisis de costo-beneficio. Si el administrador del programa ha determinado ya el precio objetivo y lo ha incluido como el sondeo de precio bajo, los procedimientos sugeridos proporcionarán estimaciones conservadoras de la VDP para los precios en el rango objetivo.

Con frecuencia, un programa tendrá distintos precios para el mismo servicio en distintos lugares.

Dependiendo de las necesidades del administrador, las respuestas de los distintos sitios de servicio se pueden analizar de forma agregada para calcular una sola curva de demanda (primero se calcula el precio máximo de la VDP sumando el incremento de precio más alto aceptado o mencionado al precio actual) o se pueden calcular curvas de demanda separadas para cada sitio o grupo de sitios con un precio común.

\section{Estimación de la demanda para distintos niveles de precio}

El análisis de la VDP descrito en la sección anterior establece la demanda relativa a distintos precios (por ejemplo, el porcentaje de entrevistados que pagarían cada precio por un bien o servicio determinado). La estimación de la demanda absoluta; es decir, cuántos clientes en el programa pagarían un precio dado, requiere de una fuente de información adicional e independiente. Para las ventas o para la clientela existente, esa fuente de datos estaría dada por el volumen actual de la variable correspondiente (el cual debería ser corregido para eliminar las variaciones estacionales o derivadas de las tendencias recientes de estas variables).

De acuerdo con la "ley de la demanda", se puede suponer que el volumen de clientes bajará si los precios aumentan. Mediante la combinación de la información de la curva de demanda agregada y las estadísticas de servicio podemos estimar el volumen de clientes que se tendrían para precios más altos del producto o servicio. Para realizar esta estimación se debe seguir el siguiente procedimiento:

\footnotetext{
${ }^{7}$ A menudo se utiliza la VDP en economía de la salud para asignar un valor monetario al beneficio en salud que un cliente recibe de un bien o servicio. El valor monetario puede definirse como el precio máximo que el cliente está dispuesto a pagar.
} 
1. Estimar la demanda agregada para el precio actual y para el precio propuesto. Si todos los entrevistados están pagando actualmente el mismo precio, la demanda del precio actual es del 100 por ciento. Sin embargo, si se cobran diferentes precios en distintos sitios, la demanda agregada para el precio actual de un servicio en un centro costoso será menor que el 100 por ciento.

2. Calcular el cociente que resulta de dividir la demanda agregada con el nuevo precio entre la demanda agregada con el precio actual. El complemento de la proporción de demanda que resulta (100 menos el valor del cociente obtenido) representa la disminución porcentual en la demanda que se podría esperar si los precios se elevaran a ese nuevo nivel.

3. Multiplicar el cociente de demanda obtenida en el paso anterior por el volumen de servicio actual. El producto de la proporción de demanda por el volumen de servicio actual representa la estimación del volumen de servicios que se podría esperar si los precios fueran incrementados al nuevo nivel de precios propuesto.

4. Multiplicar el precio actual por el volumen de servicio actual. Si todos los clientes pagan este precio, la cifra obtenida corresponderá al ingreso generado en la actualidad. Multiplicar el volumen de servicios estimado en el tercer paso por el nuevo precio propuesto; si todos los clientes pagaran el nuevo precio, éste sería el ingreso previsto que se generaría a partir de dicho nivel de precio.

Si bien es cierto que podemos predecir el número o la proporción de clientes que perderíamos si se aumentaran los precios, si la encuesta se realiza en las unidades de servicio no necesariamente podríamos predecir cuántos clientes ganaríamos si los precios actuales se redujeran. Para poder aprovechar la demanda potencial adicional, necesitaríamos contar con la estimación de cuánta gente no utiliza actualmente nuestro servicio debido a los precios actuales, y cuánto estarían dispuestas a pagar estas personas. Una encuesta dirigida a la población en general podría proporcionar esta información, pero debe señalarse que diversas encuestas, como las demográficas y las de salud, han encontrado consistentemente que el precio es una razón secundaria para no utilizar un método.

Para nuevos productos o servicios necesitaríamos una medida independiente de nuestro mercado potencial. Entre los que no compran un nuevo producto a su precio establecido actualmente están incluidos tanto quienes no están dispuestos a pagar dicho precio como aquellos que no lo utilizarían a ningún precio, ni siquiera si se los regalaran. Una aproximación del tamaño del mercado podría generarse mediante el cálculo de la proporción de entrevistados que parecen estar altamente motivados para utilizar el producto o servicio; la demanda relativa para distintos niveles de precios podría compararse para este subconjunto de entrevistados, como se hizo arriba, y extrapolar el resultado para la población en general.

\section{Seguimiento del progreso de la encuesta}

Todos los proyectos necesitan una planeación y un seguimiento, y las encuestas de VDP no son la excepción. La lista de verificación que aparece abajo puede ayudar a los investigadores a planear y seguir de cerca el desarrollo de la encuesta. La primera sección es una lista de cuestiones políticas que quienes toman este tipo de decisiones dentro de los programas deben resolver antes de que la encuesta pueda ser diseñada. Cada pregunta en la primera columna requiere una respuesta en la siguiente columna. Por ejemplo, la primera Cuestión política pregunta a la persona encargada de tomar decisiones cuál es el motivo para implementar precios o aumentarlos. Si la Decisión política es "la recuperación de costos", la siguiente cuestión política le pide que explique cuáles son los costos a recuperar.

La segunda sección, Diseño de la encuesta, presenta una lista de los elementos que se deben seleccionar antes de empezar la encuesta, como, por ejemplo, qué clínicas serán incluidas. Los establecimientos 
específicos se enumerarán en la siguiente columna, Decisión del diseño de la encuesta. La tercera sección, Implementación de la intervención, es una lista de las tareas que tendrán que ser completadas durante la encuesta, y que incluyen las entrevistas a los clientes y la limpieza y captura de la información, entre otras. La segunda columna indica los individuos o las organizaciones que serán responsables de llevar a cabo las tareas. La columna final se usa para la fecha de entrega para las tareas.

\section{Cuadro 2}

\section{Lista de verificación de responsabilidades en cuanto a decisiones y tareas para la encuesta de VDP}

\begin{tabular}{|l|l|l|}
\hline I. Cuestiones políticas & $\begin{array}{l}\text { Decisión política } \\
\text { (ilustrativo) }\end{array}$ & Fecha de entrega \\
\hline $\begin{array}{l}\text { ¿Por qué cobrar por los } \\
\text { servicios? }\end{array}$ & $\begin{array}{l}\text { Recuperación de costos } \\
\text { Aumento del ingreso } \\
\text { Otro }\end{array}$ & \\
\hline $\begin{array}{l}\text { Si es para recuperar costos, } \\
\text { ¿cuáles? }\end{array}$ & $\begin{array}{l}\text { ¿Costos variables? } \\
\text { ¿Productos? }\end{array}$ & \\
\hline ¿Qué servicios? & & \\
\hline ¿En qué establecimientos? & & \\
\hline II. Diseño de la encuesta & $\begin{array}{l}\text { Decisión del diseño de la } \\
\text { encuesta }\end{array}$ & \\
\hline Cobertura geográfica & & \\
\hline $\begin{array}{l}\text { Cobertura en } \\
\text { establecimientos (tipos) }\end{array}$ & & \\
\hline $\begin{array}{l}\text { Unidad de } \\
\text { análisis/distribución }\end{array}$ & & \\
\hline $\begin{array}{l}\text { Tamaño de la muestra por } \\
\text { celda }\end{array}$ & & \\
\hline Flujo diario de clientes & & \\
\hline Presupuesto & & \\
\hline & & \\
\hline $\begin{array}{l}\text { III. Implementación de la } \\
\text { encuesta }\end{array}$ & $\begin{array}{l}\text { Responsabilidad de } \\
\text { implementación }\end{array}$ & \\
\hline Diseño del cuestionario & & \\
\hline Marco para muestreo & & \\
\hline Trabajo de campo & & \\
\hline $\begin{array}{l}\text { Captura/limpieza de } \\
\text { información }\end{array}$ & & \\
\hline Análisis de información & & \\
\hline Preparación del informe & & \\
\hline Diseminación & & \\
\hline & & \\
\hline
\end{tabular}

Fuente: basado en una lista de verificación desarrollada por The Futures Group International para su uso en la planeación de encuestas de VDP. 


\section{Aplicaciones}

En los últimos años, la técnica de las encuestas de VDP se ha utilizado extensamente por Health Services Research Group de Family Health International, The Futures Group International, y por el Programa FRONTERAS del Population Council para ayudar a los administradores de programas en países en desarrollo a tomar decisiones informadas sobre los precios de los productos y servicios de salud reproductiva. Entre otros grupos que usan enfoques metodológicos similares están la Federación Internacional de Planificación de la Familia, Región del Hemisferio Occidental (IPPF/RHO) y el proyecto Commercial Market Strategies (CMS). En el Cuadro 3 se presenta información básica sobre estas encuestas y su aplicación. La parte restante de esta sección presenta tres estudios de caso basados en la metodología de las encuestas de VDP, entre los que se incluyen algunos hallazgos relevantes sobre la confiabilidad y la validez de la técnica.

\section{Cuadro 3}

\section{Encuestas recientes de VDP por servicios de salud reproductiva}

\begin{tabular}{|c|c|c|c|}
\hline País/Organización/Año & Muestra & Productos/Servicios & $\mathrm{AT}^{*}$ \\
\hline $\begin{array}{l}\text { Ghana: GSMF } 1995 \text {, mercadeo } \\
\text { social de métodos anticonceptivos, } \\
\text { productos nuevos y existentes }\end{array}$ & $\begin{array}{l}\text { Muestra nacional } \\
\text { representativa de } 3,016 \\
\text { mujeres }\end{array}$ & $\begin{array}{l}\text { Oferta de } \\
\text { anticonceptivos } \\
\text { Condón femenino }\end{array}$ & TFGI \\
\hline $\begin{array}{l}\text { Pakistán: Proyecto PPSPP, } 1996, \\
\text { mercadeo social de métodos } \\
\text { anticonceptivos, nuevos productos }\end{array}$ & $\begin{array}{l}\text { Muestra representativa de } \\
1753 \text { mujeres urbanas y } \\
\text { peri-urbanas casadas }\end{array}$ & $\begin{array}{l}\text { Oferta de } \\
\text { anticonceptivos }\end{array}$ & TFGI \\
\hline $\begin{array}{l}\text { Ecuador: CEMOPLAF, } 1997, \\
\text { Servicios clínicos ONG }\end{array}$ & $\begin{array}{l}\text { Muestra sistemática de } \\
3,661 \text { mujeres en } 15 \\
\text { clínicas }\end{array}$ & $\begin{array}{l}\text { DIU, atención prenatal y } \\
\text { ginecológica, VDP para } \\
\text { tiempos de espera } \\
\text { menores, servicios } \\
\text { adicionales de consejería }\end{array}$ & $\begin{array}{l}\text { FHI } \\
\text { PC } \\
\text { TFGI }\end{array}$ \\
\hline $\begin{array}{l}\text { Guatemala: APROFAM, 1999, } \\
\text { Servicios clínicos ONG }\end{array}$ & $\begin{array}{l}\text { Muestras sistemáticas en } \\
\text { clínicas; la primer encuesta } \\
\text { incluyó } 4,856 \text { mujeres en } \\
18 \text { clínicas; la segunda } \\
1,827 \text { en seis clínicas }\end{array}$ & $\begin{array}{l}\text { Prenatal, Ginecología, } \\
\text { Papanicolaou, oferta de } \\
\text { anticonceptivos, } \\
\text { Norplant }\end{array}$ & $\begin{array}{l}\text { FHI } \\
\text { PC }\end{array}$ \\
\hline $\begin{array}{l}\text { Mali: Pilplan, } 1999, \\
\text { Proyecto de mercadeo social de } \\
\text { anticonceptivos }\end{array}$ & $\begin{array}{l}\text { Muestra representativa de } \\
2,780 \text { mujeres y } 2,780 \\
\text { hombres }\end{array}$ & $\begin{array}{l}\text { Oferta de } \\
\text { anticonceptivos }\end{array}$ & TFGI \\
\hline $\begin{array}{l}\text { Guatemala: Ministerio de Salud } \\
\text { 2000, Hospital con clínica de } \\
\text { consulta externa y policlínicas }\end{array}$ & $\begin{array}{l}\text { Muestreo sistemático de } \\
2,468 \text { mujeres en seis } \\
\text { clínicas }\end{array}$ & $\begin{array}{l}\text { Esterilización femenina, } \\
\text { anticonceptivos } \\
\text { temporales, ultrasonido }\end{array}$ & $\begin{array}{l}\text { FHI } \\
\text { PC }\end{array}$ \\
\hline $\begin{array}{l}\text { Filipinas: Well Family Midwife } \\
\text { Clinics, } 2000\end{array}$ & $\begin{array}{l}\text { Muestra sistemática de } \\
2,277 \text { mujeres en } 60 \\
\text { clínicas }\end{array}$ & $\begin{array}{l}\text { Pruebas de embarazo, } \\
\text { prenatal, parto, } \\
\text { Papanicolaou, } \\
\text { anticonceptivos } \\
\text { temporales }\end{array}$ & $\begin{array}{l}\text { FHI } \\
\text { PC }\end{array}$ \\
\hline
\end{tabular}

*AT (asistencia técnica): FHI = Family Health International, Programa FRONTERAS; PC = Population Council INOPAL III o Programa FRONTERAS; TFGI = The Futures Group International. 


\section{Mali: aumento de precios de los productos en existencia}

El proyecto de mercadeo social financiado por la USAID en Mali sacó al mercado una marca de condones (Protector) en 1992 y un anticonceptivo oral (Pilplan) en 1993. Al principio del proyecto, a mediados de 1998, los precios se establecieron en 100 francos malineses (FM) por ciclo de Pilplan y FM50 por un paquete de tres condones Protector, aproximadamente 0.17 y 0.09 dólares estadounidenses, respectivamente.

El diseño del proyecto planteaba una revisión de precios a fines de 1998 con el fin de aumentar el sostenimiento del proyecto y mejorar la distribución de los métodos. Se levantó una encuesta de VDP en tres localidades urbanas y las áreas rurales que las circundan: Sikasso, Mopti, y la capital, Bamako. Sikasso y Mopti fueron seleccionadas porque representaban las áreas de venta más alta y más baja, respectivamente. La muestra incluyó 2,780 mujeres de 15 a 40 años de edad y 2,750 hombres de 15 a 45 años, y se estratificó por ciudad y por área urbana o rural; dentro de cada estrato, se seleccionaron al azar áreas de enumeración.

La secuencia de preguntas para los usuarios activos de píldoras, inyectables y condones siguió el orden descrito en la Figura 3, página 6. A las mujeres que no utilizaban píldoras o inyectables en ese momento se les preguntó si utilizarían alguno de los dos métodos en el futuro; de manera similar, a los hombres que no utilizaban condones se les preguntó si los utilizarían en el futuro. Se calculó el precio máximo que cada usuario activo o potencial estaría dispuesto a pagar por cada método.

\section{Anticonceptivos orales}

De 2,780 mujeres sexualmente activas que fueron entrevistadas, 14 por ciento, o 390, informaron que utilizaban anticonceptivos orales en ese momento. Casi todas las usuarias activas de píldoras fueron capaces de proporcionar detalles acerca de su más reciente provisión del método; sólo cinco $(1.3 \%)$ no pudieron nombrar la marca de píldoras que utilizaban y otras cinco no fueron capaces de establecer el último precio pagado. La marca de mercadeo social Pilplan, consumida por 71 por ciento de las usuarias, era claramente la líder en el mercado. La mayoría de las usuarias de Pilplan (65\%) citaron una farmacia como su más reciente fuente de abastecimiento. De estas mujeres, 98 por ciento dijeron que habían pagado FM100 por un ciclo de píldoras, el precio de venta establecido.

Todas las usuarias activas de píldoras pudieron responder al primer aumento hipotético de precio; 79 por ciento dijo que aceptaría un aumento de precio de FM100 y 21 por ciento dijo que no. Después de responder dos preguntas directas sobre aumentos de precios, a todas las usuarias se les preguntó el precio más alto que estarían dispuestas a pagar. Este precio máximo se comparó con el aumento de precio más alto que la entrevistada dijo que aceptaría; para ser internamente consistente, el precio máximo debía ser igual o mayor que el aumento más alto que estaba dispuesta a aceptar (más el precio original pagado): 93 por ciento de las entrevistadas dieron una respuesta internamente consistente (45\% mantuvo el último precio aceptado y $48 \%$ citó un precio aún mayor).

La tasa de alfabetización de las mujeres en Mali es baja: sólo 60 por ciento de las usuarias activas de píldoras dijeron que habían ido alguna vez a la escuela. Sin embargo, no se encontró que la escolaridad estuviera asociada con la habilidad para contestar el cuestionario. Las mujeres que no habían asistido a la escuela no tenían menos probabilidades de conocer el precio de sus anticonceptivos orales que aquellas que sí habían asistido ( $1 \%$ vs. $2 \%$ ), y sólo tenían una tendencia ligeramente mayor a dar respuestas internamente inconsistentes a las preguntas de la encuesta de VDP ( $\%$ vs. 4\%, $\mathrm{p}<.07)$. 
Algunas usuarias de la píldora dijeron que su última fuente de abastecimiento no había sido la usual (7 entrevistadas, o $2 \%$ ). Estas usuarias, al igual que las que no pudieron establecer el último precio pagado o que dieron respuestas internamente inconsistentes fueron eliminadas del análisis. La voluntad de pago se analizó entre 92 por ciento de las usuarias activas de la píldora que cumplieron con todos los criterios de elegibilidad (es decir, aquellas que tenían una fuente consistente de abastecimiento, la habilidad para mencionar el último precio pagado y cuyas respuestas fueran internamente consistentes); fueron clasificadas en tres categorías de CSE con base en su nivel educativo y en la propiedad de bienes de consumo duradero en el hogar ${ }^{8}$. La Figura 4 compara la VDP entre las usuarias urbanas de la píldora según la CSE. Aunque las diferencias no son grandes, se debe resaltar que las mujeres de CSE más elevada mostraban mayor probabilidad de aceptar aumentos hipotéticos a lo largo del rango total de precios que las entrevistadas de CSE más baja.

\section{Figura 4 \\ Voluntad de pago por anticonceptivos orales Usuarias urbanas actuales}

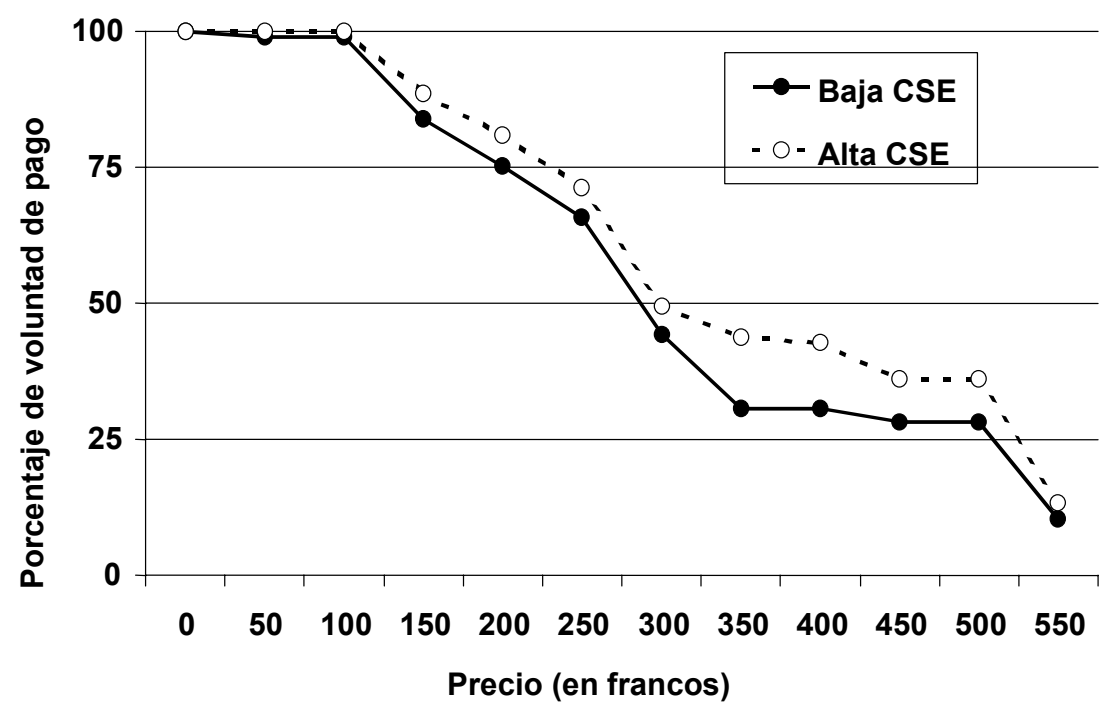

También se evaluó la VDP entre las usuarias potenciales de la píldora. Este grupo incluía a las mujeres que no estaban utilizando píldoras, inyectables, o anticoncepción quirúrgica en ese momento y que contestaron que estarían dispuestas a empezar a tomar píldoras o a volver a hacerlo. Se clasificó a 736 mujeres como usuarias potenciales.

Sólo 13 entrevistadas, o 2 por ciento de las usuarias potenciales, no fueron capaces de establecer el precio que estarían dispuestas a pagar por el método. Un 69 por ciento de las usuarias potenciales estaban dispuestas a pagar el precio más alto, FM250, y 58 por ciento, nombraron después un precio máximo aún más alto. Las usuarias potenciales y activas de píldoras mostraron una VDP casi idéntica cuando se trataba de los precios más bajos, aunque al llegar a algunos de los precios más altos la VDP disminuyó ligeramente. Sin embargo, entre las usuarias potenciales, las mujeres urbanas muestran una VDP mayor que las rurales, y las urbanas de CSE más alta demuestran mayor disposición de pago que aquellas de CSE más baja, como puede observarse en la Figura 5.

\footnotetext{
${ }^{8}$ Se utilizaron distintos criterios para clasificar a las mujeres rurales y las urbanas. Las diferencias absolutas entre las categorías son relativamente pequeñas; la mayoría de las familias, incluso en las áreas urbanas de Mali, se consideran muy pobres.
} 


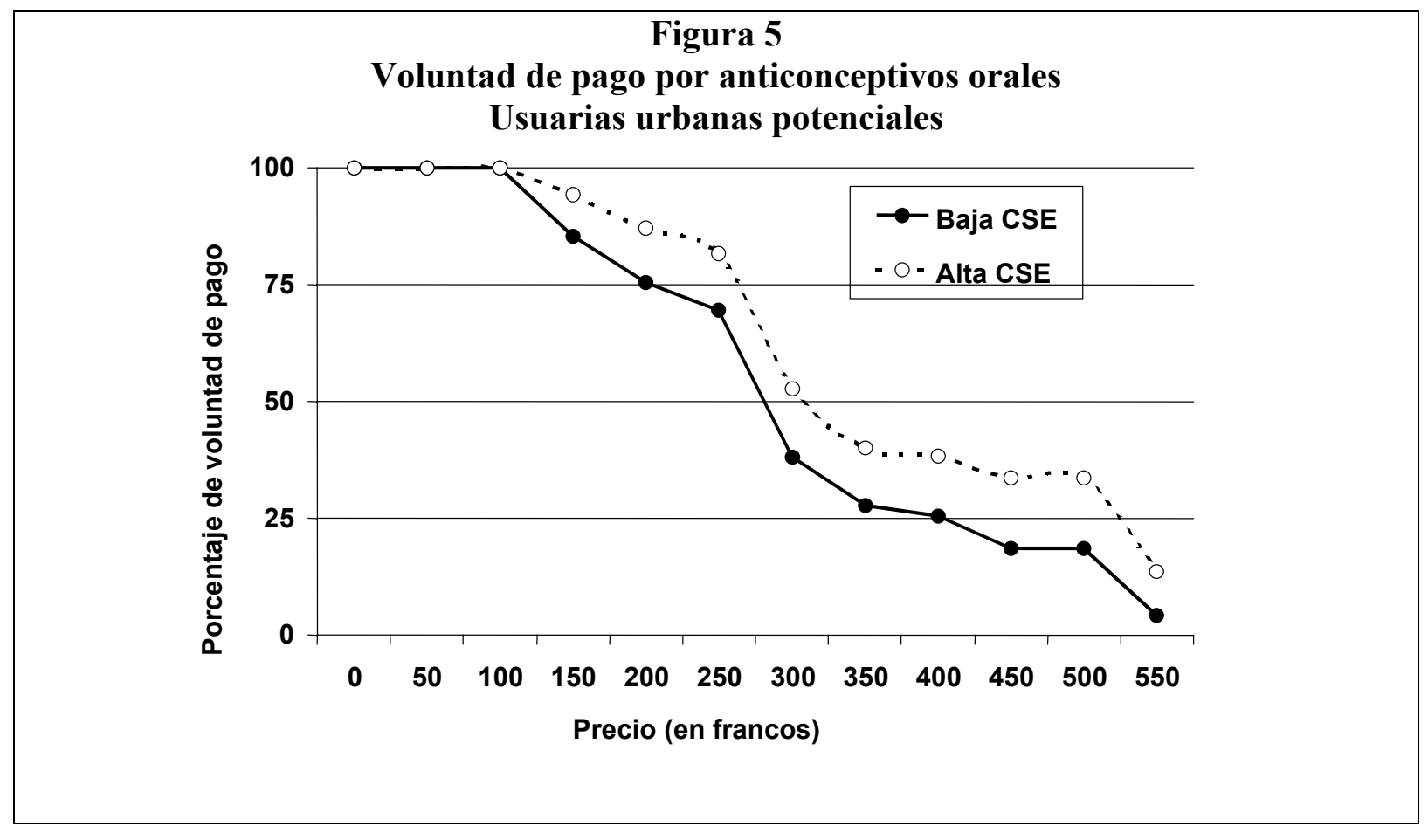

La Figura 6 presenta los ingresos esperados por la venta de Pilplan a diferentes precios. Las ventas totales en 1998 fueron de 761,000 unidades, lo que representó un monto de FM76 millones al precio de FM100. El precio más alto que se sondeó directamente fue de FM250, el cual representaría un ingreso potencial de FM128 millones - es decir, FM52 millones adicionales con respecto al ingreso del año de referencia-, aun con la pérdida esperada de una tercera parte de las clientes de Pilplan. En otras palabras, la pérdida esperada en ventas estaría más que compensada por el precio más alto del producto. La línea punteada en la Figura 6 representa los precios en que las estimaciones de VDP ya no son confiables.

\section{Condones}

Los hombres entrevistados que contestaron que habían utilizado un condón en los tres meses previos a la entrevista fueron clasificados como usuarios activos de condones. Un total de 742 entrevistados, o 27 por ciento de la muestra, respondieron a este criterio. Protector era la marca líder en el mercado en todas las áreas de estudio, representando 90 por ciento del uso más reciente de condones. Sin embargo, comparados con las usuarias femeninas de la píldora, los usuarios masculinos del condón mostraron menor consistencia tanto en la fuente de abastecimiento como en la marca: 25 por ciento de los usuarios respondieron que con frecuencia utilizaban una marca y/o fuente distinta. Esta diferencia entre los métodos no es sorprendente, ya que el uso del condón puede ser más esporádico que el de la píldora; cuando se les preguntó con quién habían utilizado el condón la última vez, 46 por ciento de los entrevistados contestaron que con "una pareja ocasional", entre ellos 36 por ciento de los hombres casados y 47 por ciento de los hombres que vivían en unión libre. Cuando se les preguntó por qué utilizaban condones, 73 por ciento de los usuarios sólo citaron la prevención de enfermedades y únicamente 7 por ciento mencionaron la anticoncepción; el 20 por ciento restante citó tanto la prevención de enfermedades como la de embarazos no deseados. 


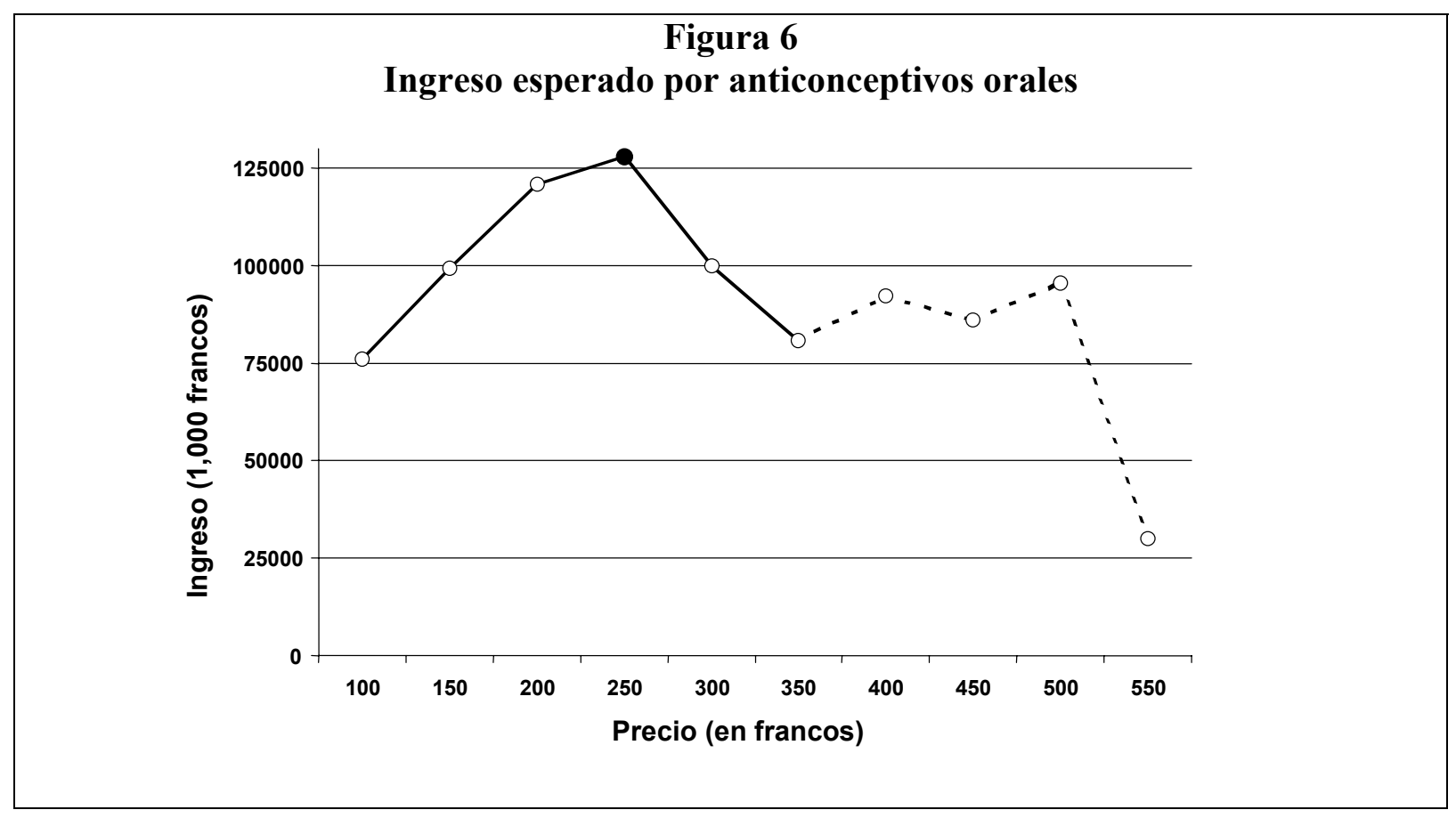

Pocos entrevistados tuvieron dificultad para contestar el precio real o la VDP hipotética. Ocho por ciento de ellos no recordaban la última marca que habían utilizado y/o su precio. Los hombres que habían asistido a la escuela tenían una probabilidad un poco menor de recordar el precio y la marca que aquellos que no tenían educación formal $(9.5 \% v s .4 .9 \% ; \mathrm{p}<.07)$. Todos los usuarios pudieron contestar el sondeo de precios hipotéticos. Un 69 por ciento de los usuarios activos aceptaron el aumento de precio más alto, y 81 por ciento, señalaron que estarían dispuestos a pagar un precio aún más alto. Siete por ciento citó un precio máximo de voluntad de pago menor que el precio más alto aceptado previamente. A pesar de que el nivel educativo en general era bajo, la educación se relacionó con la inconsistencia interna de las respuestas: 12 por ciento de los hombres sin educación dieron respuestas inconsistentes, en contraste con sólo 6 por ciento de los hombres que habían asistido a la escuela $(\mathrm{p}<.01)$.

Un total de 873 hombres, o 43 por ciento de los que no habían utilizado un condón en los últimos tres meses, respondieron que estarían interesados en utilizarlos en el futuro. Menos del uno por ciento de estos usuarios potenciales no pudieron determinar el precio que estarían dispuestos a pagar. Un 79 por ciento de los usuarios potenciales de condones aceptaron el precio más alto, FM150, y 71 por ciento, nombraron un precio aún mayor.

Como se observó entre las usuarias urbanas de la píldora, los usuarios urbanos de CSE alta mostraron sistemáticamente mayor VDP que los de CSE baja, aunque la diferencia no era grande. Estos resultados se ilustran en la Figura 7. Entre los usuarios potenciales de condones, los hombres urbanos estaban dispuestos a pagar precios más altos que los rurales, y entre los usuarios urbanos potenciales, aquellos con CSE más alta demostraron diferencias sustanciales en la voluntad de pago, la cual era superior a la de aquellos de CSE más baja. Un resultado inesperado fue que los usuarios potenciales mostraron una demanda estimada más alta en el rango de precios más bajos que los usuarios activos. 


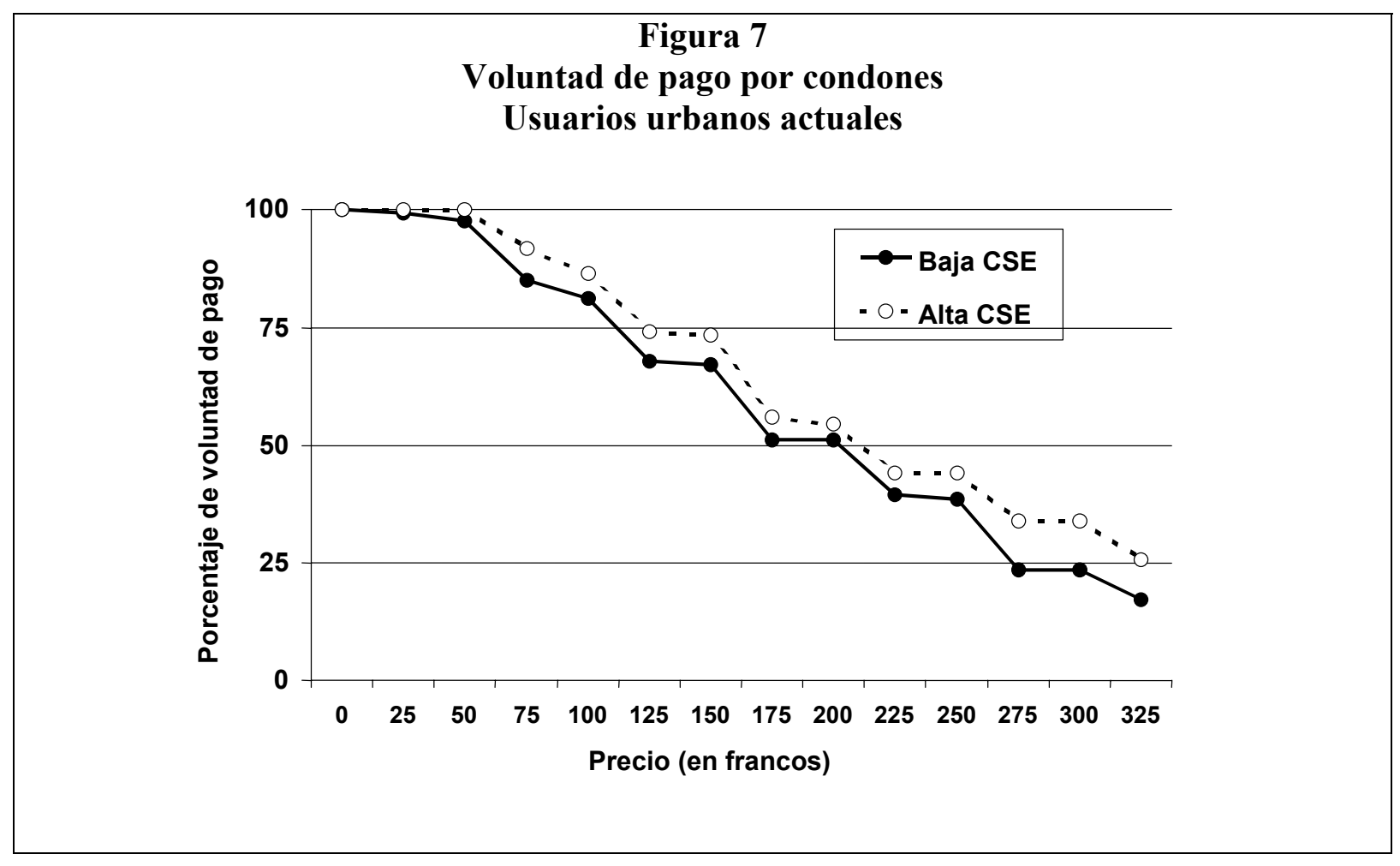

Al igual que en el caso de los anticonceptivos orales, el punto más alto de ingreso potencial para los condones correspondió al precio más alto sondeado (FM150 por un paquete de tres condones). La Figura 8 presenta la curva de ingreso estimada para la marca Protector. Hay que tomar en cuenta que los ingresos que se podrían obtener serían de poco más del doble si se subiera el precio de FM50 a FM150, lo cual significaría un alza en los ingresos de FM85 a FM176 millones. Como en la Figura 6, la línea punteada representa los precios para los cuales las estimaciones de VDP ya no son confiables.

¿Qué podemos concluir a partir de la aplicación de la metodología de voluntad de pago en Mali?

1. Aun en una zona de bajo nivel de alfabetización, los usuarios de diferentes métodos anticonceptivos pueden entender y responder coherentemente a preguntas sobre lo que podrían hacer bajo diversas condiciones hipotéticas. Casi todos los entrevistados - tanto los usuarios activos como los potenciales - podían responder sí o no a la pregunta inicial sobre los precios hipotéticos.

2. Preguntar a los entrevistados el precio máximo que estarían dispuestos a pagar amplía significativamente el rango de precios potenciales entre los entrevistados que aceptan el precio sondeado más alto. Los entrevistados que rechazan uno o más de los precios sondeados tienen menor probabilidad de mencionar un precio máximo más alto que el último precio que aceptaron. Incluir la pregunta sobre el precio máximo también permite analizar la comprensión de los entrevistados de las preguntas hipotéticas. Pocos entrevistados dieron respuestas internamente inconsistentes a esta pregunta, aunque los que no tenían educación formal presentaron una tendencia a mostrar mayores confusiones que quienes habían asistido a la escuela.

3. En general, la validez interna del estudio fue alta: los entrevistados de CSE más alta demostraron mayor VDP que los entrevistados de CSE más baja; y entre los usuarios potenciales, los urbanos demostraron mayor VDP que los rurales. Los usuarios activos y potenciales no difirieron consistentemente en su VDP. 


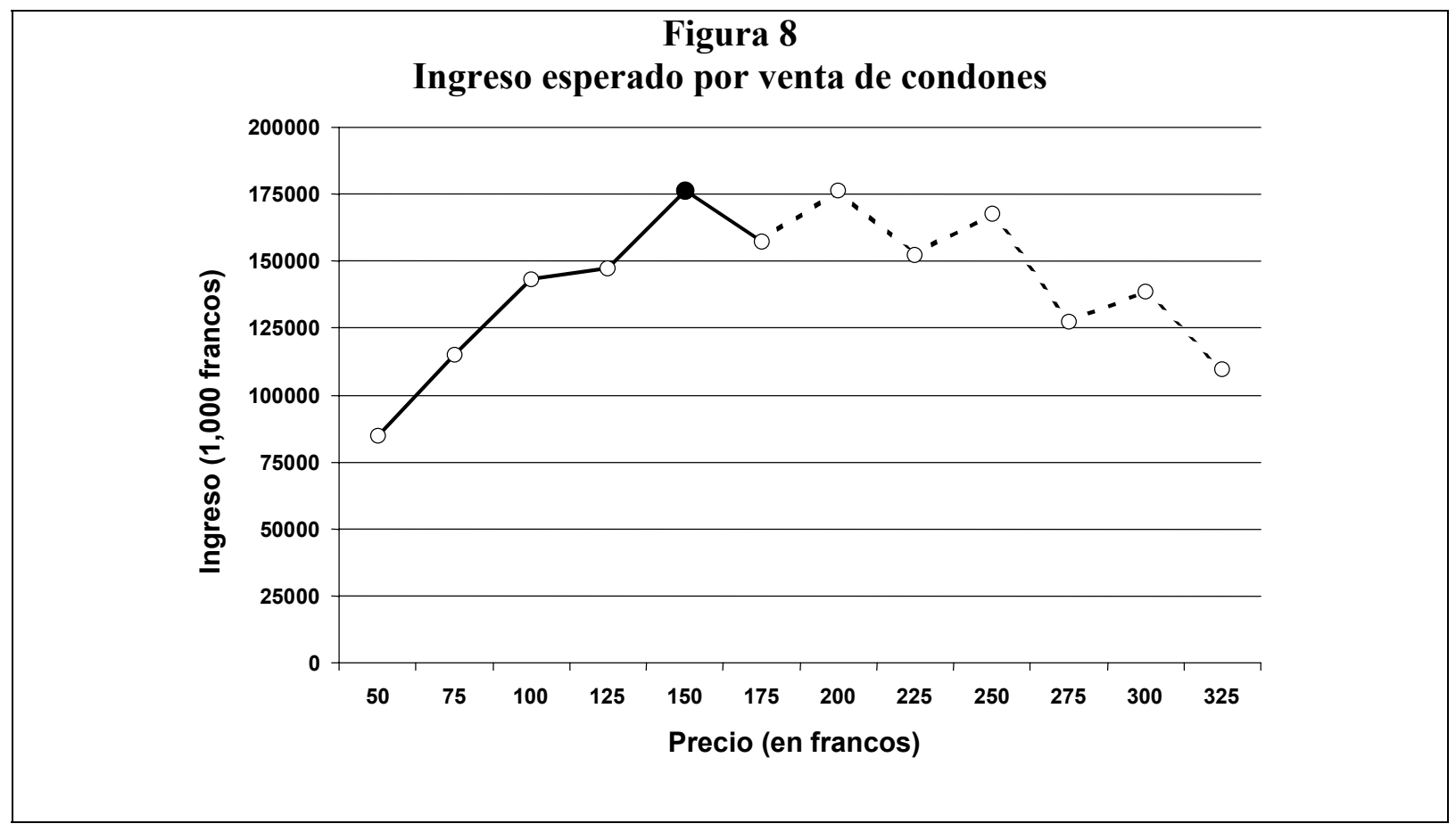

\section{Pakistán: fijar precios para nuevos productos}

Fijar los precios para nuevos productos de mercadeo social presenta varios desafíos. En primer lugar, dado que el producto es nuevo en el mercado, no existen datos específicos que puedan servir de guía para la toma de decisiones. En segundo lugar, aun en el caso de que existan bienes o servicios parecidos en los sectores públicos o comerciales, el nuevo producto puede ser tan distinto en su dosis, forma de entrega $u$ otras características, que la información existente no necesariamente sirve para hacer una comparación útil. Las encuestas de VDP también pueden proporcionar información pertinente en estas situaciones, como lo demuestra la investigación sobre el tema realizada en Pakistán.

El Proyecto de Población del Sector Privado de Pakistán (PPSPP) se diseñó para operar en dos ciudades: Faisalabad y Larkana. El diseño del proyecto planteaba la provisión de píldoras e inyectables a precios subsidiados que estuvieran por debajo de los precios comerciales. En agosto de 1996 se llevaron a cabo encuestas de VDP en las dos ciudades objetivo. Se sumó un área rural a la muestra porque el gobierno de Pakistán tenía interés en realizar investigaciones sobre los precios de los anticonceptivos del sector público en las áreas rurales.

El mercado objetivo para el PPSPP lo constituían las parejas casadas con un ingreso mensual entre 1,500 y 4,000 rupias pakistaníes (RP) (aproximadamente entre 43 y113 dólares estadounidenses). Las mujeres menores de 40 años y con al menos un hijo fueron consideradas como las más probables aceptantes de los productos de mercadeo social que ofrecía el proyecto. La muestra de la encuesta de VDP fue elegida en los distritos electorales urbanos de Faisalabad y Larkana, donde la mayoría de los entrevistados tenía el nivel de ingreso requerido. La muestra rural se tomó de localidades que estaban a una distancia entre cinco y 25 kilómetros del límite de la ciudad de Faisalabad, las cuales tenían una alta probabilidad de caer en el rango de ingresos seleccionado. Sólo las mujeres que llenaban los requisitos de edad y paridad fueron entrevistadas. Se hicieron preguntas acerca de cuatro precios: RP25, RP15, RP10 y RP3, en orden descendente. La técnica para fijar precios de acuerdo a la VDP aún se estaba desarrollando en 1996, por 
lo que no se incluyó en el cuestionario la pregunta sobre el precio máximo que el entrevistado estaría dispuesto a pagar.

Una muestra total de 1,753 mujeres fue entrevistada. A pesar de que sólo dos por ciento de la muestra utilizaba anticonceptivos orales, otro seis por ciento respondió que podría considerar utilizar este método en el futuro. Se clasificó con una fuerte motivación para utilizar el método a las mujeres cuya primera opción eran las píldoras; aquellas que elegían otro método como primera opción fueron clasificadas con una motivación débil. El grado de motivación se asoció claramente con la VDP: las mujeres cuya primera opción eran las píldoras estaban más dispuestas a aceptar todos los precios especificados que aquellas cuya primera opción era otro método, como puede observarse claramente en la Figura 9.

\section{Figura 9 \\ Voluntad de pago por anticonceptivos orales Usuarias potenciales}

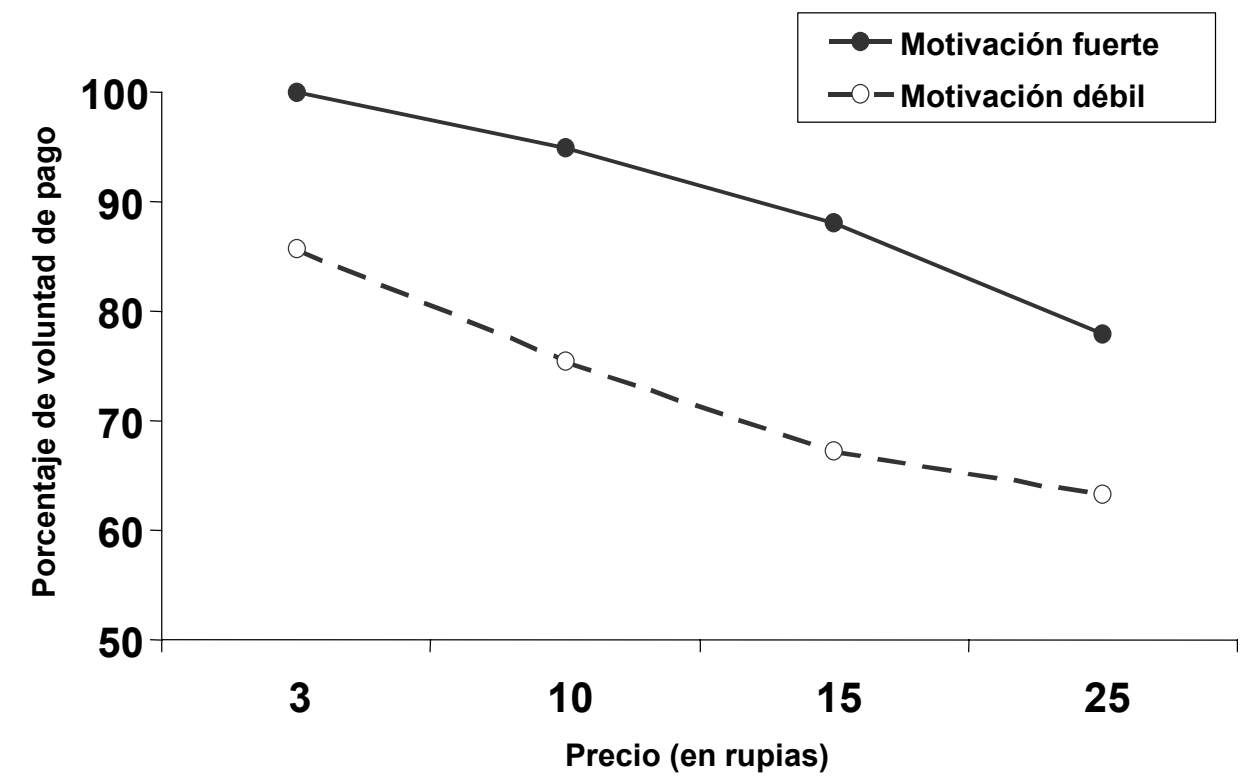

De acuerdo con la encuesta de VDP, el precio de la marca comercializada socialmente se fijó en RP15 por ciclo, precio que 88 por ciento de las mujeres con mayores probabilidades de compra dijeron que estaban dispuestas a pagar.

1. A diferencia de la investigación de Mali, la cual fue diseñada para probar la VDP para productos ya existentes en el mercado, el estudio en Pakistán tenía como propósito obtener información para fijar los precios de nuevos productos. Las lecciones metodológicas aprendidas en Pakistán refuerzan y expanden las del caso de Mali de la siguiente manera:

2. Las no-usuarias del método en cuestión son capaces de responder las preguntas de VDP. De nuevo, la proporción de respuestas no sé fue muy baja, y los entrevistadores no reportaron haber tenido problemas para aplicar el cuestionario. Los precios recomendados que se derivaron de la estimación directa de la VDP caen dentro de los criterios comúnmente usados de capacidad de pago (expresados 
como porcentaje de los ingresos del hogar) y son consistentes con los gastos reportados por las entrevistadas en cuidados preventivos de la salud ${ }^{9}$.

3. La validez interna de la metodología de VDP fue apoyada por la información empírica: las nousuarias con un fuerte interés en utilizar la píldora tenían mayor voluntad de pago que quienes estaban menos motivadas a usar el método.

\section{Ecuador: aumento de precios de los servicios ${ }^{10}$}

Los primeros dos casos demuestran la consistencia interna y la confiabilidad de la técnica de VDP. Pero, ¿qué tanta confianza puede tener un administrador de un programa en que los resultados de una encuesta de VDP sean capaces de predecir si sus clientes efectivamente pagarán un nuevo precio? En otras palabras, ¿qué tan válida es la metodología? El siguiente estudio de caso intenta responder esta pregunta.

El estudio se llevó a cabo en los Centros Médicos de Orientación y Planificación Familiar (CEMOPLAF), una ONG ecuatoriana que proporciona diversos servicios de salud reproductiva. Los clientes de CEMOPLAF son principalmente mujeres urbanas obreras, 20 por ciento de las cuales viven en condiciones de pobreza. Para compensar la inflación, CEMOPLAF aumenta periódicamente los precios de sus servicios alrededor de 20 por ciento. A pesar de estos aumentos y de los esfuerzos por controlar los costos y por atraer nuevos clientes, CEMOPLAF necesitaba elevar sus ingresos, por lo que en 1996 decidió probar aumentos de precio mayores al 20 por ciento usual.

Quince de las 21 clínicas de CEMOPLAF que atienden a clientes con perfiles socioeconómicos similares participaron en un experimento con tres distintos aumentos de precio, precedido de una encuesta de línea de base de $\operatorname{VDP}^{11} .11$ Los cambios en la utilización de las clínicas que siguieron a los aumentos de precio fueron comparados con los cambios pronosticados por la encuesta.

La encuesta de línea de base se llevó a cabo dos meses antes de que entraran en vigor los aumentos de precio programados. A las clientes que iban a la clínica para recibir atención obstétrica o ginecológica, para revisión de DIU y para cuidado prenatal, se les preguntó si estarían dispuestas a aceptar aumentos hipotéticos de precio por el servicio. Como en Mali, a las entrevistadas se les propuso un aumento de precio moderado (4,500 sucres, aproximadamente 1.37 dólares), el cual luego subía (a 9,000 sucres o 2.74 dólares) o bajaba (a 2,500 sucres o 0.76 dólares) dependiendo de la respuesta a la pregunta anterior. A las entrevistadas que aceptaron los aumentos de precio más altos se les preguntaba cuál era el precio máximo que estarían dispuestas a pagar.

Un total de 3,661 usuarias de las clínicas fueron entrevistadas, de las cuales aproximadamente una tercera parte había ido a su consulta de revisión del DIU; más de la mitad había acudido a una consulta

\footnotetext{
${ }^{9}$ La "sabiduría tradicional" sugiere que los precios de mercadeo social para anticonceptivos deberían representar entre uno y tres por ciento del ingreso de los usuarios objetivo. Con un precio de RP15 por unidad, el costo de un año de protección anticonceptiva (RP195: RP15 x 13 unidades) representa 1.3 por ciento o menos del ingreso mensual por hogar en el segmento objetivo del mercado (RP1,500 a 4,000). Entre las mujeres potencialmente interesadas en utilizar anticonceptivos orales, el promedio de los gastos anuales por hogar en medicina preventiva era de RP300, casi el doble del costo de un año de protección anticonceptiva. El precio del inyectable de tres meses se fijó a RP60, lo que representa no más de 1.6 por ciento del ingreso anual por hogar por un año de protección anticonceptiva; 80 por ciento de las usuarias potenciales estaban dispuestas a pagar ese precio.

${ }_{10}^{10}$ Para detalles del estudio, véase de Vargas et al. (1998).

${ }^{11}$ Se realizó un análisis de conglomerados para identificar clínicas que atendían una clientela con características socioeconómicas similares. Se basó en cuatro variables: porcentaje de clientes que trabajaban fuera del hogar por un salario, porcentaje que era dueño de un refrigerador, porcentaje que había consumido carne por lo menos dos de los tres días anteriores, y el ingreso familiar promedio (véase Bratt et al., 1998).
} 
ginecológica, y alrededor de 12 por ciento iba a control prenatal. En total, 79 por ciento de las entrevistadas aceptaron un aumento mediano en el precio, y 53 por ciento aceptaron el aumento de precio más alto. No hubo diferencias entre los servicios. Más aún, 59 por ciento de las mujeres que aceptaron el aumento de precio más alto citaron un precio aún mayor que estarían dispuestas a pagar.

La Figura 10 presenta la VDP para cada uno de los tres servicios de las clínicas. Debe notarse que la demanda estimada para los servicios de ginecología y de atención prenatal es prácticamente idéntica, y que la demanda para la revisión de DIU es paralela pero relativamente menor. CEMOPLAF cobra precios más altos por los servicios de ginecología y de atención prenatal con la finalidad de poder subsidiar los servicios de DIU; el precio inicial promedio para los servicios ginecológicos y prenatales era de 8,000 sucres, comparado con 6,500 sucres para las consultas de revisión del DIU.

\section{Figura 10 Voluntad de pago por servicios clínicos}

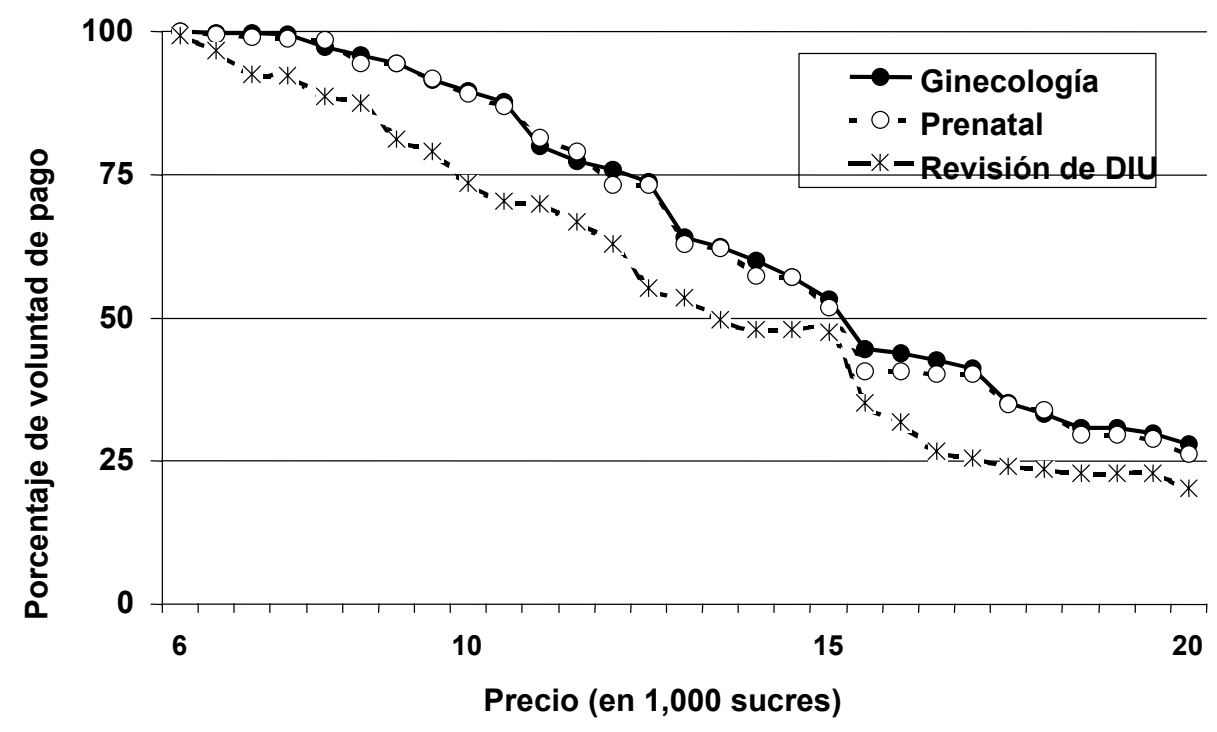

Validez predictiva. Dos meses después de la encuesta de VDP, las 15 clínicas participantes instituyeron al azar distintos aumentos de precio (20\%, $40 \%$ o $60 \%$ ) para las revisiones del DIU, las consultas ginecológicas y los controles prenatales. Posteriormente, se comparó el volumen promedio mensual de clientes en los tres meses anteriores a los aumentos de precio con el mismo indicador, valorado después de los aumentos.

La Figura 11 presenta la demanda estimada, así como la observada, para cada uno de los tres servicios clínicos después de los aumentos de precio $^{12}$. Se debe mencionar la estrecha correspondencia que existe entre la demanda pronosticada y la observada para las revisiones de DIU y para los servicios de ginecología. Para estos dos servicios, la demanda observada disminuyó cuando se aumentaron los precios;

\footnotetext{
${ }^{12}$ Las curvas de demanda agregada mostradas en la Figura 10 se usaron para calcular la demanda de los servicios en cada clínica, de acuerdo con su nuevo precio y utilizando la metodología descrita en la sección III. La Figura 11 presenta la demanda estimada como porcentaje del volumen de la línea de base (el cociente de la demanda agregada calculada con el nuevo precio entre la demanda agregada suponiendo el precio original).
} 
sin embargo, las diferencias entre los precios no eran estadísticamente significativas. Las predicciones de VDP eran menos precisas para los servicios prenatales y, paradójicamente, se observó mayor demanda después del aumento de precio más elevado. De nuevo, las diferencias de precio observadas no demostraron ser estadísticamente confiables.

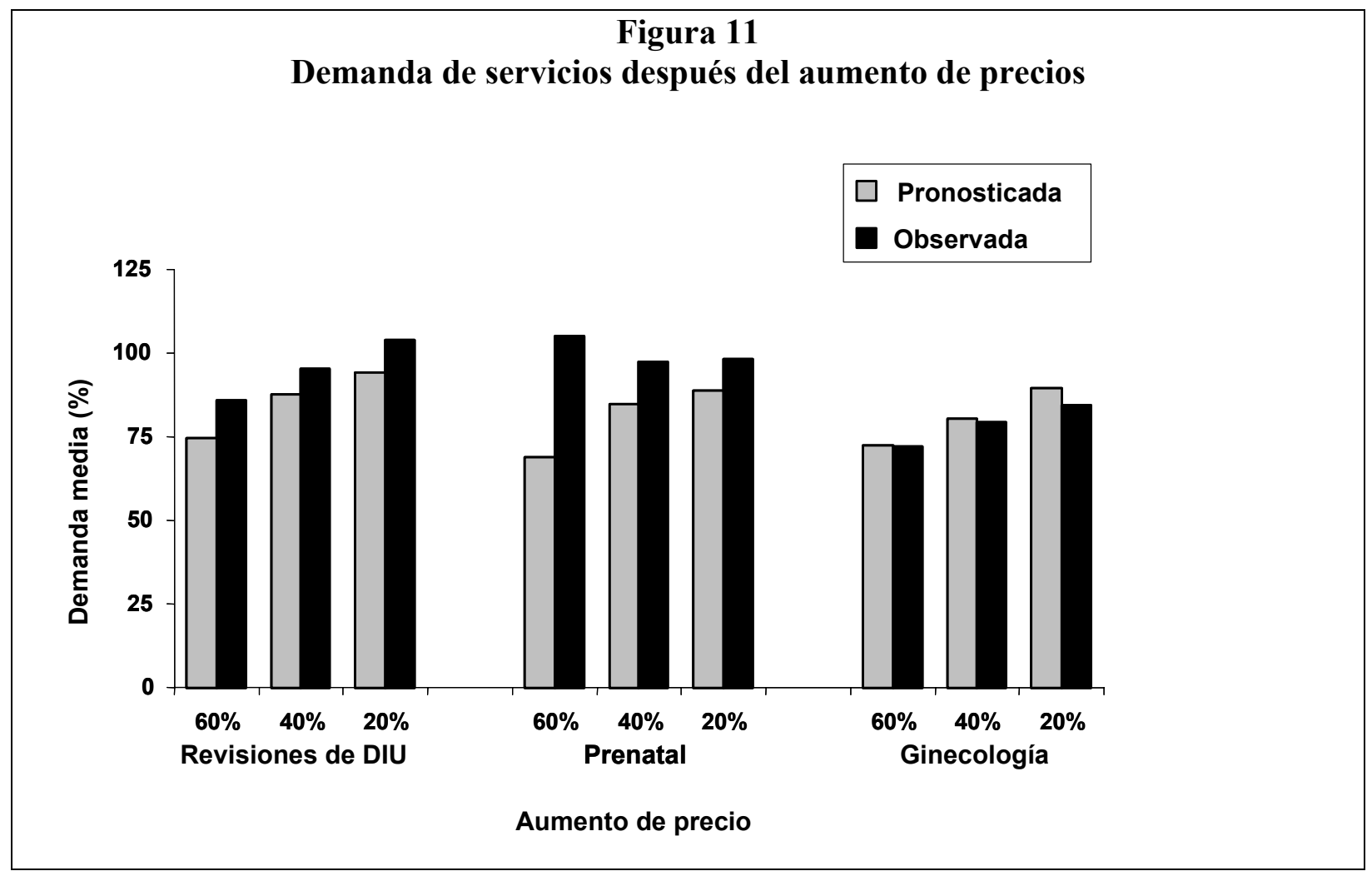

El análisis del volumen de clientes (número de consultas) posterior al aumento de precios demostró que el porcentaje de cambio pronosticado se encontraba dentro de +5 por ciento del porcentaje de cambio observado en 12 de las 44 combinaciones clínica-servicio (27\%), y dentro de +10 por ciento en otros 21 casos (48\%). Finalmente, cabe notar que las predicciones de VDP sobrestimaron la pérdida de clientes (en otras palabras, se predijo una pérdida mayor a la que se observó realmente) en 68 por ciento de los casos. En otro 14 por ciento de los casos, la pérdida de clientes se subestimó en menos de cinco por ciento. La Figura 12 presenta la distribución de la subestimación y sobrestimación de la pérdida de clientes, mostrando que la técnica de estimación directa ayuda a evitar que los programas subestimen la pérdida de clientes.

Las estimaciones de VDP pronosticaron mejor el volumen de servicios posterior al aumento de los precios que otras variables disponibles para los administradores del programa, como el volumen inicial de los servicios o la magnitud del aumento de los precios. Como una prueba conservadora de la validez predictiva, se utilizaron modelos de regresión múltiple jerárquicos, introduciendo al modelo el volumen de la clínica en la línea de base, el aumento de los precios y las predicciones de VDP, en ese orden. No es de sorprender que el volumen futuro se correlacionaba de una manera casi perfecta con el volumen de la línea de base $(\mathrm{R} 2=0.93)$. Sin embargo, los pronósticos de VDP mejoraron significativamente la predicción de los cambios con respecto a los niveles de la línea de base, de R2 $=0.095$, cuando sólo se considera el volumen de la línea de base, a R2 $=0.331$ después de incorporar la VDP.

Independientemente de la variable dependiente, los aumentos de precio no predijeron el comportamiento futuro del volumen de servicios. 
Figura 12

Precisión de las predicciones de VDP

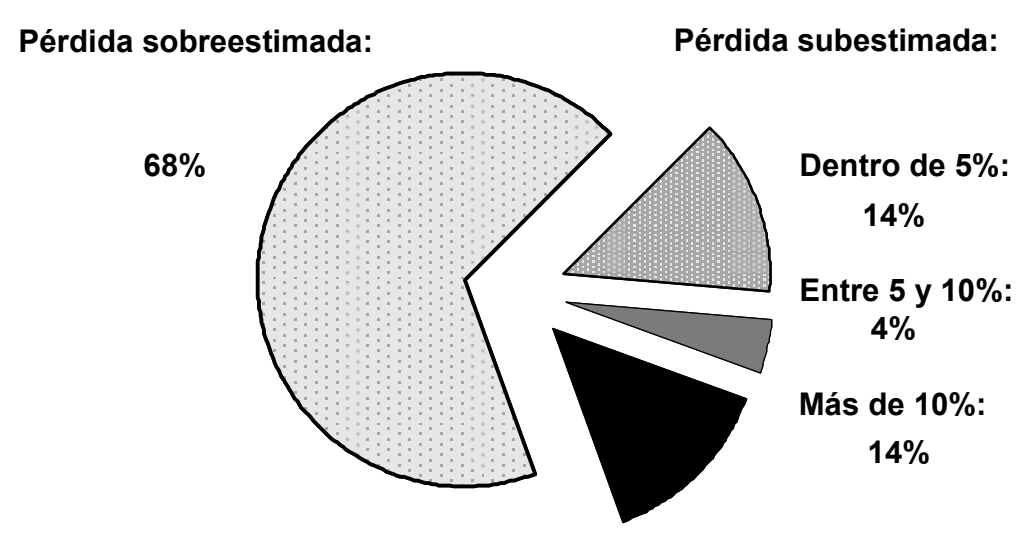

El estudio de Ecuador refuerza las lecciones aprendidas en Mali y Pakistán, y desarrolla una metodología para validar experimentalmente las estimaciones derivadas de cuestionarios de VDP.

1. Las clientas de las clínicas tuvieron poca dificultad para responder las preguntas sobre aumentos de precio hipotéticos o sobre el precio máximo que estarían dispuestas a pagar. Incluir la pregunta sobre el precio máximo amplió el rango de aumentos de precio potenciales, sin alargar excesivamente el cuestionario.

2. La validez experimental de los tres incrementos de precio fue consistente con la predicción de la disminución de la demanda cuando aumentan los precios. Las estimaciones de VDP aumentaron significativamente la capacidad de los administradores para predecir el impacto de los cambios de precio. La tendencia sistemática a sobrestimar la disminución de la demanda después de aumentar los precios hace que las encuestas de VDP sean particularmente útiles para fijar los precios de los servicios en organizaciones no lucrativas, donde la necesidad de mantener el volumen de clientes aconseja el uso de un método conservador de estimación.

\section{Prueba de validez predictiva}

Hasta la fecha, la validez predictiva de las encuestas de VDP en el ámbito de la salud reproductiva sólo ha sido probada en el estudio de CEMOPLAF en Ecuador. Es evidente la necesidad de efectuar más pruebas acerca de la validez predictiva de esta técnica. Sin embargo, es preciso recalcar que distintas consideraciones metodológicas son pertinentes para distintas aplicaciones de la VDP.

Prueba del efecto de aumentos de precio para usuarios activos de productos o servicios. Dependiendo del servicio o producto de que se trate, se pueden utilizar dos posibles enfoques. El primero de ellos utiliza información sobre los clientes activos para predecir el comportamiento de futuros clientes. Este enfoque supone que tanto los clientes activos como los futuros provienen de la misma población y que tienen capacidades y disposición de pago similares. Bajo este enfoque, la validez predictiva se mide a 
través de los siguientes pasos: 1) se recolecta la información de la línea de base sobre la utilización de los servicios, típicamente a través de las estadísticas de servicios o de la información sobre las ventas; 2) se lleva a cabo una encuesta de VDP para obtener pronósticos sobre la utilización futura de los servicios; 3 ) aleatoriamente, se aumentan los precios en algunos subconjuntos de clínicas (la validación se hace por medio de técnicas de regresión múltiple, como en el estudio de CEMOPLAF, lo cual requiere observar al menos dos niveles de precios); y 4) finalmente, la precisión de la predicción se compara con la utilización observada de los servicios, la cual se valora mediante estadísticas de servicio posteriores al aumento de precios. Se puede maximizar el número de observaciones utilizando las combinaciones de los servicios en las clínicas como unidades de análisis distintas (por ejemplo, si los precios se van a aumentar para cuatro servicios en 10 clínicas, el número de observaciones es de 4 x 10=40). El investigador deberá utilizar un número tan grande de casos como sea posible, porque los programas constituyen sistemas complejos con una importante variabilidad intrínseca. Tanto las clínicas como los servicios demuestran a menudo patrones estacionales, y la frecuencia con que aparecen estos patrones varía dependiendo de la clínica y el tipo de servicio. Por ejemplo, algunas clínicas pueden tener una trayectoria caracterizada por una utilización creciente de sus servicios a lo largo del tiempo, mientras que hay otras en las que la utilización se mantiene igual o disminuye.

El segundo enfoque para evaluar la validez predictiva de las encuestas de VDP surge cuando es factible hacer un seguimiento del comportamiento de los usuarios individuales a lo largo del tiempo. La prueba de validez más rigurosa para una encuesta consiste en comparar sus predicciones con el comportamiento futuro de los entrevistados. Por ejemplo, Griffin et al. (1995) preguntaron a un conjunto de entrevistados en la India si estarían dispuestos a pagar un precio de conexión y una cuota mensual para obtener un mejor sistema de dotación de agua. Después de que se mejoró dicho sistema, se volvieron a visitar los hogares de la encuesta. Aunque 91 por ciento de las familias dijeron que se conectarían al sistema de agua en 1988, no lo hicieron hasta 1991; y 94 por ciento de las familias que dijeron que no lo harían, actuaron de esa manera. Las oportunidades para llevar a cabo estudios longitudinales son relativamente escasas en programas de salud reproductiva, en parte por el tiempo y el esfuerzo que requieren, y en parte porque muchos servicios de salud reproductiva no se utilizan consistentemente a lo largo de periodos relativamente largos. Por ejemplo, las clientes que asisten a atención prenatal dejarán de ir a la clínica después del nacimiento del bebé, y las usuarias del DIU pueden necesitar sólo un número pequeño y poco frecuente de revisiones durante muchos años de uso del método.

Fijar los precios de nuevos productos o servicios. La validez predictiva de las técnicas de VDP, cuando se utilizan para establecer los precios de nuevos servicios o productos de salud reproductiva, parece no haber sido probada hasta la fecha. En algunas situaciones es posible usar un enfoque longitudinal, como el que reportan Griffin et al. (1995), pero para la mayoría de los productos y servicios esto no es posible. Existen varios problemas que deberán ser resueltos antes de que la validez predictiva de las encuestas de VDP para nuevos productos pueda ser establecida sobre bases firmes: por ejemplo, la inexistencia de datos correspondientes a una línea de base que pudieran ser utilizados con propósitos comparativos, o la necesidad de reconocer que el consumo de un nuevo producto o la adopción de un servicio está influenciado tanto por el precio como por una diversidad de otros factores concomitantes. 


\section{Bibliografía}

Aker, B., M. Boroush, y S. Smith. 1989. "The Choice to Contracept in Liberia: Sensitivities to Changes in Incomes and Contraceptive Prices." Informe de SOMARC. Washington D.C.: The Futures Group International.

Akin, John S. y Brad Schwartz. 1988. "The Effect of Economic Factors on Contraceptive Choice in Jamaica and Thailand: A Comparison of Mixed Multinomial Logit Results." Economic Development and Cultural Change 36(3): 503-527.

Bratt, John H., James Foreit, y Teresa de Vargas. 1998. "Three Strategies to Promote Sustainability of CEMOPLAF Clinics in Ecuador." Studies in Family Planning 29(1): 58-68.

Foreit, J.R. y K.G. Foreit. 2003. "The reliability and validity of willingness to pay surveys for reproductive health pricing decisions in developing countries." Health Policy 63 (1): 37-47.

Griffin, C., J. Briscoe, B. Singh, R. Ramasubban y R. Bhatia. 1995. "Contingent Valuation and Actual Behavior: Predicting Connections to New Water Systems in the State of Kerala, India." The World Bank Economic Review 9(3): 373-395.

Jensen, Eric R., N. Kak, K. Satjawinata, D.N. Wirawan, N. Nanjoy y Suproyoko. 1993. "Contraceptive Pricing and Prevalence: Family Planning Self-Sufficiency in Indonesia." Documento presentado en la reunión anual de la Population Association of America en Cincinnati, Ohio.

León, Federico y Agustín Cuesta. 1993. "The Need for Quasi-Experimental Methodology to Evaluate Pricing Effects." Studies in Family Planning 24(6), parte 1:375-381.

Lewis, Maureen A. 1986. "Do Contraceptive Prices Affect Demand?" Studies in Family Planning (17)3: 126-135.

National Institute of Population Studies e IRD/Macro International. 1992. Pakistan Demographic and Health Survey 1990/1991. Columbia, MD: National Institute of Population Studies (Pakistán) e IRD/Macro International Inc.

Oliver, Raylynn. 1994. The Effect of the Quality, Price, and Availability of Family Planning on Contraceptive Use in Ghana." Living Standards Measurement Working Paper, World Bank, Africa Technical and Policy Research departments. Washington, D.C.: Banco Mundial.

Phillips, Kathryn A, Rick K. Homan, Harold S. Luft, Patricia H. Hiatt, Kent R. Olson, Thomas E. Kearney y Stuart E. Heard. 1997. "Willingness to Pay for Poison Control Centers." Journal of Health Economics 16: 347.

Portnoy, Paul R. 1994. "The Contingent Valuation Debate: Why Economists Should Care." Journal of Economic Perspectives (8)4: 3-17.

Vargas, Teresa de, John H. Bratt, Varuni Dayaratna, James R. Foreit y Daniel H. Kress. 1998. "Estimating Consumer Response to Price Changes in Family Planning and Reproductive Health Services." Documento presentado en la reunión anual de la Population Association of America en Chicago, Illinois. 


\section{APÉNDICE I MODELO DE CUESTIONARIOS}

Modelo para usuarios activos y potenciales de servicios clínicos (Entrevista a la salida de las instalaciones)

Encuesta en hogares a usuarios activos y potenciales de condones (Entrevista en el hogar) 


\section{Salud reproductiva \\ Voluntad de pago \\ Modelo de cuestionario para entrevistas a la salida de las instalaciones}

\section{Consentimiento informado}

Las primeras tareas que enfrenta el entrevistador son: presentarse con el entrevistado potencial; informarle los objetivos, riesgos y beneficios de la investigación, y obtener su consentimiento para realizar la entrevista. La mayoría de las organizaciones que llevan a cabo investigaciones exigen que la persona que será entrevistada otorgue su consentimiento informado. El consentimiento informado tiene su origen en investigaciones médicas en las que existen riesgos y beneficios potenciales. Los formularios de consentimiento deben usar frases simples y afirmaciones directas, apropiadas al nivel de educación de las personas que serán entrevistadas. Quienes participen en el estudio deben tener la oportunidad de hacer preguntas y haber recibido toda la información antes de firmar el formulario. En los casos en que se requiera el consentimiento informado, se deben incluir los siguientes elementos:

1. Propósito del estudio.

2. Riesgos para el participante, que incluyan riesgos físicos, sociales y emocionales.

3. Beneficios para el participante, que incluyan, si es necesario, una declaración de que no los hay.

4. Información sobre la confidencialidad, que incluya el uso de elementos identificadores y el acceso a la información personal.

5. Lugar a dónde acudir en caso de dudas o problemas en cualquier momento.

6. Información acerca del abandono del estudio. La persona que participa en el estudio tiene el derecho de dejar de hacerlo en cualquier momento sin ninguna penalización.

7. Garantía de que los servicios están disponibles para el/la participante potencial tanto si acepta participar en el estudio como si no lo hace o si se retira del mismo.

8. Información sobre los procedimientos y la duración del estudio.

El formulario deberá ocupar una hoja de papel separada. Nótese que el investigador deberá ser capaz de vincular el formulario de consentimiento informado al cuestionario pertinente con un indicador numérico. Para la recolección de información que represente bajo riesgo, es suficiente conseguir el consentimiento de manera verbal, pero el formulario deberá estar firmado por el entrevistador como parte de la documentación.

Diferentes organizaciones tienen diferentes formas de garantizar que se cumpla con los requisitos del consentimiento informado. El cuestionario que se presenta a continuación contiene un ejemplo de una declaración de consentimiento informado. 


\title{
Salud reproductiva \\ Voluntad de pago \\ Modelo de cuestionario para entrevistas a la salida de las instalaciones
}

\author{
MODELO PARA USUARIOS ACTIVOS Y POTENCIALES DE LOS SERVICIOS \\ CLÍNICOS
}

[INSTRUCCIONES PARA EL ENTREVISTADOR: la siguiente declaración deberá leerse a todos los entrevistados potenciales]. ¿Me podría dar un minuto de su tiempo? LA AGENCIA desea seguir proporcionándole servicios convenientes, accesibles y de alta calidad. Para poder hacerlo, será necesario que LA AGENCIA incremente los precios de algunos de sus servicios. Quisiéramos saber cómo le afectarían estos cambios de precio. No hay respuestas correctas ni equivocadas, así que le agradeceremos que, por favor, sea sincero y nos diga lo que para usted es verdad. La información que se está recolectando se utilizará solamente con propósitos de planeación y su participación no implica ni riesgos ni beneficios para usted. No necesito que me proporcione su nombre ni su dirección. Todo lo que usted diga será absolutamente confidencial, y el único elemento para identificar este cuestionario será un número, y no su nombre. Nadie, incluyendo a los trabajadores de esta clínica, sabrá lo que usted nos ha dicho y a nadie se le proporcionará su nombre. Los servicios estarán disponibles para usted tanto si decide participar como si decide no hacerlo. La entrevista dura alrededor de 15 minutos. Usted podrá dar por terminada la entrevista en cualquier momento, sin que esto conlleve ninguna consecuencia. ¿Tiene alguna pregunta? ¿Le gustaría participar? Si desea obtener mayor información acerca de este estudio, por favor diríjase a en

1. Participación SÍ (Proceda a realizar la entrevista)

NO (Agradezca al entrevistado y deséele un buen día)

[El entrevistador conservará todos los cuestionarios, independientemente de que el entrevistado potencial decida participar o no].

2. Número de cuestionario: [_] [_] [_] [_]

3. Número de Clínica:

4. Nombre del entrevistador:

5. Fecha de la entrevista: Día __ Mes__ Año

6. Hora en que comenzó la entrevista:

7. Hora en que terminó la entrevista: 
A. Preguntas demográficas

\begin{tabular}{|c|c|c|c|}
\hline P. & PREGUNTA & CODIGO DE RESPUESTA & PASE A \\
\hline 100 & $\begin{array}{l}\text { ¿Cuántos años cumplió en su último } \\
\text { cumpleaños? }\end{array}$ & Años & \\
\hline 101 & ¿Cuál es su estado civil? & $\begin{array}{ll}\text { Casada(o)/Unión libre } & 1 \\
\text { Viudo(a), Separado(a), Divorciado(a) } & 2 \\
\text { Soltero } & 3\end{array}$ & \\
\hline 102 & ¿Cuántos hijos vivos tiene? & $\begin{array}{ll}\text { Ninguno } & 00 \\
\text { Cantidad } & \\
\end{array}$ & $\begin{array}{l}\text { PASE A } \\
104\end{array}$ \\
\hline 103 & $\begin{array}{l}\text { ¿Cuántos hijos vivos tiene que estén en los } \\
\text { siguientes grupos de edad? }\end{array}$ & $\begin{array}{l}\text { NO. DE HIJOS } \\
\end{array}$ & \\
\hline 104 & $\begin{array}{l}\text { ¿Cuál es el máximo grado que aprobó en la } \\
\text { escuela? } \\
\text { SONDEAR PARA EL AÑO MÁS ALTO } \\
\text { COMPLETADO }\end{array}$ & 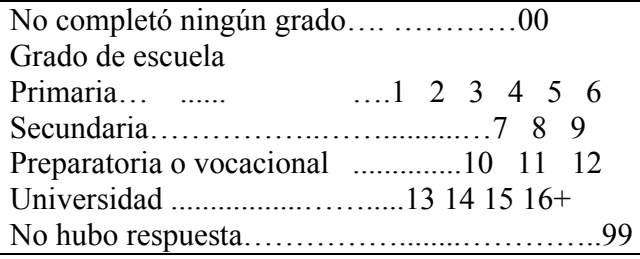 & \\
\hline
\end{tabular}

\section{B. Preguntas sobre capacidad de pago}

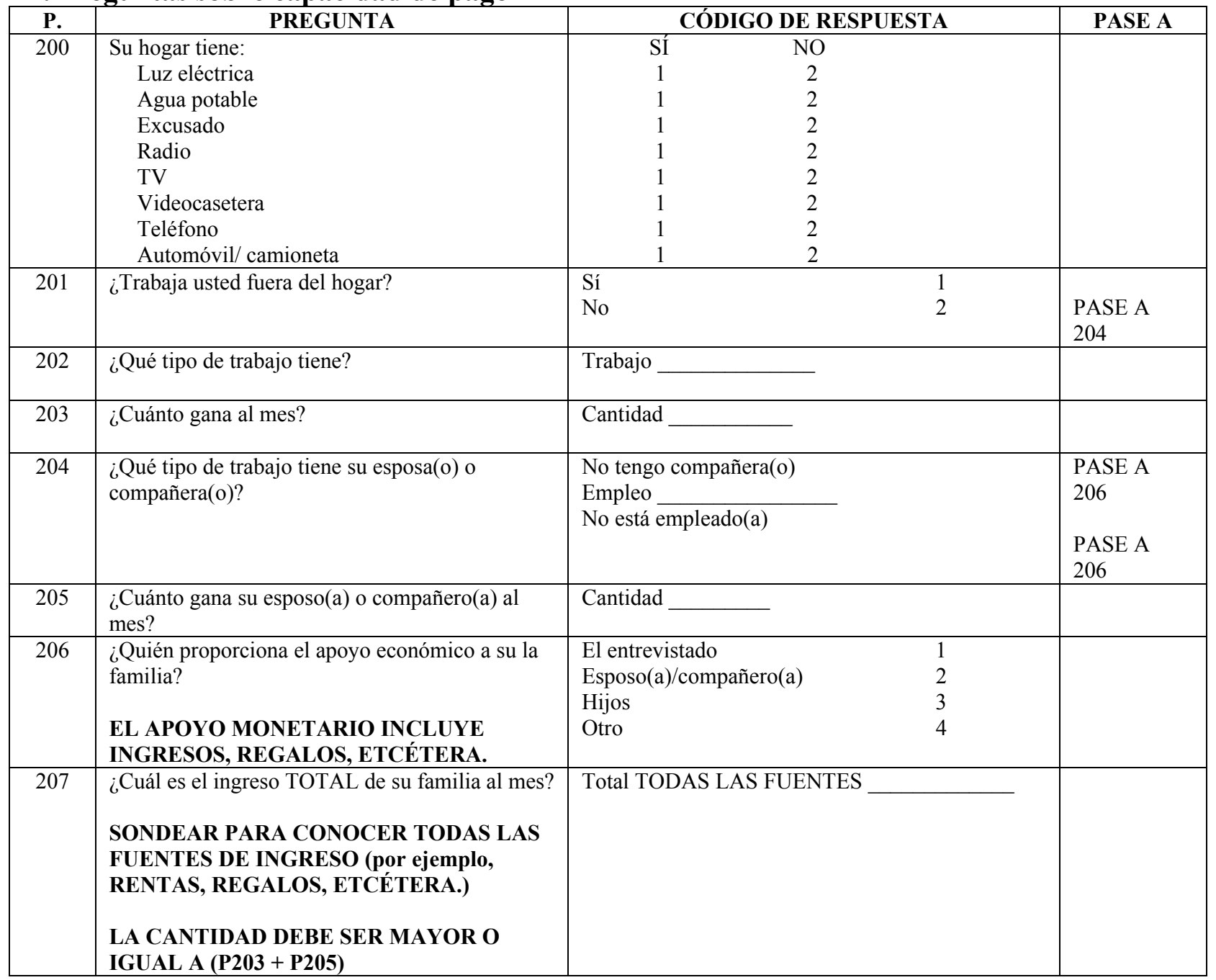




\section{Tipo de visita}

\begin{tabular}{|c|c|c|c|c|}
\hline $\mathbf{P .}$ & PREGUNTA & \multicolumn{2}{|c|}{ CODIGO DE REPUESTA } & PASE A \\
\hline 300 & ¿Es esta su primer visita a LA AGENCIA? & $\begin{array}{l}\text { Sí } \\
\text { No }\end{array}$ & $\begin{array}{l}1 \\
2\end{array}$ & PASE A 302 \\
\hline 301 & $\begin{array}{l}\text { ¿Su visita hoy es una revisita programada } \\
\text { durante una cita anterior? }\end{array}$ & $\begin{array}{l}\text { Sí } \\
\text { No }\end{array}$ & $\begin{array}{l}1 \\
2\end{array}$ & \\
\hline 302 & $\begin{array}{l}\text { ¿Cuál fue el servicio principal que recibió usted } \\
\text { hoy? }\end{array}$ & $\begin{array}{l}\text { Ginecología } \\
\text { Anticonceptivo inyectable } \\
\text { Inserción de DIU } \\
\text { Revisita de DIU } \\
\text { Visita para píldora } \\
\text { Cuidado prenatal } \\
\text { Otro: especificar }\end{array}$ & $\begin{array}{l}1 \\
2 \\
3 \\
4 \\
5 \\
6\end{array}$ & $\begin{array}{l}\text { PASE A } 400 \\
\text { PASE A } 500 \\
\text { PASE A } 600 \\
\text { PASE A } 700 \\
\text { PASE A } 800 \\
\text { PASE A } 900 \\
\text { PASE AL } \\
\text { FINAL }\end{array}$ \\
\hline
\end{tabular}

\section{Preguntas de voluntad de pago: usuarios activos}

\section{Ginecología}

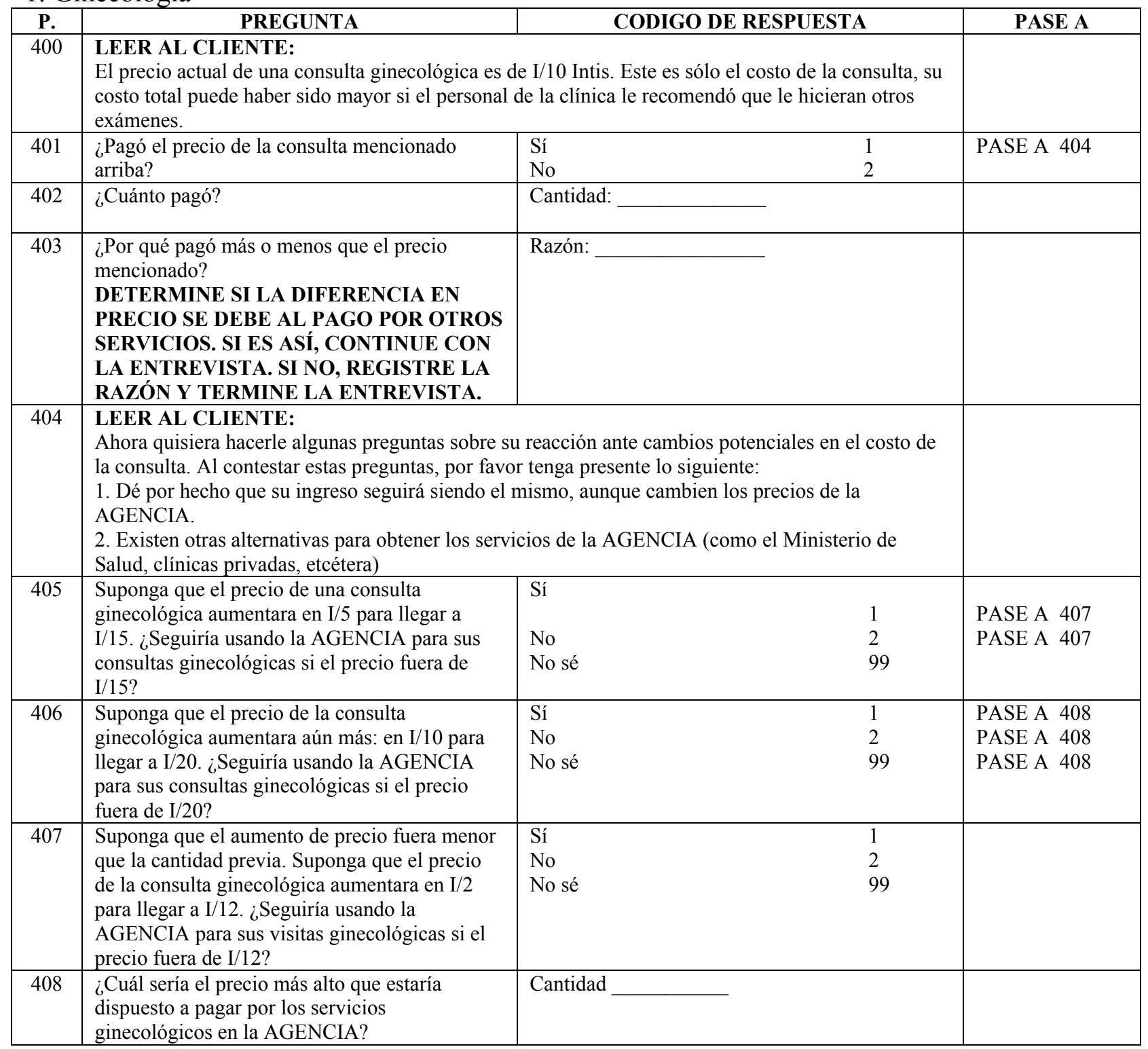




\begin{tabular}{|c|c|c|c|c|}
\hline 409 & $\begin{array}{l}\text { Si la AGENCIA subiera el precio del servicio } \\
\text { ginecológico más allá de lo que es capaz o está } \\
\text { dispuesto a pagar, ¿qué haría? }\end{array}$ & $\begin{array}{l}\text { Quedarme sin el servicio } \\
\text { Ir a otro lugar } \\
\text { No sé } \\
\text { Otro: especificar }\end{array}$ & $\begin{array}{l}1 \\
2 \\
99 \\
88\end{array}$ & $\begin{array}{ll}\text { PASE A } & 1000 \\
\text { PASE A } & 410 \\
\text { PASE A } 1000 \\
\text { PASE A } 1000\end{array}$ \\
\hline 410 & $\begin{array}{l}\text { ¿A dónde iría? } \\
\text { NO LEA LAS OPCIONES } \\
\text { MARQUE TODAS LAS MENCIONADAS }\end{array}$ & $\begin{array}{l}\text { Sector público } \\
\text { Otra ONG } \\
\text { Sector privado } \\
\text { Farmacia } \\
\text { Otro: especificar } \\
\text { No sé }\end{array}$ & $\begin{array}{l}1 \\
2 \\
3 \\
4 \\
88 \\
99\end{array}$ & $\begin{array}{ll}\text { PASE A } 1000 \\
\text { PASE A } 1000 \\
\text { PASE A } 1000 \\
\text { PASE A } 1000 \\
\text { PASE A } 1000 \\
\text { PASE A } 1000\end{array}$ \\
\hline
\end{tabular}

2. Anticonceptivo inyectable

\begin{tabular}{|c|c|c|c|c|}
\hline P. & PREGUNTA & \multicolumn{2}{|c|}{ CODIGO DE RESPUESTA } & PASE A \\
\hline 500 & \multicolumn{3}{|c|}{$\begin{array}{l}\text { LEER AL CLIENTE: } \\
\text { El costo actual del anticonceptivo inyectable es I/12 Intis. Este es sólo solamente el costo de la } \\
\text { consulta y de la inyección, el costo total puede ser mayor si el personal de la clínica le recomendó } \\
\text { que se le hicieran otros exámenes. }\end{array}$} & \\
\hline 501 & ¿Pagó el precio que mencionamos arriba? & $\begin{array}{l}\text { Sí } \\
\text { No }\end{array}$ & $\begin{array}{l}1 \\
2 \\
\end{array}$ & PASE A 504 \\
\hline 502 & ¿Cuánto pagó? & Cantidad: & & \\
\hline 503 & $\begin{array}{l}\text { ¿Por qué pagó más o menos que el precio } \\
\text { establecido arriba? } \\
\text { DETERMINE SI LA DIFERENCIA EN } \\
\text { PRECIO SE DEBE AL PAGO POR OTROS } \\
\text { SERVICIOS. SI ES ASÍ, CONTINUE CON } \\
\text { LA ENTREVISTA. SI NO, REGISTRE LA } \\
\text { RAZÓN Y TERMINE LA ENTREVISTA. }\end{array}$ & Razón: & & \\
\hline 504 & \multicolumn{3}{|c|}{$\begin{array}{l}\text { LEER AL CLIENTE: } \\
\text { Ahora quisiera hacerle algunas preguntas sobre su respuesta a cambios potenciales en el costo de la } \\
\text { consulta. Al contestar estas preguntas, por favor tenga en mente lo siguiente: } \\
\text { 1. Suponga que su ingreso seguirá siendo el mismo aunque cambien los precios de la AGENCIA. } \\
\text { 2. Existen otras alternativas para obtener los servicios de la AGENCIA (como el Ministerio de } \\
\text { salud, clínicas privadas, etcétera). }\end{array}$} & \\
\hline 505 & $\begin{array}{l}\text { Suponga que el precio del anticonceptivo } \\
\text { inyectable aumentara en } \mathrm{I} / 5 \text { para llegar a } \mathrm{I} / 17 \text {. } \\
\text { ¿Vendría a la AGENCIA por su inyección si el } \\
\text { precio fuera } \mathrm{I} / 17 \text { ? }\end{array}$ & $\begin{array}{l}\text { Sí } \\
\text { No } \\
\text { No sé }\end{array}$ & $\begin{array}{l}1 \\
2 \\
99\end{array}$ & $\begin{array}{l}\text { PASE A } 507 \\
\text { PASE A } 507\end{array}$ \\
\hline 506 & $\begin{array}{l}\text { Suponga que el precio del anticonceptivo } \\
\text { inyectable aumentara aún más: en } \mathrm{I} / 10 \text { para } \\
\text { llegar a I/22. ¿Vendría a la AGENCIA por su } \\
\text { inyección si el precio fuera } I / 22 \text { ? }\end{array}$ & $\begin{array}{l}\text { Sí } \\
\text { No } \\
\text { No sé }\end{array}$ & $\begin{array}{l}1 \\
2 \\
99\end{array}$ & $\begin{array}{l}\text { PASE A } 508 \\
\text { PASE A } 508 \\
\text { PASE A } 508\end{array}$ \\
\hline 507 & $\begin{array}{l}\text { Suponga que el aumento de precio fuera menor } \\
\text { que la cantidad previa. Suponga que el precio } \\
\text { del anticonceptivo inyectable aumentara en } \mathrm{I} / 3 \\
\text { para llegar a I/15. ¿Vendría a la AGENCIA por } \\
\text { su inyección si el precio fuera I/15? }\end{array}$ & $\begin{array}{l}\text { Sí } \\
\text { No } \\
\text { No sé }\end{array}$ & $\begin{array}{l}1 \\
2 \\
99\end{array}$ & \\
\hline 508 & $\begin{array}{l}\text { ¿Cuál sería el precio más alto que estaría } \\
\text { dispuesto a pagar por el anticonceptivo } \\
\text { inyectable de la AGENCIA? }\end{array}$ & Cantidad & & \\
\hline 509 & $\begin{array}{l}\text { Si la AGENCIA subiera el precio del } \\
\text { anticonceptivo inyectable más allá de lo que } \\
\text { estuviera dispuesta o pudiera pagar, ¿qué haría? }\end{array}$ & $\begin{array}{l}\text { No utilizaría un método anticonce } \\
\text { Ir a otro lugar } \\
\text { Cambiar a un método más barato } \\
\quad \text { especificar: } \\
\text { Otro: especificar } \\
\text { No sé }\end{array}$ & $\begin{array}{r}1 \\
2 \\
3 \\
88 \\
99\end{array}$ & $\begin{array}{ll}\text { PASE A } & 1000 \\
\text { PASE A } & 510 \\
\text { PASE A } & 1000 \\
\text { PASE A } & 1000 \\
\text { PASE A } & 1000 \\
\text { PASE A } & 1000 \\
\end{array}$ \\
\hline 510 & $\begin{array}{l}\text { ¿A dónde iría? } \\
\text { NO LEA LAS OPCIONES } \\
\text { MARQUE TODAS LAS MENCIONADAS }\end{array}$ & $\begin{array}{l}\text { Sector público } \\
\text { Otra ONG } \\
\text { Sector privado } \\
\text { Farmacia } \\
\text { Otro: especificar } \\
\text { No sé }\end{array}$ & $\begin{array}{l}1 \\
2 \\
3 \\
4 \\
88 \\
99\end{array}$ & $\begin{array}{ll}\text { PASE A } & 1000 \\
\text { PASE A } & 1000 \\
\text { PASE A } & 1000 \\
\text { PASE A } & 1000 \\
\text { PASE A } & 1000 \\
\text { PASE A } & 1000\end{array}$ \\
\hline
\end{tabular}


3. Inserción de DIU

\begin{tabular}{|c|c|c|c|c|}
\hline P. & PREGUNTA & \multicolumn{2}{|c|}{ CODIGO DE RESPUESTA } & PASE A \\
\hline 600 & \multicolumn{3}{|c|}{$\begin{array}{l}\text { LEER AL CLIENTE: } \\
\text { El costo actual de la Inserción de DIU es I/15 Intis. Este es sólo solamente el costo de la consulta y } \\
\text { el DIU, su costo total puede ser mayor si el personal de la clínica recomendó que se le hicieran otros } \\
\text { exámenes. }\end{array}$} & \\
\hline 601 & ¿Pagó el precio que mencionamos arriba? & $\begin{array}{l}\text { Sí } \\
\text { No }\end{array}$ & & PASE A 604 \\
\hline 602 & ¿Cuánto pagó? & Cantidad: & & \\
\hline 603 & $\begin{array}{l}\text { ¿Por qué pagó más/ menos que ese precio? } \\
\\
\text { DETERMINE SI LA DIFERENCIA EN } \\
\text { PRECIO SE DEBE AL PAGO POR OTROS } \\
\text { SERVICIOS. SI ES ASÍ, CONTINUE CON } \\
\text { LA ENTREVISTA. SI NO, REGISTRE LA } \\
\text { RAZÓN Y TERMINE LA ENTREVISTA. }\end{array}$ & Razón: & & \\
\hline 604 & \multicolumn{3}{|c|}{$\begin{array}{l}\text { LEER AL CLIENTE: } \\
\text { Ahora quisiera hacerle algunas preguntas sobre su respuesta a cambios potenciales en el costo de la } \\
\text { consulta. Al contestar estas preguntas, por favor tenga en mente lo siguiente: } \\
\text { 1. Dé por hecho que su ingreso seguirá siendo el mismo, aunque cambien los precios de la } \\
\text { AGENCIA. } \\
\text { 2. Existen otras alternativas para obtener los servicios de la AGENCIA (como el Ministerio de } \\
\text { Salud, clínicas privadas, etcétera) }\end{array}$} & \\
\hline 605 & $\begin{array}{l}\text { Suponga que el precio de la inserción de DIU } \\
\text { aumentara en } \mathrm{I} / 5 \text { para llegar a } \mathrm{I} / 20 \text {, ¿vendría a } \\
\text { la AGENCIA por su inserción de DIU si el } \\
\text { precio fuera de } \mathrm{I} / 20 \text { ? }\end{array}$ & $\begin{array}{l}\text { Sí } \\
\text { No } \\
\text { No sé }\end{array}$ & $\begin{array}{l}1 \\
2 \\
99\end{array}$ & $\begin{array}{l}\text { PASE A } 607 \\
\text { PASE A } 607\end{array}$ \\
\hline 606 & $\begin{array}{l}\text { Suponga que el precio de la inserción de DIU } \\
\text { aumentara aún más, en I/10 para llegar a } \mathrm{I} / 25 \text {. } \\
\text { ¿Vendría a la AGENCIA por su inserción de } \\
\text { DIU si el precio fuera I/25? }\end{array}$ & $\begin{array}{l}\text { Sí } \\
\text { No } \\
\text { No sé }\end{array}$ & $\begin{array}{l}1 \\
2 \\
99\end{array}$ & $\begin{array}{l}\text { PASE A } 608 \\
\text { PASE A } 608 \\
\text { PASE A } 608\end{array}$ \\
\hline 607 & $\begin{array}{l}\text { Suponga que el aumento de precio fuera menor } \\
\text { que la cantidad previa. Suponga que el precio } \\
\text { de la inserción de DIU aumentara en I/3 para } \\
\text { llegar a I/18. ¿vendría a la AGENCIA por su } \\
\text { inserción de DIU si el precio fuera I/18? }\end{array}$ & $\begin{array}{l}\text { Sí } \\
\text { No } \\
\text { No sé }\end{array}$ & $\begin{array}{l}1 \\
2 \\
99\end{array}$ & \\
\hline 608 & $\begin{array}{l}\text { ¿Cuál sería el precio más alto que estaría } \\
\text { dispuesto a pagar por la inserción de DIU en la } \\
\text { AGENCIA? }\end{array}$ & Cantidad & & \\
\hline 609 & $\begin{array}{l}\text { Si la AGENCIA subiera el precio de la } \\
\text { inserción de DIU más allá de lo que pudiera o } \\
\text { estuviera dispuesta a pagar, ¿qué haría? }\end{array}$ & $\begin{array}{l}\text { No utilizaría un método anticonce } \\
\text { Ir a otro lugar } \\
\text { Cambiar a un método más barato } \\
\text { Especificar: } \\
\text { Otro: especificar } \\
\text { No sé }\end{array}$ & $\begin{array}{r}1 \\
2 \\
3 \\
88 \\
99 \\
\end{array}$ & $\begin{array}{ll}\text { PASE A } & 1000 \\
\text { PASE A } & 610 \\
\text { PASE A } & 1000 \\
\text { PASE A } & 1000 \\
\text { PASE A } & 1000 \\
\text { PASE A } & 1000 \\
\end{array}$ \\
\hline 610 & $\begin{array}{l}\text { ¿A dónde iría? } \\
\text { NO LEA LAS OPCIONES } \\
\text { MARQUE TODAS LAS MENCIONADAS }\end{array}$ & $\begin{array}{l}\text { Sector público } \\
\text { Otra ONG } \\
\text { Sector privado } \\
\text { Farmacia } \\
\text { Otro: especificar } \\
\text { No sé }\end{array}$ & $\begin{array}{l}1 \\
2 \\
3 \\
4 \\
88 \\
99 \\
\end{array}$ & $\begin{array}{ll}\text { PASE A } & 1000 \\
\text { PASE A } & 1000 \\
\text { PASE A } 1000 \\
\text { PASE A } 1000 \\
\text { PASE A } 1000 \\
\text { PASE A } 1000 \\
\end{array}$ \\
\hline
\end{tabular}




\begin{tabular}{|c|c|c|c|c|}
\hline $\mathbf{P .}$ & PREGUNTA & \multicolumn{2}{|c|}{ CODIGO DE RESPUESTA } & PASE A \\
\hline 700 & \multicolumn{3}{|c|}{$\begin{array}{l}\text { LEER AL CLIENTE: } \\
\text { El costo actual de las consultas de revisión del DIU es de I/10 Intis. Este es sólo el costo de la } \\
\text { consulta, pero el costo total puede ser mayor si el personal de la clínica le recomendó que se le } \\
\text { hicieran otros exámenes. }\end{array}$} & \\
\hline 701 & ¿Pagó el precio que mencionamos arriba? & $\begin{array}{l}\text { Sí } \\
\text { No }\end{array}$ & & PASE A 704 \\
\hline 702 & ¿Cuánto pagó? & Cantidad: & & \\
\hline 703 & $\begin{array}{l}\text { ¿Por qué pagó más o menos que el precio que } \\
\text { establecimos arriba? } \\
\text { DETERMINE SI LA DIFERENCIA EN } \\
\text { PRECIO SE DEBE AL PAGO POR OTROS } \\
\text { SERVICIOS. SI ES ASÍ, CONTINUE CON } \\
\text { LA ENTREVISTA. SI NO, REGISTRE LA } \\
\text { RAZÓN Y TERMINE LA ENTREVISTA. }\end{array}$ & Razón: & & \\
\hline 704 & \multicolumn{3}{|c|}{$\begin{array}{l}\text { LEER AL CLIENTE: } \\
\text { Ahora quisiera hacerle algunas preguntas sobre su respuesta a cambios potenciales en el costo de la } \\
\text { consulta. Al contestar estas preguntas, por favor tenga en mente lo siguiente: } \\
\text { 1. Suponga que su ingreso seguirá siendo el mismo aunque cambien los precios de la AGENCIA. } \\
\text { 2. Existen otras alternativas para obtener los servicios de la AGENCIA- }\end{array}$} & \\
\hline 705 & $\begin{array}{l}\text { Suponga que el precio de las revisitas de DIU } \\
\text { aumentara en } \mathrm{I} / 5 \text { para llegar a } \mathrm{I} / 15 \text {. ¿vendría a } \\
\text { la AGENCIA para las revisitas de DIU si el } \\
\text { precio fuera de } \mathrm{I} / 15 \text { ? }\end{array}$ & $\begin{array}{l}\text { Sí } \\
\text { No } \\
\text { No sé }\end{array}$ & $\begin{array}{l}1 \\
2 \\
99\end{array}$ & $\begin{array}{l}\text { PASE A } 707 \\
\text { PASE A } 707\end{array}$ \\
\hline 706 & $\begin{array}{l}\text { Suponga que el precio de la revisita de DIU } \\
\text { aumentara aún más, en I/10 para llegar a } \mathrm{I} / 20 \text {. } \\
\text { ¿vendría a la AGENCIA a su consulta de } \\
\text { revisión de DIU si el precio fuera } \mathrm{I} / 20 \text { ? }\end{array}$ & $\begin{array}{l}\text { Sí } \\
\text { No } \\
\text { No sé }\end{array}$ & $\begin{array}{l}1 \\
2 \\
99\end{array}$ & $\begin{array}{l}\text { PASE A } 708 \\
\text { PASE A } 708 \\
\text { PASE A } 708\end{array}$ \\
\hline 707 & $\begin{array}{l}\text { Suponga que el aumento de precio fuera menor } \\
\text { que la cantidad previa. Suponga que el precio } \\
\text { de la revisita de DIU aumentara en } \mathrm{I} / 2 \text { para } \\
\text { llegar a } \mathrm{I} / 12 \text {. ¿vendría a la AGENCIA por su } \\
\text { revisita de DIU si el precio fuera I/12? }\end{array}$ & $\begin{array}{l}\text { Sí } \\
\text { No } \\
\text { No sé }\end{array}$ & $\begin{array}{l}1 \\
2 \\
99\end{array}$ & \\
\hline 708 & $\begin{array}{l}\text { ¿Cuál sería el precio más alto que estaría } \\
\text { dispuesto a pagar por la consulta de revisión de } \\
\text { DIU en la AGENCIA? }\end{array}$ & Cantidad & & \\
\hline 709 & $\begin{array}{l}\text { Si la AGENCIA subiera el precio de la revisita } \\
\text { de DIU más allá de lo que quisiera o pudiera } \\
\text { pagar ¿qué haría? }\end{array}$ & $\begin{array}{l}\text { Quedarme sin el servicio } \\
\text { Ir a otro lugar } \\
\text { No sé } \\
\text { Otro: especificar }\end{array}$ & $\begin{array}{l}1 \\
2 \\
99 \\
88\end{array}$ & $\begin{array}{ll}\text { PASE A } & 1000 \\
\text { PASE A } & 710 \\
\text { PASE A } & 1000 \\
\text { PASE A } & 1000\end{array}$ \\
\hline 710 & $\begin{array}{l}\text { ¿A dónde iría? } \\
\text { NO LEA LAS OPCIONES } \\
\text { MARQUE TODAS LAS MENCIONADAS }\end{array}$ & $\begin{array}{l}\text { Sector público } \\
\text { Otra ONG } \\
\text { Sector privado } \\
\text { Farmacia } \\
\text { Otro: especificar } \\
\text { No sé }\end{array}$ & $\begin{array}{l}1 \\
2 \\
3 \\
4 \\
88 \\
99\end{array}$ & $\begin{array}{ll}\text { PASE A } 1000 \\
\text { PASE A } 1000 \\
\text { PASE A } 1000 \\
\text { PASE A } 1000 \\
\text { PASE A } 1000 \\
\text { PASE A } 1000\end{array}$ \\
\hline
\end{tabular}


5. Compra de hormonales orales

\begin{tabular}{|c|c|c|c|c|}
\hline $\mathbf{P .}$ & PREGUNTA & \multicolumn{2}{|c|}{ CODIGO DE RESPUESTA } & PASE A \\
\hline 800 & \multicolumn{3}{|c|}{$\begin{array}{l}\text { LEER AL CLIENTE: } \\
\text { El costo actual de (la MARCA) de anticonceptivos orales es I/3 Intis. Este es sólo el costo de un } \\
\text { ciclo de píldoras, pero el costo total de la consulta puede ser mayor si el personal de la clínica le } \\
\text { recomendó que se le hicieran otros exámenes. }\end{array}$} & \\
\hline 801 & ¿Pagó el precio que mencionamos arriba? & $\begin{array}{l}\text { Sí } \\
\text { No }\end{array}$ & $\begin{array}{l}1 \\
2\end{array}$ & PASE A 804 \\
\hline 802 & ¿Cuánto pagó? & Cantidad: & & \\
\hline 803 & $\begin{array}{l}\text { ¿Por qué pagó más o menos que el precio } \\
\text { establecido? } \\
\text { DETERMINE SI LA DIFERENCIA EN } \\
\text { PRECIO SE DEBE AL PAGO POR OTROS } \\
\text { SERVICIOS. SI ES ASÍ, CONTINUE CON } \\
\text { LA ENTREVISTA. SI NO, REGISTRE LA } \\
\text { RAZÓN Y TERMINE LA ENTREVISTA. }\end{array}$ & Razón: & & \\
\hline 804 & \multicolumn{3}{|c|}{$\begin{array}{l}\text { LEER AL CLIENTE: } \\
\text { Ahora quisiera hacerle algunas preguntas sobre su respuesta a cambios potenciales en el costo de la } \\
\text { consulta. Al contestar estas preguntas, por favor tenga en mente lo siguiente: } \\
\text { 1. Suponga que su ingreso seguirá siendo el mismo aunque cambien los precios de la AGENCIA. } \\
\text { 2. Existen otras alternativas para obtener los servicios de la AGENCIA (como el Ministerio de } \\
\text { Salud, clínicas privadas, etcétera) }\end{array}$} & \\
\hline 805 & $\begin{array}{l}\text { Suponga que el precio de la MARCA de } \\
\text { anticonceptivos orales aumentara en } I / 2 \text { para } \\
\text { llegar a } I / 5 . \text { ¿Compraría las píldoras de la } \\
\text { AGENCIA si el precio fuera de } I / 5 \text { ? }\end{array}$ & $\begin{array}{l}\text { Sí } \\
\text { No } \\
\text { No sé }\end{array}$ & $\begin{array}{l}1 \\
2 \\
99\end{array}$ & $\begin{array}{l}\text { PASE A } 807 \\
\text { PASE A } 807\end{array}$ \\
\hline 806 & $\begin{array}{l}\text { Suponga que el precio de la MARCA de } \\
\text { anticonceptivos orales aumentara aún más, en } \\
\mathrm{I} / 3 \text { para llegar a } / 6 \text {. ¿Compraría las píldoras de } \\
\text { la AGENCIA si el precio fuera de } / / 6 \text { ? }\end{array}$ & $\begin{array}{l}\text { Sí } \\
\text { No } \\
\text { No sé }\end{array}$ & $\begin{array}{l}1 \\
2 \\
99\end{array}$ & $\begin{array}{l}\text { PASE A } 808 \\
\text { PASE A } 808 \\
\text { PASE A } 808\end{array}$ \\
\hline 807 & $\begin{array}{l}\text { Suponga que el aumento de precio fuera menor } \\
\text { que la cantidad previa. Suponga que el precio } \\
\text { de la MARCA de anticonceptivos orales } \\
\text { aumentara en I/1 para llegar a } / / 4 \text {. ¿Compraría } \\
\text { las píldoras de la AGENCIA si el precio fuera } \\
\text { de I/4? }\end{array}$ & $\begin{array}{l}\text { Sí } \\
\text { No } \\
\text { No sé }\end{array}$ & $\begin{array}{l}1 \\
2 \\
99\end{array}$ & \\
\hline 808 & $\begin{array}{l}\text { ¿Cuál sería el precio más alto que estaría } \\
\text { dispuesto a pagar por la MARCA de } \\
\text { anticonceptivos orales de la AGENCY? }\end{array}$ & Cantidad & & \\
\hline 809 & $\begin{array}{l}\text { Si la AGENCIA subiera el precio de la } \\
\text { MARCA de anticonceptivos más allá de lo que } \\
\text { pudiera o estuviera dispuesto a pagar ¿qué } \\
\text { haría? }\end{array}$ & $\begin{array}{l}\text { No utilizaría un método anticonce } \\
\text { Ir a otro lugar } \\
\text { Cambiar a un método más barato } \\
\text { Especificar: } \\
\text { Otro: especificar } \\
\text { No sé }\end{array}$ & $\begin{array}{l}1 \\
2 \\
3 \\
\\
88 \\
99\end{array}$ & $\begin{array}{ll}\text { PASE A } & 1000 \\
\text { PASE A } & 810 \\
\text { PASE A } & 1000 \\
\text { PASE A } & 1000 \\
\text { PASE A } & 1000 \\
\text { PASE A } & 1000 \\
\end{array}$ \\
\hline 810 & $\begin{array}{l}\text { ¿A dónde iría? } \\
\text { NO LEA LAS OPCIONES } \\
\text { MARQUE TODAS LAS MENCIONADAS }\end{array}$ & $\begin{array}{l}\text { Sector público } \\
\text { Otra ONG } \\
\text { Sector privado } \\
\text { Farmacia } \\
\text { Otro: especificar } \\
\text { No sé }\end{array}$ & $\begin{array}{l}1 \\
2 \\
3 \\
4 \\
88 \\
99 \\
\end{array}$ & $\begin{array}{ll}\text { PASE A } & 1000 \\
\text { PASE A } & 1000 \\
\text { PASE A } 1000 \\
\text { PASE A } 1000 \\
\text { PASE A } 1000 \\
\text { PASE A } 1000 \\
\end{array}$ \\
\hline
\end{tabular}


6. Cuidado prenatal

\begin{tabular}{|c|c|c|c|c|}
\hline P. & PREGUNTA & \multicolumn{2}{|c|}{ CODIGO DE RESPUESTA } & PASE A \\
\hline 900 & \multicolumn{3}{|c|}{$\begin{array}{l}\text { LEER AL CLIENTE: } \\
\text { El costo actual de una consulta de cuidado prenatal es de } \mathrm{I} / 15 \text { Intis. Este es solamente el costo de la } \\
\text { consulta, pero el costo total puede ser mayor si el personal de la clínica le recomendó que se le } \\
\text { hicieran otros exámenes. }\end{array}$} & \\
\hline 901 & ¿Pagó el precio que mencionamos arriba? & $\begin{array}{l}\text { Sí } \\
\text { No }\end{array}$ & $\begin{array}{l}1 \\
2\end{array}$ & PASE A 904 \\
\hline 902 & ¿Cuánto pagó? & Cantidad: & & \\
\hline 903 & $\begin{array}{l}\text { ¿Por qué pagó más o menos que el precio } \\
\text { establecido? } \\
\text { DETERMINE SI LA DIFERENCIA EN } \\
\text { PRECIO SE DEBE AL PAGO POR OTROS } \\
\text { SERVICIOS. SI ES ASÍ, CONTINUE CON } \\
\text { LA ENTREVISTA. SI NO, REGISTRE LA } \\
\text { RAZÓN Y TERMINE LA ENTREVISTA.. }\end{array}$ & Razón: & & \\
\hline 904 & \multicolumn{3}{|c|}{$\begin{array}{l}\text { LEER AL CLIENTE: } \\
\text { Ahora quisiera hacerle algunas preguntas sobre su respuesta a cambios potenciales en el costo de la } \\
\text { consulta. Al contestar estas preguntas, por favor tenga en mente lo siguiente: } \\
\text { 1. Suponga que su ingreso seguirá siendo el mismo aunque cambien los precios de la AGENCIA. } \\
\text { 2. Existen otras alternativas para obtener los servicios de la AGENCIA (como el Ministerio de } \\
\text { Salud, clínicas privadas, etcétera) }\end{array}$} & \\
\hline 905 & $\begin{array}{l}\text { Suponga que el precio del cuidado prenatal } \\
\text { aumentara en } I / 5 \text { para llegar a } I / 20 \text {. ¿Vendría a } \\
\text { la AGENCIA para su cuidado prenatal si el } \\
\text { precio fuera } I / 20 \text { ? }\end{array}$ & $\begin{array}{l}\text { Sí } \\
\text { No } \\
\text { No sé }\end{array}$ & $\begin{array}{l}1 \\
2 \\
99\end{array}$ & $\begin{array}{l}\text { PASE A } 907 \\
\text { PASE A } 907\end{array}$ \\
\hline 906 & $\begin{array}{l}\text { Suponga que el precio del cuidado prenatal } \\
\text { aumentara aún más, en } \mathrm{I} / 10 \text { para llegar a } \mathrm{I} / 25 \text {. } \\
\text { ¿Vendría a la AGENCIA para su cuidado } \\
\text { prenatal si el precio fuera I/25? }\end{array}$ & $\begin{array}{l}\text { Sí } \\
\text { No } \\
\text { No sé }\end{array}$ & $\begin{array}{l}1 \\
2 \\
99\end{array}$ & $\begin{array}{l}\text { PASE A } 908 \\
\text { PASE A } 908 \\
\text { PASE A } 908\end{array}$ \\
\hline 907 & $\begin{array}{l}\text { Suponga que el aumento de precio fuera menor } \\
\text { que la cantidad previa. Suponga que el precio } \\
\text { del cuidado prenatal aumentara en I/2 para } \\
\text { llegar a } / 17 \text {. ¿Vendría a la AGENCIA para su } \\
\text { cuidado prenatal si el precio fuera I/17? }\end{array}$ & $\begin{array}{l}\text { Sí } \\
\text { No } \\
\text { No sé }\end{array}$ & $\begin{array}{l}1 \\
2 \\
99\end{array}$ & \\
\hline 908 & $\begin{array}{l}\text { ¿Cuál sería el precio más alto que estaría } \\
\text { dispuesto a pagar por el cuidado prenatal de la } \\
\text { AGENCIA? }\end{array}$ & Cantidad & & \\
\hline 909 & $\begin{array}{l}\text { Si la AGENCIA subiera el precio del cuidado } \\
\text { prenatal más allá de lo que pudiera o estuviera } \\
\text { dispuesta a pagar, ¿qué haría? }\end{array}$ & $\begin{array}{l}\text { Quedarme sin el servicio } \\
\text { Ir a otro lugar } \\
\text { No sé } \\
\text { Otro: especificar }\end{array}$ & $\begin{array}{l}1 \\
2 \\
99 \\
88 \\
\end{array}$ & $\begin{array}{ll}\text { PASE A } & 1000 \\
\text { PASE A } 910 \\
\text { PASE A } 1000 \\
\text { PASE A } 1000 \\
\end{array}$ \\
\hline 910 & $\begin{array}{l}\text { ¿A dónde iría? } \\
\text { NO LEA LAS OPCIONES } \\
\text { MARQUE TODAS LAS MENCIONADAS }\end{array}$ & $\begin{array}{l}\text { Sector público } \\
\text { Otra ONG } \\
\text { Sector privado } \\
\text { Farmacia } \\
\text { Otro: especificar } \\
\text { No sé }\end{array}$ & $\begin{array}{l}1 \\
2 \\
3 \\
4 \\
88 \\
99\end{array}$ & $\begin{array}{ll}\text { PASE A } 1000 \\
\text { PASE A } 1000 \\
\text { PASE A } 1000 \\
\text { PASE A } 1000 \\
\text { PASE A } 1000 \\
\text { PASE A } 1000\end{array}$ \\
\hline
\end{tabular}




\section{(LAS SIGUIENTES PREGUNTAS SE LE HACEN A TODOS LOS ENTREVISTADOS QUE HAN COMPLETADO UNA SECUENCIA PREVIA DE VDP)}

\section{E. Preguntas VDP: usuarios potenciales}

1. Esterilización femenina

\begin{tabular}{|c|c|c|c|c|}
\hline $\mathbf{P .}$ & PREGUNTA & \multicolumn{2}{|c|}{ CODIGO DE RESPUESTA } & PASE A \\
\hline 1000 & $\begin{array}{l}\text { ¿Ha oído hablar de la operación para no tener } \\
\text { más hijos (VSC, siglas en inglés)? }\end{array}$ & $\begin{array}{l}\text { Sí } \\
\text { No } \\
\text { No sé }\end{array}$ & $\begin{array}{l}1 \\
2 \\
99\end{array}$ & $\begin{array}{ll}\text { PASE A } & 1100 \\
\text { PASE A } & 1100\end{array}$ \\
\hline 1001 & $\begin{array}{l}\text { ¿Está interesada en tener esta operación en los } \\
\text { próximos dos años? }\end{array}$ & $\begin{array}{l}\text { Sí } \\
\text { No } \\
\text { Ya la tuve } \\
\text { No sé }\end{array}$ & $\begin{array}{l}1 \\
2 \\
3 \\
99\end{array}$ & $\begin{array}{ll}\text { PASE A } & 1100 \\
\text { PASE A } 1100 \\
\text { PASE A } 1100\end{array}$ \\
\hline 1002 & \multicolumn{3}{|c|}{$\begin{array}{l}\text { LEER AL CLIENTE: } \\
\text { Ahora quisiera hacerle algunas preguntas sobre su respuesta a cambios potenciales en el costo de la } \\
\text { operación. Al contestar estas preguntas, por favor tenga en mente lo siguiente: } \\
\text { 1. Suponga que su ingreso seguirá siendo el mismo aunque cambien los precios de la AGENCIA. } \\
\text { 2. Existen otras alternativas para obtener los servicios de la AGENCIA (como el Ministerio de } \\
\text { Salud, clínicas privadas, etcétera) }\end{array}$} & \\
\hline 1003 & $\begin{array}{l}\text { Si el precio de esta operación fuera I/200, } \\
\text { ¿compraría este servicio en la AGENCIA? }\end{array}$ & $\begin{array}{l}\text { Sí } \\
\text { No } \\
\text { No sé }\end{array}$ & $\begin{array}{l}1 \\
2 \\
99 \\
\end{array}$ & $\begin{array}{ll}\text { PASE A } & 1005 \\
\text { PASE A } & 1005\end{array}$ \\
\hline 1004 & $\begin{array}{l}\text { Si el precio de esta operación fuera I/300, } \\
\text { ¿compraría este servicio en la AGENCIA? }\end{array}$ & $\begin{array}{l}\text { Sí } \\
\text { No } \\
\text { No sé }\end{array}$ & $\begin{array}{l}1 \\
2 \\
99\end{array}$ & $\begin{array}{ll}\text { PASE A } 1006 \\
\text { PASE A } 1006 \\
\text { PASE A } 1006\end{array}$ \\
\hline 1005 & $\begin{array}{l}\text { Si el precio de esta operación fuera I/100, } \\
\text { ¿compraría este servicio en la AGENCIA? }\end{array}$ & $\begin{array}{l}\text { Sí } \\
\text { No } \\
\text { No sé }\end{array}$ & $\begin{array}{l}1 \\
2 \\
99\end{array}$ & \\
\hline 1006 & $\begin{array}{l}\text { ¿Cuál sería el precio más alto que estaría } \\
\text { dispuesto a pagar por esta operación en la } \\
\text { AGENCIA? }\end{array}$ & Cantidad & & \\
\hline 1007 & $\begin{array}{l}\text { Si estuviera interesado en obtener esta } \\
\text { operación pero no pudiera pagarle a la } \\
\text { AGENCIA, ¿qué haría? }\end{array}$ & $\begin{array}{l}\text { Quedarme sin el servicio } \\
\text { Ir a otro lugar por este servicio } \\
\text { Otro: especificar } \\
\text { No sé }\end{array}$ & $\begin{array}{l}1 \\
2 \\
88 \\
99\end{array}$ & $\begin{array}{ll}\text { PASE A } 1008 \\
\text { PASE A } 1009 \\
\text { PASE A } 1100 \\
\text { PASE A } 1100\end{array}$ \\
\hline 1008 & $\begin{array}{l}\text { Usted mencionó que no tendría esta operación } \\
\text { si no pudiera pagar el precio de la AGENCIA. } \\
\text { ¿Utilizaría otro método anticonceptivo? }\end{array}$ & $\begin{array}{l}\text { Sí: especificar } \\
\text { No } \\
\text { No sé }\end{array}$ & $\begin{array}{l}1 \\
2 \\
99\end{array}$ & $\begin{array}{ll}\text { PASE A } 1100 \\
\text { PASE A } 1100 \\
\text { PASE A } 1100\end{array}$ \\
\hline 1009 & $\begin{array}{l}\text { ¿Adónde iría? } \\
\text { NO LEA LAS OPCIONES } \\
\text { MARQUE TODAS LAS MENCIONADAS }\end{array}$ & $\begin{array}{l}\text { Sector público } \\
\text { Otra ONG } \\
\text { Sector privado } \\
\text { Otro: especificar } \\
\text { No sé }\end{array}$ & $\begin{array}{l}1 \\
2 \\
3 \\
88 \\
99 \\
\end{array}$ & \\
\hline
\end{tabular}

F. VDP de mejoramiento de las instalaciones y de la calidad de los servicios

1. VDP de reducción de los tiempos de espera

\begin{tabular}{|c|c|c|c|}
\hline $\mathbf{P}$. & PREGUNTA & CODIGO DE RESPUESTA & PASE A \\
\hline 1100 & $\begin{array}{l}\text { ¿Cuánto tiempo tuvo que esperar antes de que } \\
\text { lo atendiera el personal de la clínica? }\end{array}$ & Tiempo en minutos & \\
\hline 1101 & $\begin{array}{l}\text { ¿Usted considera que este tiempo fue excesivo, } \\
\text { razonable o corto? }\end{array}$ & $\begin{array}{l}\text { Excesivo } \\
\text { Razonable } \\
\text { Corto } \\
\end{array}$ & \\
\hline 1102 & $\begin{array}{l}\text { Suponga que pudiéramos reducir el tiempo de } \\
\text { espera a la mitad pero que su consulta costara } 3 \\
\text { Intis más ( o CANTIDAD PAGADA + 3). } \\
\text { ¿Estaría dispuesto a pagar por esta mejora? }\end{array}$ & $\begin{array}{l}\text { Sí } \\
\text { No } \\
\text { No sé }\end{array}$ & $\begin{array}{ll}\text { PASE A } 1104 \\
\text { PASE A } 1104\end{array}$ \\
\hline
\end{tabular}




\begin{tabular}{|c|c|c|c|c|}
\hline 1103 & $\begin{array}{l}\text { Suponga que pudiéramos reducir el tiempo de } \\
\text { espera a la mitad pero que su consulta costara } 6 \\
\text { Intis más, (o CANTIDAD PAGADA +6). } \\
\text { ¿Estaría dispuesto a pagar por esta mejora? }\end{array}$ & $\begin{array}{l}\text { Sí } \\
\text { No } \\
\text { No sé }\end{array}$ & $\begin{array}{r}1 \\
2 \\
99\end{array}$ & $\begin{array}{ll}\text { PASE A } 1105 \\
\text { PASE A } 1105 \\
\text { PASE A } 1105\end{array}$ \\
\hline 1104 & $\begin{array}{l}\text { Suponga que pudiéramos reducir el tiempo de } \\
\text { espera a la mitad pero que su consulta costara } \\
\text { un Inti más, (o CANTIDAD PAGADA +1). } \\
\text { ¿Estaría dispuesto a pagar por esta mejora? }\end{array}$ & $\begin{array}{l}\text { Sí } \\
\text { No } \\
\text { No sé }\end{array}$ & $\begin{array}{r}1 \\
2 \\
99\end{array}$ & \\
\hline 1105 & $\begin{array}{l}\text { ¿Cuánto es lo máximo que estaría dispuesto a } \\
\text { pagar por una consulta si esta mejora se llevara } \\
\text { a cabo? }\end{array}$ & Cantidad & & \\
\hline
\end{tabular}

2. VDP de servicios de consejería

\begin{tabular}{|c|c|c|c|c|}
\hline Q. & PREGUNTA & \multicolumn{2}{|c|}{ CODIGO DE RESPUESTA } & PASE A \\
\hline 1200 & $\begin{array}{l}\text { ¿Cuánto tiempo pasó su proveedor explicando } \\
\text { los procedimientos y brindándole consejería } \\
\text { sobre sus problemas de salud reproductiva? }\end{array}$ & Tiempo en & & \\
\hline 1201 & $\begin{array}{l}\text { ¿Considera que la cantidad de tiempo que el } \\
\text { proveedor pasó con usted fue excesiva, } \\
\text { razonable o corta? }\end{array}$ & $\begin{array}{l}\text { Excesivo } \\
\text { Razonable } \\
\text { Corto }\end{array}$ & $\begin{array}{l}1 \\
2 \\
3\end{array}$ & PASE A 1300 \\
\hline 1202 & $\begin{array}{l}\text { Suponga que pudiéramos incrementar en } 10 \\
\text { minutos el tiempo de consejería que pasa con } \\
\text { su proveedor, pero que su consulta costaría } 3 \\
\text { Intis más (o CANTIDAD PAGADA +3). } \\
\text { ¿Estaría dispuesto a pagar por esta mejora? }\end{array}$ & $\begin{array}{l}\text { Sí } \\
\text { No } \\
\text { No sé }\end{array}$ & $\begin{array}{r}1 \\
2 \\
99\end{array}$ & $\begin{array}{ll}\text { PASE A } 1204 \\
\text { PASE A } 1204\end{array}$ \\
\hline 1203 & $\begin{array}{l}\text { Suponga que pudiéramos incrementar en } 10 \\
\text { minutos el tiempo de consejería que pasa con } \\
\text { su proveedor pero que su consulta costaría } 6 \\
\text { Intis más (o CANTIDAD PAGADA +6). } \\
\text { ¿Estaría dispuesto a pagar por esta mejora? }\end{array}$ & $\begin{array}{l}\text { Sí } \\
\text { No } \\
\text { No sé }\end{array}$ & $\begin{array}{r}1 \\
2 \\
99\end{array}$ & $\begin{array}{ll}\text { PASE A } 1205 \\
\text { PASE A } 1205 \\
\text { PASE A } 1205\end{array}$ \\
\hline 1204 & $\begin{array}{l}\text { Suponga que pudiéramos incrementar en } 10 \\
\text { minutos el tiempo de consejería que pasa con } \\
\text { su proveedor pero que su consulta costaría } 1 \\
\text { Inti más (o CANTIDAD PAGADA +1). } \\
\text { ¿Estaría dispuesto a pagar por esta mejora? }\end{array}$ & $\begin{array}{l}\text { Sí } \\
\text { No } \\
\text { No sé }\end{array}$ & $\begin{array}{r}1 \\
2 \\
99\end{array}$ & \\
\hline 1205 & $\begin{array}{l}\text { ¿Cuánto es lo máximo que estaría dispuesto a } \\
\text { pagar por su consulta si esta mejora se llevara a } \\
\text { cabo? }\end{array}$ & Cantidad & & \\
\hline
\end{tabular}

3. VDP por mejoramiento de las instalaciones de la clínica

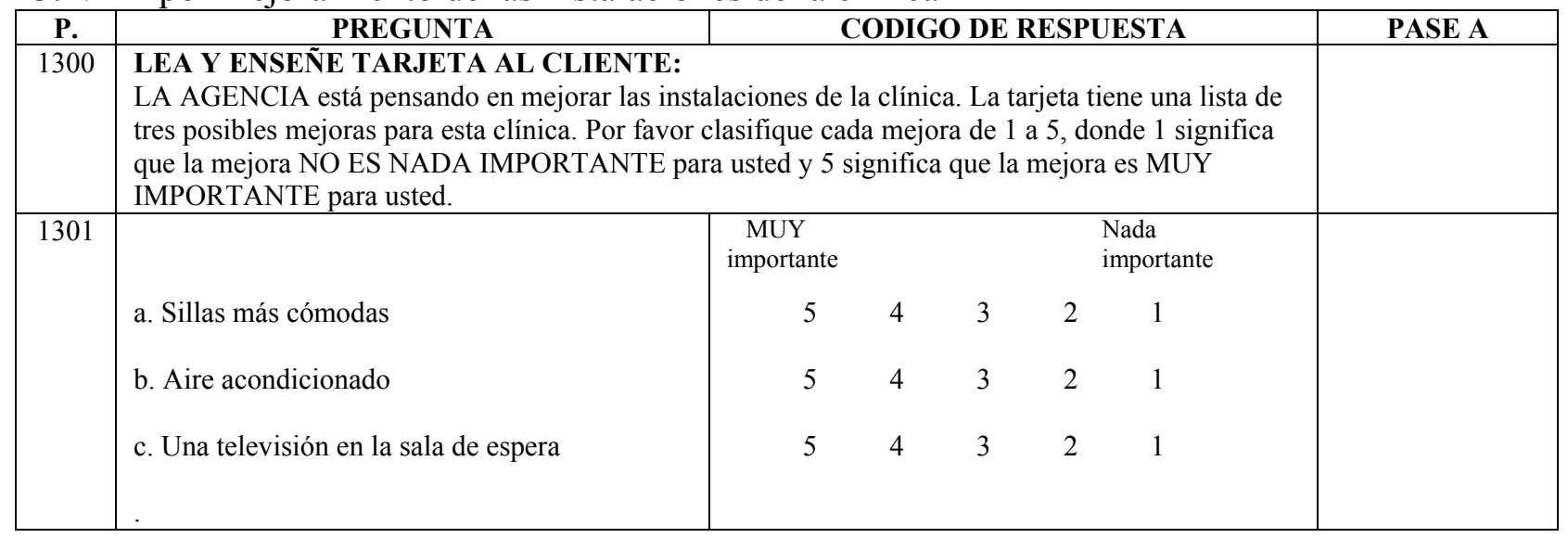




\begin{tabular}{|c|c|c|}
\hline 1302 & NOTA: SI EL ENTREVISTADO TIENE DOS O MÁS SELECCIONES CON LA MISMA \\
& CALIFICACIÓN MÁXIMA, PREGÚNTELE QUÉ ASPECTO DE LAS INSTALACIONES ES \\
MÁS IMPORTANTE PARA ÉL. SI TUVIERA QUE ESCOGER, ¿CUÁL ESCOGERÍA?. & \\
& Sí la opción "a" es la más importante PASE A 1303. \\
& Sí la opción "b" es la más importante PASE A 1307. \\
& Sí la opción "c" es la más importante PASE A 1311. \\
\hline
\end{tabular}

\begin{tabular}{|c|c|c|c|c|}
\hline 1303 & $\begin{array}{l}\text { Usted calificó la disponibilidad de sillas más } \\
\text { cómodas como la mejora más importante. } \\
\text { ¿Estaría dispuesta a pagar dos Intis más (o la } \\
\text { CANTIDAD PAGADA +2) en su próxima } \\
\text { visita si la clínica agregara esta mejora? }\end{array}$ & $\begin{array}{l}\text { Sí } \\
\text { No } \\
\text { No sé }\end{array}$ & $\begin{array}{r}1 \\
2 \\
99\end{array}$ & $\begin{array}{ll}\text { PASE A } & 1305 \\
\text { PASE A } & 1305\end{array}$ \\
\hline 1304 & $\begin{array}{l}\text { ¿Estaría dispuesto a pagar tres Intis más (o la } \\
\text { CANTIDAD PAGADA }+\mathbf{3} \text { ), en su próxima } \\
\text { visita si la clínica agregara sillas más cómodas? }\end{array}$ & $\begin{array}{l}\text { Sí } \\
\text { No } \\
\text { No sé }\end{array}$ & $\begin{array}{r}1 \\
2 \\
99 \\
\end{array}$ & $\begin{array}{ll}\text { PASE A } 1306 \\
\text { PASE A } 1306 \\
\text { PASE A } 1306 \\
\end{array}$ \\
\hline 1305 & $\begin{array}{l}\text { ¿Estaría dispuesta a pagar un Intis más (o la } \\
\text { CANTIDAD PAGADA +1), en su próxima } \\
\text { visita si la clínica agregara sillas más cómodas? }\end{array}$ & $\begin{array}{l}\text { Sí } \\
\text { No } \\
\text { No sé }\end{array}$ & $\begin{array}{r}1 \\
2 \\
99\end{array}$ & \\
\hline 1306 & $\begin{array}{l}\text { ¿Cuánto es lo máximo que estaría dispuesto a } \\
\text { pagar por su consulta si esta mejora se llevara a } \\
\text { cabo? }\end{array}$ & Cantidad & & \\
\hline 1307 & $\begin{array}{l}\text { Usted calificó la disponibilidad de aire } \\
\text { acondicionado como la mejora más } \\
\text { importante. ¿Estaría dispuesto a pagar dos Intis } \\
\text { más (o la CANTIDAD PAGADA +2) en su } \\
\text { próxima visita si la clínica agregara esta } \\
\text { facilidad? }\end{array}$ & $\begin{array}{l}\text { Sí } \\
\text { No } \\
\text { No sé }\end{array}$ & $\begin{array}{r}1 \\
2 \\
99\end{array}$ & $\begin{array}{ll}\text { PASE A } & 1309 \\
\text { PASE A } 1309\end{array}$ \\
\hline 1308 & $\begin{array}{l}\text { ¿Estaría dispuesta a pagar tres Intis más (o la } \\
\text { CANTIDAD PAGADA +3) en su próxima } \\
\text { visita si la clínica agregara aire acondicionado? }\end{array}$ & $\begin{array}{l}\text { Sí } \\
\text { No } \\
\text { No sé }\end{array}$ & $\begin{array}{r}1 \\
2 \\
99 \\
\end{array}$ & $\begin{array}{ll}\text { PASE A } 1310 \\
\text { PASE A } 1310 \\
\text { PASE A } 1310 \\
\end{array}$ \\
\hline 1309 & $\begin{array}{l}\text { ¿Estaría dispuesta a pagar un Inti más (o la } \\
\text { CANTIDAD PAGADA +1), en su próxima } \\
\text { visita si la clínica agregara aire acondicionado? }\end{array}$ & $\begin{array}{l}\text { Sí } \\
\text { No } \\
\text { No sé }\end{array}$ & $\begin{array}{r}1 \\
2 \\
99 \\
\end{array}$ & \\
\hline 1310 & $\begin{array}{l}\text { ¿Cuánto es lo máximo que estaría dispuesto a } \\
\text { pagar por su consulta si esta mejora se llevara a } \\
\text { cabo? }\end{array}$ & Cantidad & & \\
\hline 1311 & $\begin{array}{l}\text { Usted calificó la disponibilidad televisión en } \\
\text { la sala de espera como la mejora más } \\
\text { importante. ¿Estaría dispuesta a pagar dos Intis } \\
\text { más (o la CANTIDAD PAGADA +2) en su } \\
\text { próxima visita si la clínica agregara esta } \\
\text { facilidad? }\end{array}$ & $\begin{array}{l}\text { Sí } \\
\text { No } \\
\text { No sé }\end{array}$ & $\begin{array}{r}1 \\
2 \\
99\end{array}$ & $\begin{array}{ll}\text { PASE A } & 1313 \\
\text { PASE A } & 1313\end{array}$ \\
\hline 1312 & $\begin{array}{l}\text { ¿Estaría dispuesto a pagar tres Intis más (o la } \\
\text { CANTIDAD PAGADA }+\mathbf{3} \text { ) en su próxima } \\
\text { visita si la clínica agregara esta facilidad? }\end{array}$ & $\begin{array}{l}\text { Sí } \\
\text { No } \\
\text { No sé }\end{array}$ & $\begin{array}{r}1 \\
2 \\
99\end{array}$ & $\begin{array}{ll}\text { PASE A } 1314 \\
\text { PASE A } 1314 \\
\text { PASE A } 1314\end{array}$ \\
\hline 1313 & $\begin{array}{l}\text { ¿Estaría dispuesta a pagar un Inti más (o la } \\
\text { CANTIDAD PAGADA +1) en su próxima } \\
\text { visita si la clínica agregara esta facilidad? }\end{array}$ & $\begin{array}{l}\text { Sí } \\
\text { No } \\
\text { No sé }\end{array}$ & $\begin{array}{r}1 \\
2 \\
99\end{array}$ & \\
\hline 1314 & $\begin{array}{l}\text { ¿Cuánto es lo máximo que estaría dispuesto a } \\
\text { pagar por su consulta si esta mejora se llevara a } \\
\text { cabo? }\end{array}$ & Cantidad & & \\
\hline
\end{tabular}

\begin{tabular}{|l|l} 
FINAL & TERMINE LA ENTREVISTA Y AGRADEZCA AL ENTREVISTADO POR SU TIEMPO
\end{tabular} 


\section{Condones \\ Voluntad de pago \\ Modelo de cuestionario para hombres casados \\ o sexualmente activos, de 15 a 45 años \\ (Basado en un estudio de The Futures Group/INFO-STAT en Mali, 1999) \\ ENCUESTA DE HOGAR PARA USUARIOS DE CONDONES Y USUARIOS POTENCIALES}

¡Hola! Mi nombres es . Trabajo para una organización de investigación

llamada - Quisiera hacerle algunas preguntas sobre condones, un producto que se puede utilizar para prevenir o evitar embarazos, infecciones de transmisión sexual y el SIDA. La entrevista no es obligatoria; sin embargo, le agradecería mucho si me pudiera contestar algunas preguntas. Todo lo que me diga será confidencial, y nadie sabrá cómo contestó personalmente las preguntas que le voy a preguntar.

Participación Sí-- $\rightarrow$

No-- $\rightarrow$
Continuar

Terminar la entrevista

Cuestionario Número:

Fecha:

Nombre del entrevistador:
Región:
1. Bamako
2. Sikasso
3. Mopti

Zona:

1. Urbana

2. Rural

Ciudad/Pueblo:

Vecindad:

Nombre del entrevistado:

Nota: las preguntas se basan en condones vendidos en paquetes de tres piezas 


\begin{tabular}{|c|c|c|}
\hline PREGUNTA & CODIGO DE RESPUESTA & PASE A \\
\hline 1. ¿Cuántos años tiene? & 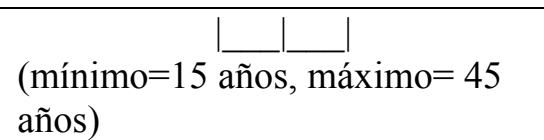 & \\
\hline $\begin{array}{l}\text { 2. Estado Civil/actividad } \\
\text { sexual }\end{array}$ & $\begin{array}{l}\text { 1. Casado } \\
\text { 2. Unión libre } \\
\text { 3. Sin una relación, pero } \\
\text { activo sexualmente } \\
\text { 4. Sin una relación y no } \\
\text { activo sexualmente }\end{array}$ & \\
\hline 3. ¿Cuántos hijos vivos tiene? & & \\
\hline 4. ¿Ha ido a la escuela? & $\begin{array}{ll}\text { 1. } & \text { Sí } \\
\text { 2. } & \text { No }\end{array}$ & $\rightarrow$ PASE A 6 \\
\hline 5. ¿Hasta qué nivel aprobó? & $\begin{array}{ll}\text { 1. } & \text { Primaria } \\
\text { 2. } & \text { Secundaria } \\
\text { 3. } & \text { Preparatoria } \\
\text { 4. } & \text { Universidad } \\
\end{array}$ & \\
\hline 6. ¿Cuál es su profesión? & $\begin{array}{ll}\text { 1. } & \text { Estudiante } \\
\text { 2. } & \text { Desempleado } \\
\text { 3. } & \text { Trabajo de oficina } \\
\text { 4. Empleado de una tienda } \\
\text { 5. Trabajo por cuenta propia } \\
\text { 6. Agricultor } \\
\text { 7. } \text { Pastor/Criador } \\
\text { 8. Pescador } \\
\text { 88. } \\
\end{array}$ & \\
\hline $\begin{array}{l}\text { 7. ¿Su hogar dispone de } \\
\text { alguno de los siguientes } \\
\text { bienes? }\end{array}$ & 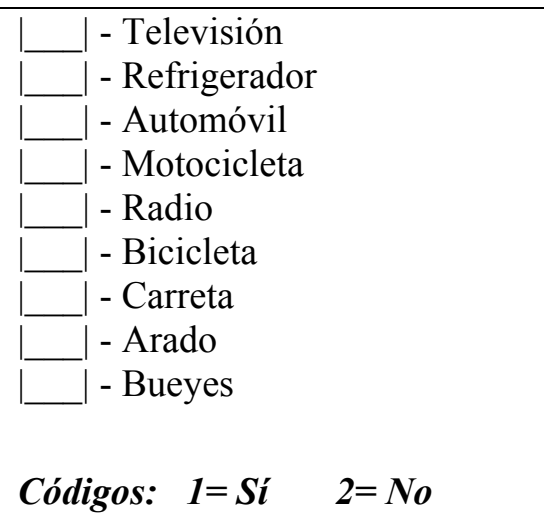 & \\
\hline
\end{tabular}


Entrevistador: explique al entrevistado que ahora le hará una serie de preguntas sobre el uso del condón.

\begin{tabular}{|c|c|c|}
\hline PREGUNTA & $\begin{array}{l}\text { CODIGO DE } \\
\text { RESPUESTA }\end{array}$ & PASE A \\
\hline $\begin{array}{l}\text { 8. ¿Ha oído hablar del condón, } \\
\text { un método anticonceptivo y de } \\
\text { prevención de enfermedades que } \\
\text { utiliza el hombre? }\end{array}$ & $\begin{array}{ll}\text { 1. } & \text { Sí } \\
\text { 2. } & \text { No }\end{array}$ & $\rightarrow$ Terminar la entrevista \\
\hline $\begin{array}{l}\text { 9. ¿Alguna vez ha utilizado un } \\
\text { condón? }\end{array}$ & $\begin{array}{ll}\text { 1. } & \text { Sí } \\
\text { 2. } & \text { No }\end{array}$ & $\rightarrow$ PASE A 27 \\
\hline $\begin{array}{l}\text { 10. ¿Ha utilizado un condón en } \\
\text { los últimos } 3 \text { meses? }\end{array}$ & $\begin{array}{ll}\text { 1. } & \text { Sí } \\
\text { 2. } & \text { No } \\
\end{array}$ & $\rightarrow$ PASE A 23 \\
\hline $\begin{array}{l}\text { 11.La última vez que utilizó un } \\
\text { condón, ¿de qué marca era? } \\
\text { (enseñe el paquete si es } \\
\text { necesario, sólo acepte una } \\
\text { respuesta) }\end{array}$ & $\begin{array}{l}\text { 1. Condón Protector } \\
\text { 88. Otro que no sea } \\
\text { Protector } \\
\text { 99. No recuerda }\end{array}$ & \\
\hline $\begin{array}{l}\text { 12. ¿Qué otra(s) marca(s) ha } \\
\text { utilizado en los últimos tres } \\
\text { meses? (varias respuestas } \\
\text { posibles) }\end{array}$ & $\begin{array}{l}\text { 1. Sólo esa } \\
\text { 88. Otra } \\
\text { 99. No recuerda }\end{array}$ & \\
\hline $\begin{array}{l}\text { 13. La última vez que utilizó un } \\
\text { condón, ¿dónde lo consiguió? }\end{array}$ & $\begin{array}{l}\text { 1. Tienda } \\
\text { 2. Farmacia } \\
\text { 3. Centro de salud } \\
\text { comunitario } \\
\text { 4. Otro centro de salud } \\
\text { 88. Distribuidor } \\
\text { comunitario } \\
\text { Otro } \\
\text { 99. No sabe/No recuerda }\end{array}$ & \\
\hline $\begin{array}{l}\text { 14. La última vez que compró } \\
\text { condones, ¿cuántos paquetes de } \\
\text { tres compró? }\end{array}$ & 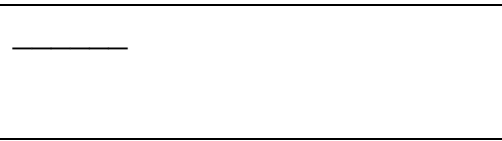 & \\
\hline $\begin{array}{l}\text { 15. La última vez que compró } \\
\text { condones, ¿cuánto pagó por cada } \\
\text { paquete de tres? }\end{array}$ & $\begin{array}{l}\text { Costo por paquete de } \\
\text { tres condones }\end{array}$ & \\
\hline $\begin{array}{l}\text { Entrevistador: si la cantidad } \\
\text { en la PREGUNTA } 14 \text { es más } \\
\text { que } 3 \text { ayude al entrevistado a } \\
\text { calcular la cantidad pagada } \\
\text { por paquete de } 3 \text {, dividiendo el } \\
\text { total pagado entre el número } \\
\text { de paquetes comprados. }\end{array}$ & $\begin{array}{l}\text { Código } 0 \mathrm{~F}=\text { Nada/ gratis } \\
\text { Código } 99=\text { No recuerda }\end{array}$ & \\
\hline
\end{tabular}




\begin{tabular}{|c|c|c|}
\hline PREGUNTA & $\begin{array}{l}\text { CODIGO DE } \\
\text { RESPUESTA }\end{array}$ & PASE A \\
\hline $\begin{array}{l}\text { 16. Usted dijo que la última vez que } \\
\text { compró un paquete de } 3 \text { condones } \\
\text { pagó } \quad \text { (cite el precio de la } \\
\text { PREGUNTA 15). Si el precio } \\
\text { aumentara a (Cantidad pagada }+ \\
\text { 50), ¿seguiría comprando estos } \\
\text { condones? }\end{array}$ & $\begin{array}{ll}\text { 1. } & \text { Sí } \\
\text { 2. } & \text { No }\end{array}$ & $\rightarrow$ PASE A 18 \\
\hline $\begin{array}{l}\text { 17. Si el precio aumentara a } \\
\text { (Cantidad pagada }+100), \text { ¿seguiría } \\
\text { comprando estos condones? }\end{array}$ & $\begin{array}{ll}\text { 1. } & \text { Sí } \\
\text { 2. } & \text { No }\end{array}$ & $\begin{array}{l}\rightarrow \text { PASE A } 19 \\
\rightarrow \text { PASE A } 19\end{array}$ \\
\hline $\begin{array}{l}\text { 18. Si el precio aumentara a } \\
(\text { Cantidad pagada }+25), \text { ¿seguiría } \\
\text { comprando estos condones? }\end{array}$ & $\begin{array}{ll}\text { 1. } & \text { Sí } \\
\text { 2. } & \text { No }\end{array}$ & \\
\hline $\begin{array}{l}\text { 19. ¿Cuál es el precio máximo que } \\
\text { pagaría por un paquete de tres } \\
\text { condones? }\end{array}$ & Pago máximo & \\
\hline $\begin{array}{l}\text { 20. Si el precio de los condones en } \\
\text { (cite lugar de PREGUNTA } \\
\text { 13) excediera lo que puede o está } \\
\text { dispuesto a pagar, ¿qué haría? (cite } \\
\text { las respuestas) }\end{array}$ & $\begin{array}{l}\text { 1. Buscar una marca más barata } \\
\text { en el mismo lugar } \\
\text { 2. Buscar la misma marca en } \\
\text { un lugar más barato } \\
\text { 3. Buscar una marca más barata } \\
\text { y un lugar más barato } \\
\text { 4. Dejaría de usarlos } \\
\text { 88. Otro, }\end{array}$ & \\
\hline $\begin{array}{l}\text { 21. ¿Cuál es la razón principal por la } \\
\text { que usa el condón? }\end{array}$ & $\begin{array}{ll}\text { 1. } & \text { Prevención del embarazo } \\
\text { 2. Protección contra } \\
\text { ITS/VIH/SIDA } \\
\text { 3. Ambas }\end{array}$ & \\
\hline $\begin{array}{l}\text { 22. ¿Con quién utilizó condones la } \\
\text { última vez? }\end{array}$ & $\begin{array}{l}\text { 1. Mi esposa } \\
\text { 2. Una pareja regular que no es } \\
\text { mi esposa } \\
\text { 3. Una pareja ocasional } \\
\text { 88. Otra, } \\
\text { 99. No respuesta } \\
\end{array}$ & $\rightarrow$ Terminar entrevista \\
\hline $\begin{array}{l}\text { 23. ¿Hace cuánto fue la última vez } \\
\text { que utilizó un condón? }\end{array}$ & $\begin{array}{ll}\text { 1. } & 4-6 \text { meses } \\
\text { 2. } & 7-12 \text { meses } \\
\text { 3. } & \text { Más de } 1 \text { año } \\
\text { 99. } & \text { No recuerda } \\
\end{array}$ & $\begin{array}{l}\rightarrow \text { PASE A } 27 \\
\rightarrow \text { PASE A } 27\end{array}$ \\
\hline $\begin{array}{l}\text { 24. ¿Por qué razón ha utilizado el } \\
\text { condón en el pasado? }\end{array}$ & $\begin{array}{l}\text { 1. Prevención del embarazo } \\
\text { 2. Protección contra } \\
\text { ITS/VIH/SIDA } \\
\text { 3. Ambas }\end{array}$ & \\
\hline
\end{tabular}




\begin{tabular}{|c|c|c|}
\hline PREGUNTA & $\begin{array}{l}\text { CODIGO DE } \\
\text { RESPUESTA }\end{array}$ & PASE A \\
\hline $\begin{array}{l}\text { 25. ¿Con quién utilizó condones } \\
\text { la última vez? }\end{array}$ & $\begin{array}{l}\text { 1. Mi esposa } \\
\text { 2. Una compañera regular } \\
\text { que no es mi esposa } \\
\text { 3. Una pareja ocasional } \\
\text { 88. Otro, } \\
\text { 99. No hubo respuesta }\end{array}$ & \\
\hline $\begin{array}{l}\text { 26. ¿Dónde compra los condones } \\
\text { usualmente? }\end{array}$ & $\begin{array}{l}\text { 1. Tienda } \\
\text { 2. Farmacia } \\
\text { 5. Centro de salud } \\
\text { comunitario } \\
\text { 6. Otro centro de salud } \\
\text { 3. Distribuidor comunitario } \\
\text { 88. Otros, } \\
\text { 99. No sé/ No me acuerdo }\end{array}$ & \\
\hline $\begin{array}{l}\text { 27. ¿Por qué razón dejó de } \\
\text { utilizar los condones? }\end{array}$ & $\begin{array}{l}\text { 1. No tenía los } \\
\text { medios/demasiado caro } \\
\text { 2. Quería tener hijos } \\
\text { 3. Ya no me gusta usarlos, } \\
\text { Razón } \\
\text { 4. No se consiguen } \\
\text { fácilmente } \\
\text { 5. No soy activo } \\
\text { sexualmente } \\
\text { 88. Otro, especificar }\end{array}$ & \\
\hline $\begin{array}{l}\text { 28. ¿Utilizaría un condón en el } \\
\text { futuro? }\end{array}$ & $\begin{array}{l}\text { 1. Sí } \\
\text { 2. No } \\
\text { 99. No sé }\end{array}$ & $\begin{array}{l}\rightarrow \text { PASE A } 34 \\
\rightarrow \text { Terminar la entrevista }\end{array}$ \\
\hline $\begin{array}{l}29 . \text { ¿Compraría un paquete de } 3 \\
\text { condones por } 100 \mathrm{~F} \text { ? }\end{array}$ & $\begin{array}{ll}\text { 1. } & \text { Sí } \\
\text { 2. } & \text { No }\end{array}$ & $\rightarrow$ PASE A 31 \\
\hline $\begin{array}{l}\text { 30. ¿Compraría un paquete de } 3 \\
\text { condones por } 150 \mathrm{~F} \text { ? }\end{array}$ & $\begin{array}{ll}\text { 1. } & \text { Sí } \\
\text { 2. } & \text { No }\end{array}$ & $\begin{array}{l}\rightarrow \text { PASE A } 32 \\
\rightarrow \text { PASE A } 32\end{array}$ \\
\hline $\begin{array}{l}\text { 31. ¿Compraría un paquete de } 3 \\
\text { condones por } 75 \mathrm{~F} \text { ? }\end{array}$ & $\begin{array}{ll}\text { 1. } & \text { Sí } \\
\text { 2. } & \text { No }\end{array}$ & $\begin{array}{l}\rightarrow \text { PASE A } 32 \\
\rightarrow \text { PASE A } 32\end{array}$ \\
\hline $\begin{array}{l}\text { 32. ¿Cuál es el precio máximo } \\
\text { que pagaría por un paquete de } 3 \\
\text { condones? }\end{array}$ & $\begin{array}{l}\text { Pago máximo } \\
0=\text { No compraría }\end{array}$ & \\
\hline $\begin{array}{l}\text { 33. ¿Cuál es la razón principal } \\
\text { por la cual usaría condones en el } \\
\text { futuro? }\end{array}$ & $\begin{array}{l}\text { 1. Prevención del embarazo } \\
\text { 2. Proteger contra } \\
\text { ITS/VIH/SIDA } \\
\text { 3. Ambas } \\
\end{array}$ & \\
\hline
\end{tabular}




\begin{tabular}{|c|c|c|}
\hline PREGUNTA & $\begin{array}{l}\text { CODIGO DE } \\
\text { RESPUESTA }\end{array}$ & PASE A \\
\hline $\begin{array}{l}\text { 34. ¿Por qué razones no } \\
\text { utilizaría el condón? } \\
\text { (Circular todas las respuestas) }\end{array}$ & $\begin{array}{l}\text { 1. Religión } \\
\text { 2. Limita el placer } \\
\text { 3. Los condones fomentan el } \\
\text { libertinaje } \\
\text { 4. Utilizo otro método de } \\
\text { planificación familiar } \\
\text { 5. Por el precio } \\
\text { 6. No es fácil conseguir } \\
\text { condones } \\
\text { 7. Estoy en contra de la } \\
\text { planificación familiar } \\
\text { 8. No tengo pareja sexual } \\
\text { 88. Otro: }\end{array}$ & \\
\hline
\end{tabular}

\section{FIN DE LA ENTREVISTA}

Entrevistador: verifique que no se le haya olvidado ninguna pregunta. Agradezca al entrevistado por su atención. 


\section{APÉNDICE II}

\section{MODELO DEL MANUAL DEL ENTREVISTADOR}

Instrucciones para completar las preguntas del cuestionario modelo relacionadas con aumentos de precios: usuarios activos y potenciales de servicios clínicos

(Entrevista a la salida de los servicios)

\section{MODELO DEL MANUAL DE CODIFICACIÓN}

Instrucciones para codificar el cuestionario modelo: usuarios activos y potenciales de servicios clínicos

(Entrevista a la salida de los servicios) 


\section{Voluntad de pago Modelo del manual del entrevistador}

Instrucciones para completar las preguntas del cuestionario modelo relacionadas con aumentos de precio: usuarios activos y potenciales de servicios clínicos (entrevista a la salida de los servicios)

\section{INSTRUCCIONES GENERALES}

A. Siempre utilice un lápiz (de punta suave o mediana).

B. Use letras de molde y escriba claramente todas las letras y números.

C. Llene todas las preguntas que son aplicables a la persona entrevistada.

D. No deje en blanco espacios que deben ser llenados. Si la respuesta a una pregunta es una no-respuesta, circule 99 como código de "No respuesta". Si un número es cero, escriba 00.

E. Los comentarios se deben apuntar en el momento que son hechos. Informe a su supervisor de todos los comentarios o preguntas tan pronto como sea posible.

F. El supervisor deberá tomar nota de todos los comentarios y preguntas y reportarlos al coordinador del estudio.

G. Todas las instrucciones para los entrevistados deberán escribirse en letra mayúscula y negritas. Estas instrucciones no se deberán leer al entrevistado. Por ejemplo:

\begin{tabular}{|c|l|l|l|}
\hline P. & PREGUNTA & CODIGO DE RESPUESTA & PASE A \\
\hline 207 & ¿Cuál es el ingreso TOTAL de su familia al mes? & Total TODAS LAS FUENTES _- & \\
& $\begin{array}{l}\text { SONDEAR PARA CONOCER TODAS LAS } \\
\text { FUENTES DE INGRESO (por ejemplo, } \\
\text { RENTAS, REGALOS, ETC.) }\end{array}$ & \\
& $\begin{array}{l}\text { LA CANTIDAD DEBERÁ SER MAYOR O } \\
\text { IGUAL A (P.203 + P.205) }\end{array}$ & \\
\hline
\end{tabular}

\section{ESTRUCTURA DEL CUESTIONARIO}

\section{A. Organización}

El cuestionario se organiza en filas y columnas. Por ejemplo:

\begin{tabular}{|c|l|ll|c|}
\hline P. & \multicolumn{1}{|c|}{ PREGUNTA } & CODIGO DE RESPUESTA & PASE A \\
\hline 300 & Es Esta es su primer visita a la AGENCIA? & lí & 1 & 2 \\
\hline 301 & $\begin{array}{l}\text { Su visita hoy es una revisita programada durante una } \\
\text { ita anterior? }\end{array}$ & Jo & 1 & 2 \\
\hline
\end{tabular}


La primera columna contiene el número de la pregunta. La segunda columna especifica la pregunta que se deberá leer al entrevistado, así como cualquier instrucción para el entrevistador. Estas instrucciones están escritas en negritas.

La tercer columna contiene las respuestas y sus códigos. Asegúrese de circular el código apropiado (por ejemplo, en la pregunta 300 el código para "Sín" es 1 y el código para "No" es 2). Para las preguntas abiertas, asegúrese de registrar textualmente la respuesta. Por ejemplo:

\begin{tabular}{|c|c|c|c|}
\hline $\mathbf{P .}$ & PREGUNTA & CODIGO DE RESPUESTA & PASE A \\
\hline 201 & ¿Trabaja usted fuera de casa? & $\begin{array}{l}\text { Sí } \\
\text { No }\end{array}$ & PASE A 204 \\
\hline 202 & ¿Qué tipo de trabajo tiene? & Trabajo & \\
\hline
\end{tabular}

Si las hay, la cuarta columna contiene las instrucciones de los pases.

\section{B. Pases}

Las instrucciones en la cuarta columna, etiquetadas "PASE A" le dicen al entrevistador a qué pregunta deberá ir para continuar la entrevista. Distintas respuestas en la columna tres con frecuencia le indican a los entrevistados que deberán continuar la entrevista en (pasar a) preguntas diferentes.

Por ejemplo:

\begin{tabular}{|c|l|ll|l|}
\hline P. & \multicolumn{1}{|c|}{ PREGUNTA } & \multicolumn{1}{|c|}{ CODIGO DE RESPUESTA } & \multicolumn{1}{c|}{ PASE A } \\
\hline 302 & iCuál fue el servicio principal que recibió usted & Ginecología & 1 & PASE A 400 \\
& hoy? & Anticonceptivo inyectable & 2 & PASE A 500 \\
& & Inserción de DIU & 3 & PASE A 600 \\
& & Revisita de DIU & 4 & PASE A 700 \\
& & Visita para píldora & 5 & PASE A 800 \\
& & Cuidado prenatal & 6 & PASE A 900 \\
& & Otro: especificar & & \\
& & & PASE AL & FINAL \\
\hline
\end{tabular}

En el caso de la pregunta 302, a los entrevistados que indican que fueron a la clínica a recibir servicios de ginecología se les debe continuar la entrevista en la pregunta 400. Los que contestaron que fueron para una inserción de DIU "pasan a" la pregunta 600.

Seguir correctamente las indicaciones de pases es posiblemente la parte más difícil de cualquier cuestionario para un entrevistador. Se debe tener cuidado especial cuando se trata de seguir las indicaciones dictadas por los pases. La omisión de una instrucción de pase por parte del entrevistador puede resultar en una pérdida de información importante y en alguna confusión para la persona entrevistada. Los supervisores deben revisar con cuidado todos los cuestionarios para tratar de detectar si existe un patrón de errores en la aplicación de los pases.

\section{Fechas}

Cuando se pide una fecha (por ejemplo, la fecha de la entrevista), siempre se deberán utilizar dos números. Por ejemplo, si la fecha es 6 de mayo del 2000, se debe registrar de la siguiente manera: día $\underline{06}$, mes $\underline{05}$, año $\underline{00}$. 


\section{Dinero}

No utilice decimales. Por ejemplo, escriba 25 pesos en lugar de 25.00 pesos. Si el entrevistado cita un número que no es entero, se debe redondear hacia abajo. Así, una respuesta de 10.75 pesos deberá ser redondeada a 10 pesos y una cifra menor de un peso debe ser redondeado a 00 pesos. Las cantidades menores a 10 deberán ser precedidas por un cero. Por ejemplo, 5 pesos se debe escribir 05 pesos.

\section{SELECCIÓN DE LAS PERSONAS QUE SERÁN ENTREVISTADAS}

A. Entreviste solamente a mujeres que hayan venido para recibir alguno de los servicios listados en el cuestionario. Estos servicios incluyen:

- Ginecología

- Anticonceptivo inyectable

- Inserción de DIU

- $\quad$ Revisita de DIU

- $\quad$ Visita para píldora

- $\quad$ Cuidado prenatal

B. Las entrevistas deberán ser llevadas a cabo en la clínica y durante el horario laboral

C. La partera deberá presentar al paciente con el entrevistador cuando el cliente haya terminado su visita a la partera, haya recibido todos los servicios y hecho todas sus compras.

D. El entrevistador deberá llenar el número de cuestionario, el código de la clínica, el nombre del entrevistador, la fecha y la hora en que la entrevista comenzó y terminó. El código de la clínica deberá ser entregado al entrevistador por separado en una tarjeta o una hoja de papel por separado.

\section{INTRODUCCIÓN}

Las primeras tareas que enfrenta el entrevistador son: presentarse con el entrevistado potencial; informarle los objetivos, riesgos y beneficios de la investigación, y obtener su consentimiento para realizar la entrevista. La mayoría de las organizaciones que llevan a cabo investigaciones exigen que la persona que será entrevistada otorgue su consentimiento informado. El consentimiento informado tiene su origen en investigaciones médicas en las que existen riesgos y beneficios potenciales. Los formularios de consentimiento deben usar frases simples y afirmaciones directas, apropiadas al nivel de educación de las personas que serán entrevistadas. Quienes participen en el estudio deben tener la oportunidad de hacer preguntas y haber recibido toda la información antes de firmar el formulario. En los casos en que se requiera el consentimiento informado, se deben incluir los siguientes elementos:

1. Propósito del estudio.

2. Riesgos para el participante, que incluyan riesgos físicos, sociales y emocionales.

3. Beneficios para el participante, que incluyan, si es necesario, una declaración de que no los hay.

4. Información sobre la confidencialidad, que incluya el uso de elementos identificadores y el acceso a la información personal.

5. Lugar a dónde acudir en caso de dudas o problemas en cualquier momento.

6. Información acerca del abandono del estudio. La persona que participa en el estudio tiene el derecho de dejar de hacerlo en cualquier momento sin ninguna penalización. 
7. Garantía de que los servicios están disponibles para el/la participante potencial tanto si acepta participar en el estudio como si no lo hace o si se retira del mismo.

8. Información sobre los procedimientos y la duración del estudio.

El formulario deberá ocupar una hoja de papel separada. Nótese que el investigador deberá ser capaz de vincular el formulario de consentimiento informado al cuestionario pertinente con un indicador numérico. Para la recolección de información que represente bajo riesgo, es suficiente conseguir el consentimiento de manera verbal, pero el formulario deberá estar firmado por el entrevistador como parte de la documentación.

Diferentes organizaciones tienen diferentes formas de garantizar que se cumpla con los requisitos del consentimiento informado. A continuación se presenta un ejemplo obtenido de una encuesta de VDP.

\section{INSTRUCCIONES PARA EL ENTREVISTADOR: la siguiente declaración deberá leerse a todos los entrevistados potenciales:}

¿Me podría dar un minuto de su tiempo? LA AGENCIA desea seguir proporcionándole servicios convenientes, accesibles y de alta calidad. Para poder hacerlo, será necesario que LA AGENCIA incremente los precios de algunos de sus servicios. Quisiéramos saber cómo le afectarían estos cambios de precio. No hay respuestas correctas ni equivocadas, así que le agradeceremos que, por favor, sea sincero y nos diga lo que para usted es verdad. La información que se está recolectando se utilizará solamente con propósitos de planeación y su participación no implica ni riesgos ni beneficios para usted. No necesito que me proporcione su nombre ni su dirección. Todo lo que usted diga será absolutamente confidencial, y el único elemento para identificar este cuestionario será un número, y no su nombre. Nadie, incluyendo a los trabajadores de esta clínica, sabrá lo que usted nos ha dicho y a nadie se le proporcionará su nombre. Los servicios estarán disponibles para usted tanto si decide participar como si decide no hacerlo. La entrevista dura alrededor de 15 minutos. Usted podrá dar por terminada la entrevista en cualquier momento, sin que esto conlleve ninguna consecuencia. ¿Tiene alguna pregunta? ¿Le gustaría participar? Si desea obtener mayor información acerca de este estudio, por favor diríjase a en
1. Participación
Sí
(Proceda a realizar la entrevista)
NO (Agradezca al entrevistado y deséele un buen día)

El entrevistador conservará todos los cuestionarios, independientemente de que el entrevistado potencial decida participar o no. 


\section{INSTRUCCIONES PARA COMPLETAR LAS PREGUNTAS INDIVIDUALES}

El manual final del entrevistador debe incluir instrucciones completas para poder llenar cada una de las preguntas del cuestionario. Por ejemplo:

PREGUNTA 302: esta es la pregunta más importante del cuestionario. Dirige al entrevistador a las distintas secciones que deben ser llenadas, con base en el servicio principal que recibió el cliente durante su visita a la clínica.

\begin{tabular}{|c|l|ll|l|}
\hline P. & PREGUNTA & CODIGO DE RESPUESTA & PASE A \\
\hline 302 & \multirow{2}{*}{ ¿Cuál fue el servicio principal que recibió hoy? } & Ginecología & 1 & PASE A 400 \\
& & Anticonceptivo inyectable & 2 & PASE A 500 \\
& & Inserción de DIU & 3 & PASE A 600 \\
& & Revisita de DIU & 4 & PASE A 700 \\
& & Visita para píldora & 5 & PASE A 800 \\
& & Cuidado prenatal & 6 & PASE A 900 \\
& & Otro: especificar & 88 & PASE AL \\
\hline
\end{tabular}

Basándose en la respuesta dada a esta pregunta, el entrevistador necesita hacer el pase correcto a la siguiente sección. Una vez que el entrevistador está en la sección correcta, deberá hacer todas las preguntas incluidas en dicha sección.

Si la mujer recibió dos o más servicios, el entrevistador deberá sondear y preguntar: “¿Cuál fue el principal servicio que recibió hoy?” En todos los casos, el entrevistado deberá identificar un servicio principal único. El entrevistado deberá identificar el servicio principal que recibió; el entrevistador no deberá identificarlo por él o por ella.

\section{PREGUNTAS SOBRE LA VOLUNTAD DE PAGO}

El énfasis de la encuesta radica en determinar la voluntad que tiene el cliente de pagar los servicios de salud reproductiva incluidos en este cuestionario.

La primera tarea que enfrenta el entrevistador consiste en determinar cuánto acaba de pagar el entrevistado por el servicio que recibió. Una vez que esté en la sección apropiada, el cuestionario le da instrucciones al entrevistador para que le diga al cliente cuál es el costo actual del servicio y enfatizar que éste es tan solo el costo del servicio principal que recibió pero que el precio total que pagó puede haber sido mayor. Después, se le pregunta al cliente si pagó el precio actual.

\begin{tabular}{|c|c|c|c|}
\hline P. & PREGUNTA & CODIGO DE RESPUESTA & PASE A \\
\hline 400 & \multicolumn{2}{|c|}{$\begin{array}{l}\text { LEER AL CLIENTE: } \\
\text { El precio actual de la consulta ginecológica es de I/10 Intis. Este es sólo el costo de la consulta, el } \\
\text { costo total puede haber sido mayor si el personal de la clínica le recomendó que le hicieran otros } \\
\text { exámenes. }\end{array}$} & \\
\hline 401 & ¿Pagó el precio de consulta mencionado arriba? & 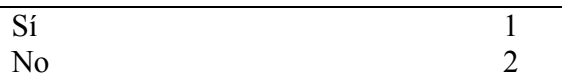 & PASE A 404 \\
\hline
\end{tabular}

Si el cliente respondió "no" en la pregunta 401, el entrevistador debe preguntar la razón. En este punto, el entrevistador deberá determinar si la diferencia se debe al costo de otros servicios que se hayan adquirido, a un adeudo anterior, o si se deben a que el cliente recibió un descuento porque no podía pagar el precio determinado. Esto quizá signifique que sea necesario preguntarle a los doctores o al cajero de la clínica. Si se determina que el 
cliente es demasiado pobre para pagar el precio actual del servicio, el entrevistador agradecerá al cliente y terminará la entrevista. Si la razón por la que se proporciona un precio distinto al precio estándar se debió a una confusión ocasionada por el hecho de haber realizado compras múltiples o por el pago de un adeudo anterior, el entrevistador deberá apuntar el precio estándar y continuar con la entrevista.

\begin{tabular}{|c|l|l|l|}
\hline P. & \multicolumn{1}{|c|}{ PREGUNTA } & \multicolumn{1}{|c|}{ CODIGO DE RESPUESTA } & PASE A \\
\hline 402 & ¿Cuánto pagó? & Cantidad: & \\
\hline 403 & $\begin{array}{l}\text { ¿Por qué pago más o menos que el precio } \\
\text { mencionado? }\end{array}$ & Razón: & \\
& $\begin{array}{l}\text { DETERMINE SI LA DIFERENCIA DE } \\
\text { PRECIO SE DEBE AL PAGO POR OTROS } \\
\text { SERVICIOS. SI ES ASÍ, CONTINUE CON LA } \\
\text { ENTREVISTA. SI NO, REGISTRE LA } \\
\text { RAZÓN Y TERMINE LA ENTREVISTA. }\end{array}$ & & \\
\end{tabular}

La segunda tarea del entrevistador consiste en leerle al cliente lo siguiente:

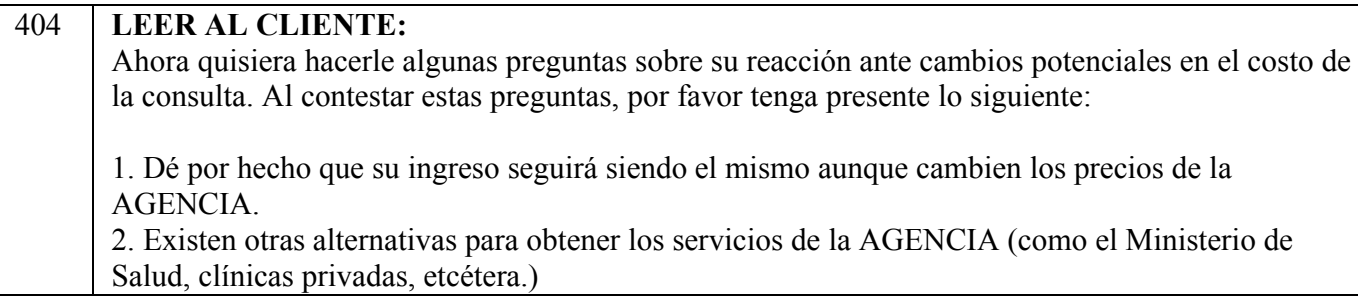

Es fundamental que el cliente comprenda los supuestos recién establecidos. .

La secuencia de preguntas de voluntad de pago (VDP). Una vez que el entrevistador haya verificado que el cliente pagó el precio actual y le haya leído los supuestos anteriores, deberá realizar las preguntas sobre los precios que el entrevistado estaría dispuesto a pagar. La secuencia de preguntas sobre la voluntad de pago consiste en realizar dos preguntas sobre aumentos de precio predeterminados, así como una tercera pregunta, abierta, para determinar la cantidad máxima que la persona entrevistada estaría dispuesta a pagar por el servicio

El primer paso para efectuar las preguntas de voluntad de pago consiste en decirle a la persona entrevistada que dé por hecho que el precio del servicio aumentará en una cantidad determinada, por ejemplo, en 5 Intis.

\begin{tabular}{|c|c|c|c|}
\hline P. & PREGUNTA & CODIGO DE RESPUESTA & PASE A \\
\hline 405 & $\begin{array}{l}\text { Suponga que el precio de la consulta ginecológica } \\
\text { aumentara en } \mathrm{I} / 5 \text { para llegar a } \mathrm{I} / 15 \text {. ¿Seguiría } \\
\text { usando la AGENCIA para sus consultas } \\
\text { ginecológicas si el precio fuera de } \mathrm{I} / 15 \text { ? }\end{array}$ & $\begin{array}{l}\text { Sí } \\
\text { No } \\
\text { No sé }\end{array}$ & $\begin{array}{l}\text { PASE A } 407 \\
\text { PASE A } 407\end{array}$ \\
\hline
\end{tabular}

Si el cliente está dispuesto a pagar un aumento de 5 Intis, continuamos con la siguiente pregunta (406) para determinar si también está dispuesto a pagar un aumento de precio mayor.

\begin{tabular}{|c|c|c|c|c|}
\hline $\mathbf{P}$. & PREGUNTA & \multicolumn{2}{|c|}{ CODIGO DE RESPUESTA } & PASE A \\
\hline 406 & $\begin{array}{l}\text { Suponga que el precio de la consulta ginecológica } \\
\text { aumentara aún más: en } \mathrm{I} / 10 \text { para llegar a } \mathrm{I} / 20 \text {. } \\
\text { ¿Seguiría usando la AGENCIA para sus consultas } \\
\text { ginecológicas si el precio fuera de } \mathrm{I} / 20 \text { ? }\end{array}$ & $\begin{array}{l}\text { Sí } \\
\text { No } \\
\text { No sé }\end{array}$ & $\begin{array}{l}1 \\
2 \\
99\end{array}$ & $\begin{array}{l}\text { PASE A } 408 \\
\text { PASE A } 408 \\
\text { PASE A } 408\end{array}$ \\
\hline
\end{tabular}

Si el cliente no está dispuesto a pagar un aumento de 5 Intis en la pregunta 405, entonces saltamos a la pregunta 407 para determinar si está dispuesto a pagar un aumento de precio menor. 


\begin{tabular}{|c|l|ll|c|}
\hline P. & PREGUNTA & CODIGO DE RESPUESTA & PASE A \\
\hline 407 & Suponga que el aumento de precio fuera menor & Sí & 2 & \\
& $\begin{array}{l}\text { que la cantidad previa. Suponga que el precio de la } \\
\text { consulta ginecológica aumentara en I/2 para llegar }\end{array}$ & No No sé & 99 & \\
& $\begin{array}{l}\text { a I/12. ¿Seguiría usando la AGENCIA para sus } \\
\text { consultas ginecológicas si el precio fuera de I/12? }\end{array}$ & & \\
\hline
\end{tabular}

Por favor, note usted que hay un total de tres preguntas cerradas sobre la voluntad de pago, pero que a ningún entrevistado se le harán más de dos de este tipo de preguntas.

A todos los clientes, sin importar cuáles fueron sus respuestas a las preguntas anteriores, se les hace la siguiente pregunta abierta acerca del precio máximo que estarían dispuestos a pagar por el servicio:

\begin{tabular}{|c|l|l|c|}
\hline P. & PREGUNTA & CODIGO DE RESPUESTA & PASE A \\
\hline 408 & $\begin{array}{l}\text { ¿Cuál sería el precio más alto que estaría dispuesto } \\
\text { a pagar por los servicios de ginecología de la } \\
\text { AGENCIA? }\end{array}$ & Cantidad _ & \\
\hline
\end{tabular}

Finalmente, se debe preguntar al cliente qué haría si el precio del servicio aumentara hasta el punto en que no quisiera o no pudiera pagarlo (preguntas 409 y 410). En el caso de métodos anticonceptivos, se incluye "Cambiar a un método más barato" como una opción de respuesta.

\begin{tabular}{|c|c|c|c|c|}
\hline P. & PREGUNTA & \multicolumn{2}{|c|}{ CODIGO DE RESPUESTA } & PASE A \\
\hline 409 & $\begin{array}{l}\text { Si la AGENCIA subiera el precio de los } \\
\text { servicios de ginecología más allá de lo que es } \\
\text { capaz o está dispuesto a pagar, ¿qué haría? }\end{array}$ & $\begin{array}{l}\text { Quedarme sin el servicio } \\
\text { Ir a otro lugar } \\
\text { No sé } \\
\text { Otro: especificar }\end{array}$ & $\begin{array}{l}1 \\
2 \\
99 \\
88\end{array}$ & $\begin{array}{ll}\text { PASE A } & 1000 \\
\text { PASE A } & 410 \\
\text { PASE A } & 1000 \\
\text { PASE A } & 1000\end{array}$ \\
\hline 410 & $\begin{array}{l}\text { ¿Adónde iría? } \\
\text { NO LEA LAS OPCIONES } \\
\text { MARQUE TODAS LAS MENCIONADAS }\end{array}$ & $\begin{array}{l}\text { Sector público } \\
\text { Otra ONG } \\
\text { Sector privado } \\
\text { Farmacia } \\
\text { Otro: especificar } \\
\text { No sé }\end{array}$ & $\begin{array}{l}1 \\
2 \\
3 \\
4 \\
88 \\
99\end{array}$ & $\begin{array}{ll}\text { PASE A } & 1000 \\
\text { PASE A } 1000 \\
\text { PASE A } 1000 \\
\text { PASE A } 1000 \\
\text { PASE A } 1000 \\
\text { PASE A } 1000\end{array}$ \\
\hline
\end{tabular}

Al final de esta sección, el entrevistador encontrará la instrucción de pase para que pueda transferir la entrevista a la pregunta 1000 y a la parte que resta por aplicar del cuestionario (vdp para usuarios potenciales y vdp para el mejoramiento de las instalaciones y de la calidad de los servicios). Estas preguntas se le hacen a todos los entrevistados que hayan completado la secuencia anterior de preguntas sobre voluntad de pago. 


\author{
Salud reproductiva \\ Voluntad de pago \\ Modelo del manual de códigos \\ Cuestionario modelo para usuarios potenciales y activos de servicios clínicos \\ (Entrevistas en los servicios) \\ The Population Council \\ Junio del 2001
}

DICCIONARIO DE DATOS Y GUIA DE CÓDIGOS

\begin{tabular}{|c|c|c|c|}
\hline $\mathbf{P}$. & $\begin{array}{c}\text { NOMBRE DE } \\
\text { VARIABLE }\end{array}$ & ETIQUETA DE VARIABLE & VALORES \\
\hline 1 & PARTIND & Indicador de Participación & $\begin{array}{ll}1 & \text { Sí } \\
2 & \text { No }\end{array}$ \\
\hline 2 & QUESNO & Número de Cuestionario & Código de 4-dígitos Rango 0001 - \\
\hline 3 & CLINICNO & Número de Clínica & $\begin{array}{ll}101 & \text { Clínica1 } \\
102 & \text { Clínica2 } \\
103 & \text { Clínica3 } \\
\end{array}$ \\
\hline 4 & INTNAME & Nombre del entrevistador & $\begin{array}{ll}101 & \text { Nombre1 } \\
102 & \text { Nombre2 } \\
103 & \text { Nombre3 }\end{array}$ \\
\hline 5 & INTDATE & Fecha de la entrevista & Día-Mes-Año \\
\hline 6 & TIMEBEG & Hora en que empezó la entrevista & $24: 00$ \\
\hline 7 & TIMEEND & Hora en que terminó la entrevista & $24: 00$ \\
\hline
\end{tabular}




\section{A. Preguntas demográficas}

\begin{tabular}{|c|c|c|c|}
\hline 100 & Edad & Edad en años cumplidos & Código de 2 dígitos \\
\hline 101 & MARITAL & Estado Civil & $\begin{array}{ll}1 & \text { Casado/a o Unión Libre } \\
2 & \text { Viudo/a, Separado/a, Divorciado/a } \\
3 & \text { Soltero/a } \\
\end{array}$ \\
\hline 102 & CHILDREN & Número TOTAL de hijos vivos & Código de 2 dígitos \\
\hline 103 & CHILD1 & $\begin{array}{l}\text { Número de hijos vivos menores de un } \\
\text { año }\end{array}$ & Código de 1 dígito \\
\hline 103 & CHILD2 & Número de hijos vivos de $1 \mathrm{a}-3$ años & Código de 1 dígito \\
\hline 103 & CHILD3 & $\begin{array}{l}\text { Número de hijos vivos de } 4 \text { o más años } \\
\text { de edad }\end{array}$ & Código de 2 dígitos \\
\hline 104 & EDULEVEL & $\begin{array}{l}\text { Grado de escolaridad más alto } \\
\text { completado }\end{array}$ & $\begin{array}{ll}00 & \text { No completó ningún grado } \\
1 & \text { Primer grado de primaria } \\
2 & \text { Segundo grado de primaria } \\
3 & \text { Tercer grado de primaria } \\
4 & \text { Cuarto grado de primaria } \\
5 & \text { Quinto grado de primaria } \\
6 & \text { Sexto grado de primaria } \\
7 & \text { Primero de secundaria } \\
8 & \text { Segundo de secundaria } \\
9 & \text { Tercero de secundaria } \\
10 & \text { Un año de preparatoria/Vocacional } \\
11 & \text { Dos años de preparatoria /Vocacional } \\
12 & \text { Tres años de preparatoria /Vocacional } \\
13 & \text { Un año de universidad } \\
14 & \text { Dos años de universidad } \\
15 & \text { Tres años de universidad } \\
16+ & \text { Cuatro o más años de universidad } \\
99 & \text { No hubo respuesta } \\
\end{array}$ \\
\hline
\end{tabular}

\section{B. Preguntas sobre capacidad de pago}

\begin{tabular}{|c|c|c|c|c|}
\hline 200 & HHELEC & ¿Su hogar tiene luz eléctrica? & $\begin{array}{l}1 \\
2 \\
99 \\
\end{array}$ & $\begin{array}{l}\text { Sí } \\
\text { No } \\
\text { No hubo respuesta }\end{array}$ \\
\hline 200 & HHWATER & ¿Su hogar tiene agua potable? & $\begin{array}{l}1 \\
2 \\
99\end{array}$ & $\begin{array}{l}\text { Sí } \\
\text { No } \\
\text { No hubo respuesta }\end{array}$ \\
\hline 200 & HHFLTOIL & ¿Su hogar tiene excusado? & $\begin{array}{l}1 \\
2 \\
99 \\
\end{array}$ & $\begin{array}{l}\text { Sí } \\
\text { No } \\
\text { No hubo respuesta }\end{array}$ \\
\hline 200 & HHRADIO & ¿Su hogar tiene radio? & $\begin{array}{l}1 \\
2 \\
99 \\
\end{array}$ & $\begin{array}{l}\text { Sí } \\
\text { No } \\
\text { No hubo respuesta }\end{array}$ \\
\hline 200 & HHTV & ¿Su hogar tiene televisión? & $\begin{array}{l}1 \\
2 \\
99\end{array}$ & $\begin{array}{l}\text { Sí } \\
\text { No } \\
\text { No hubo respuesta }\end{array}$ \\
\hline 200 & HHVCR & ¿Su hogar tiene videocasetera? & $\begin{array}{l}1 \\
2 \\
99 \\
\end{array}$ & $\begin{array}{l}\text { Sí } \\
\text { No } \\
\text { No hubo respuesta }\end{array}$ \\
\hline 200 & HHTELE & ¿Su hogar tiene teléfono? & $\begin{array}{l}1 \\
2 \\
99\end{array}$ & $\begin{array}{l}\text { Sí } \\
\text { No } \\
\text { No hubo respuesta }\end{array}$ \\
\hline 200 & HHVEHCL & ¿Su hogar tiene automóvil o camioneta? & $\begin{array}{l}1 \\
2 \\
99 \\
\end{array}$ & $\begin{array}{l}\text { Sí } \\
\text { No } \\
\text { No hubo respuesta }\end{array}$ \\
\hline 201 & WORKOUT & ¿Trabaja fuera del hogar? & $\begin{array}{l}1 \\
2 \\
99\end{array}$ & $\begin{array}{l}\text { Sí } \\
\text { No } \\
\text { No hubo respuesta }\end{array}$ \\
\hline 202 & JOBTYPE & ¿Qué tipo de trabajo tiene? & \multicolumn{2}{|c|}{ Transcribir la respuesta textualmente } \\
\hline 203 & MOINC1 & Ingreso mensual del entrevistado & \multicolumn{2}{|c|}{ Código de 4 dígitos } \\
\hline
\end{tabular}




\begin{tabular}{|c|c|c|c|c|c|}
\hline 204 & WORKPART & ¿Su pareja trabaja? & $\begin{array}{l}1 \\
2 \\
3 \\
99\end{array}$ & $\begin{array}{l}\text { Sí } \\
\text { No } \\
\text { No tiene pareja } \\
\text { No hubo respuesta }\end{array}$ & $\begin{array}{ll}\text { PASE A } 206 \\
\text { PASE A } 206 \\
\text { PASE A } 206\end{array}$ \\
\hline 204 & JOBTYPEP & Tipo de trabajo de la pareja & \multicolumn{3}{|c|}{ Transcribir la respuesta textualmente } \\
\hline 205 & MOINC2 & Ingreso mensual de la pareja & \multicolumn{3}{|c|}{ Código de 4 dígitos } \\
\hline 206 & SUPPORT & $\begin{array}{l}\text { ¿Quién proporciona el apoyo económico } \\
\text { a la familia? }\end{array}$ & $\begin{array}{l}1 \\
2 \\
3 \\
4\end{array}$ & \multicolumn{2}{|l|}{$\begin{array}{l}\text { Entrevistado } \\
\text { Esposo/a/pareja } \\
\text { Hijos } \\
\text { Otro }\end{array}$} \\
\hline 207 & INCTOTAL & $\begin{array}{l}\text { Ingreso familiar total - TODAS LAS } \\
\text { FUENTES }\end{array}$ & \multicolumn{3}{|c|}{ Código de 4 dígitos } \\
\hline
\end{tabular}

\section{Tipo de visita}

\begin{tabular}{|c|c|c|c|c|c|}
\hline 300 & VISIT1 & ¿Primera visita a la AGENCIA? & $\begin{array}{l}1 \\
2 \\
\end{array}$ & $\begin{array}{l}\text { Sí } \\
\text { No }\end{array}$ & PASE A 302 \\
\hline 301 & REVISIT & $\begin{array}{l}\text { ¿Revisita programada durante la visita } \\
\text { anterior? }\end{array}$ & $\begin{array}{l}1 \\
2\end{array}$ & $\begin{array}{l}\text { Sí } \\
\text { No }\end{array}$ & \\
\hline 302 & SERVICE & Principal servicio recibido & $\begin{array}{l}1 \\
2 \\
3 \\
4 \\
5 \\
6 \\
88\end{array}$ & $\begin{array}{l}\text { Ginecología } \\
\text { Anticonceptivo inyectable } \\
\text { Inserción de DIU } \\
\text { Revisita DIU } \\
\text { Visita para píldora } \\
\text { Prenatal } \\
\text { Otro }\end{array}$ & $\begin{array}{ll}\text { PASE A } 401 \\
\text { PASE A } 501 \\
\text { PASE A } 601 \\
\text { PASE A } 701 \\
\text { PASE A } 801 \\
\text { PASE A } 901 \\
\text { PASE AL FINAL }\end{array}$ \\
\hline
\end{tabular}

\section{Preguntas de voluntad de pago: usuarios activos.}

1. Ginecología

\begin{tabular}{|c|c|c|c|c|c|}
\hline 401 & GYNPAY & $\begin{array}{l}\text { ¿Pagó el precio establecido de la consulta } \\
\text { ginecológica? }\end{array}$ & $\begin{array}{l}1 \\
2 \\
99\end{array}$ & $\begin{array}{l}\text { Sí } \\
\text { No } \\
\text { No hubo respuesta }\end{array}$ & PASE A 405 \\
\hline 402 & GYNPAID & Cantidad pagada & \multicolumn{3}{|c|}{ Código de 2 dígitos } \\
\hline 403 & GYNREAS & $\begin{array}{l}\text { Razón por la que no se pagó el precio } \\
\text { establecido }\end{array}$ & \multicolumn{3}{|c|}{ Transcribir la respuesta textualmente } \\
\hline 405 & GYNWTPM & $\begin{array}{l}\text { Voluntad de pago de I/5 más por los } \\
\text { servicios de ginecología }\end{array}$ & $\begin{array}{l}1 \\
2 \\
99\end{array}$ & $\begin{array}{l}\text { Sí } \\
\text { No } \\
\text { No sé }\end{array}$ & $\begin{array}{l}\text { PASE A } 407 \\
\text { PASE A } 407\end{array}$ \\
\hline 406 & GYNWTPH & $\begin{array}{l}\text { Voluntad de pago de } \mathrm{I} / 10 \text { más por los } \\
\text { servicios de ginecología }\end{array}$ & $\begin{array}{l}1 \\
2 \\
99 \\
\end{array}$ & $\begin{array}{l}\text { Sí. } \\
\text { No } \\
\text { No sé }\end{array}$ & $\begin{array}{l}\text { PASE A } 408 \\
\text { PASE A } 408 \\
\text { PASE A } 408 \\
\end{array}$ \\
\hline 407 & GYNWTPL & $\begin{array}{l}\text { Voluntad de pago de } \mathrm{I} / 2 \text { más por los } \\
\text { servicios de ginecología }\end{array}$ & $\begin{array}{l}1 \\
2 \\
99\end{array}$ & $\begin{array}{l}\text { Sí } \\
\text { No } \\
\text { No sé }\end{array}$ & \\
\hline 408 & GYNWTPS & $\begin{array}{l}\text { Cantidad máxima de voluntad de pago } \\
\text { por los servicios de ginecología }\end{array}$ & \multicolumn{3}{|c|}{ Código de 3 dígitos } \\
\hline 409 & GYNALT & $\begin{array}{l}\text { ¿Qué haría si el precio fuera demasiado } \\
\text { alto? }\end{array}$ & $\begin{array}{l}1 \\
2 \\
88 \\
99\end{array}$ & $\begin{array}{l}\text { Quedarme sin el servicio } \\
\text { Ir a otro lugar } \\
\text { Otra } \\
\text { No sé }\end{array}$ & $\begin{array}{ll}\text { PASE A } & 1000 \\
\text { PASE A } & 410 \\
\text { PASE A } & 1000 \\
\text { PASE A } & 1000\end{array}$ \\
\hline 410 & GYNALTP & $\begin{array}{l}\text { Proveedor alternativo de servicios } \\
\text { ginecológicos si el precio fuera } \\
\text { demasiado alto }\end{array}$ & $\begin{array}{l}1 \\
2 \\
3 \\
4 \\
88 \\
99\end{array}$ & $\begin{array}{l}\text { Sector público } \\
\text { Otra ONG } \\
\text { Sector privado } \\
\text { Farmacia } \\
\text { Otra } \\
\text { No sé }\end{array}$ & $\begin{array}{ll}\text { PASE A } & 1000 \\
\text { PASE A } & 1000 \\
\text { PASE A } & 1000 \\
\text { PASE A } & 1000 \\
\text { PASE A } & 1000 \\
\text { PASE A } & 1000\end{array}$ \\
\hline
\end{tabular}


2. Anticonceptivo inyectable

\begin{tabular}{|c|c|c|c|c|c|}
\hline 501 & INCPAY & $\begin{array}{l}\text { ¿Pagó el precio establecido para la } \\
\text { consulta? }\end{array}$ & $\begin{array}{l}1 \\
2 \\
99\end{array}$ & $\begin{array}{l}\text { Sí } \\
\text { No } \\
\text { No hubo respuesta }\end{array}$ & PASE A 505 \\
\hline 502 & INCPAID & Cantidad pagada & \multicolumn{3}{|c|}{ Código de 3 dígitos } \\
\hline 503 & INCREAS & $\begin{array}{l}\text { Razón por la cual no pagó el precio } \\
\text { establecido }\end{array}$ & \multicolumn{3}{|c|}{ Transcribir la respuesta textualmente } \\
\hline 505 & INCWTPM & $\begin{array}{l}\text { Voluntad de pago de I/5 más por el } \\
\text { anticonceptivo inyectable }\end{array}$ & $\begin{array}{l}1 \\
2 \\
99 \\
\end{array}$ & $\begin{array}{l}\text { Sí } \\
\text { No } \\
\text { No sé }\end{array}$ & $\begin{array}{l}\text { PASE A } 507 \\
\text { PASE A } 507 \\
\end{array}$ \\
\hline 506 & INCWTPH & $\begin{array}{l}\text { Voluntad de pago de } \mathrm{I} / 10 \text { más por el } \\
\text { anticonceptivo inyectable }\end{array}$ & $\begin{array}{l}1 \\
2 \\
99 \\
\end{array}$ & $\begin{array}{l}\text { Sí } \\
\text { No } \\
\text { No sé }\end{array}$ & $\begin{array}{l}\text { PASE A } 508 \\
\text { PASE A } 508 \\
\text { PASE A } 508 \\
\end{array}$ \\
\hline 507 & INCWTPL & $\begin{array}{l}\text { Voluntad de pago de } \mathrm{I} / 3 \text { más por el } \\
\text { anticonceptivo inyectable }\end{array}$ & & $\begin{array}{l}\text { Sí } \\
\text { No } \\
\text { No sé } \\
\end{array}$ & \\
\hline 508 & INCWTPS & $\begin{array}{l}\text { Cantidad máxima de voluntad de pago } \\
\text { por el anticonceptivo inyectable. }\end{array}$ & \multicolumn{3}{|c|}{ Código de 3 dígitos } \\
\hline 509 & INCALT & $\begin{array}{l}\text { Proveedor de servicios alternativos si el } \\
\text { precio del anticonceptivo inyectable } \\
\text { fuera demasiado alto }\end{array}$ & $\begin{array}{l}1 \\
2 \\
3 \\
88 \\
99\end{array}$ & $\begin{array}{l}\text { No usar anticonceptivos } \\
\text { Ir a otro lugar } \\
\text { Cambiar a método más barato } \\
\text { Otro } \\
\text { No sé }\end{array}$ & $\begin{array}{ll}\text { PASE A } & 1000 \\
\text { PASE A } & 510 \\
\text { PASE A } & 1000 \\
\text { PASE A } & 1000 \\
\text { PASE A } & 1000\end{array}$ \\
\hline 510 & INCALTP & $\begin{array}{l}\text { Proveedor alternativo de anticonceptivo } \\
\text { inyectable si el precio fuera demasiado } \\
\text { alto }\end{array}$ & $\begin{array}{l}1 \\
2 \\
3 \\
4 \\
88 \\
99\end{array}$ & $\begin{array}{l}\text { Sector público } \\
\text { Otra ONG } \\
\text { Sector privado } \\
\text { Farmacia } \\
\text { Otro } \\
\text { No sé }\end{array}$ & $\begin{array}{ll}\text { PASE A } & 1000 \\
\text { PASE A } & 1000 \\
\text { PASE A } 1000 \\
\text { PASE A } 1000 \\
\text { PASE A } 1000 \\
\text { PASE A } 1000\end{array}$ \\
\hline
\end{tabular}

\section{Inserción de DIU}

\begin{tabular}{|c|c|c|c|c|c|}
\hline 601 & IUDPAY & $\begin{array}{l}\text { ¿Pagó el precio establecido para la } \\
\text { consulta? }\end{array}$ & $\begin{array}{l}1 \\
2 \\
99\end{array}$ & $\begin{array}{l}\text { Sí } \\
\text { No } \\
\text { No hubo respuesta }\end{array}$ & PASE A 605 \\
\hline 602 & IUDPAID & Cantidad pagada & \multicolumn{3}{|c|}{ Código de 2 dígitos } \\
\hline 603 & IUDREAS & $\begin{array}{l}\text { Razón por la que no se pagó el precio } \\
\text { establecido }\end{array}$ & \multicolumn{3}{|c|}{ Transcribir la respuesta textualmente } \\
\hline 605 & IUDWTPM & $\begin{array}{l}\text { Voluntad de pago de I/5 más por la } \\
\text { inserción de DIU }\end{array}$ & $\begin{array}{l}1 \\
2 \\
99\end{array}$ & $\begin{array}{l}\text { Sí } \\
\text { No } \\
\text { No sé }\end{array}$ & $\begin{array}{l}\text { PASE A } 607 \\
\text { PASE A } 607\end{array}$ \\
\hline 606 & IUDWTPH & $\begin{array}{l}\text { Voluntad de pago de I/10 más por la } \\
\text { inserción de DIU }\end{array}$ & $\begin{array}{l}1 \\
2 \\
99\end{array}$ & $\begin{array}{l}\text { Sí } \\
\text { No } \\
\text { No sé }\end{array}$ & $\begin{array}{l}\text { PASE A } 608 \\
\text { PASE A } 608 \\
\text { PASE A } 608\end{array}$ \\
\hline 607 & IUDWTPL & $\begin{array}{l}\text { Voluntad de pago de I/3 más por la } \\
\text { inserción de DIU }\end{array}$ & & $\begin{array}{l}\text { Sí } \\
\text { No } \\
\text { No sé }\end{array}$ & \\
\hline 608 & IUDWTPS & $\begin{array}{l}\text { Cantidad máxima de voluntad de pago } \\
\text { por la inserción de DIU. }\end{array}$ & \multicolumn{3}{|c|}{ Código de 3 dígitos } \\
\hline 609 & IUDALT & $\begin{array}{l}\text { ¿Qué haría si el precio fuera demasiado } \\
\text { alto? }\end{array}$ & $\begin{array}{l}1 \\
2 \\
3 \\
88 \\
99 \\
\end{array}$ & $\begin{array}{l}\text { No usar anticonceptivos } \\
\text { Ir a otro lugar } \\
\text { Cambiar a método más } \\
\text { Otro } \\
\text { No sé }\end{array}$ & $\begin{array}{cl}\text { PASE A } & 1000 \\
\text { PASE A } & 610 \\
\text { oPASE A } & 1000 \\
\text { PASE A } 1000 \\
\text { PASE A } 1000 \\
\end{array}$ \\
\hline 610 & INCALTP & $\begin{array}{l}\text { Proveedor alternativo de inserción del } \\
\text { DIU si el precio fuera demasiado alto }\end{array}$ & $\begin{array}{l}1 \\
2 \\
3 \\
4 \\
88 \\
99\end{array}$ & $\begin{array}{l}\text { Sector público } \\
\text { Otra ONG } \\
\text { Sector privado } \\
\text { Farmacia } \\
\text { Otro } \\
\text { No sé }\end{array}$ & $\begin{array}{ll}\text { PASE A } & 1000 \\
\text { PASE A } 1000 \\
\text { PASE A } 1000 \\
\text { PASE A } 1000 \\
\text { PASE A } 1000 \\
\text { PASE A } 1000\end{array}$ \\
\hline
\end{tabular}


4. Revisita de DIU

\begin{tabular}{|c|c|c|c|c|c|}
\hline 701 & IREPAY & $\begin{array}{l}\text { ¿Pagó el precio establecido por la } \\
\text { consulta? }\end{array}$ & $\begin{array}{l}1 \\
2 \\
99\end{array}$ & $\begin{array}{l}\text { Sí } \\
\text { No } \\
\text { No sé }\end{array}$ & PASE A 705 \\
\hline 702 & IREPAID & Cantidad pagada & \multicolumn{3}{|c|}{ Código de 2 dígitos } \\
\hline 703 & IREREAS & $\begin{array}{l}\text { Razón por la que no se pagó el precio } \\
\text { establecido }\end{array}$ & \multicolumn{3}{|c|}{ Transcribir la respuesta textualmente } \\
\hline 705 & IREWTPM & $\begin{array}{l}\text { Voluntad de pago de I/5 más por la } \\
\text { revisita de DIU }\end{array}$ & $\begin{array}{l}1 \\
2 \\
99 \\
\end{array}$ & $\begin{array}{l}\text { Sí } \\
\text { No } \\
\text { No sé }\end{array}$ & $\begin{array}{l}\text { PASE A } 707 \\
\text { PASE A } 707\end{array}$ \\
\hline 706 & IREWTPH & $\begin{array}{l}\text { Voluntad de pago de } \mathrm{I} / 10 \text { más por la } \\
\text { revisita de DIU }\end{array}$ & $\begin{array}{l}1 \\
2 \\
99\end{array}$ & $\begin{array}{l}\text { Sí } \\
\text { No } \\
\text { No sé }\end{array}$ & $\begin{array}{l}\text { PASE A } 708 \\
\text { PASE A } 708 \\
\text { PASE A } 708\end{array}$ \\
\hline 707 & IREWTPL & $\begin{array}{l}\text { Voluntad de pago de I/2 más por la } \\
\text { revisita de DIU }\end{array}$ & $\begin{array}{l}1 \\
2 \\
99\end{array}$ & $\begin{array}{l}\text { Sí } \\
\text { No } \\
\text { No sé }\end{array}$ & \\
\hline 708 & IREWTPS & $\begin{array}{l}\text { Máxima voluntad de pago por la revisita } \\
\text { de DIU }\end{array}$ & \multicolumn{3}{|c|}{ Código de tres } \\
\hline 709 & IREALT & $\begin{array}{l}\text { ¿Qué haría si el precio fuera demasiado } \\
\text { alto? }\end{array}$ & $\begin{array}{l}1 \\
2 \\
88 \\
99\end{array}$ & $\begin{array}{l}\text { Quedarme sin el servicio } \\
\text { Ir a otro lugar } \\
\text { Otro } \\
\text { No sé }\end{array}$ & $\begin{array}{ll}\text { PASE A } & 1000 \\
\text { PASE A } & 710 \\
\text { PASE A } & 1000 \\
\text { PASE A } & 1000\end{array}$ \\
\hline 710 & IREALTP & $\begin{array}{l}\text { Proveedor alternativo para la revisita de } \\
\text { DIU si el precio fuera demasiado alto }\end{array}$ & $\begin{array}{l}1 \\
2 \\
3 \\
4 \\
88 \\
99 \\
\end{array}$ & $\begin{array}{l}\text { Sector público } \\
\text { Otra ONG } \\
\text { Sector privado } \\
\text { Farmacia } \\
\text { Otro } \\
\text { No sé }\end{array}$ & $\begin{array}{ll}\text { PASE A } & 1000 \\
\text { PASE A } & 1000 \\
\text { PASE A } & 1000 \\
\text { PASE A } & 1000 \\
\text { PASE A } & 1000 \\
\text { PASE A } & 1000\end{array}$ \\
\hline
\end{tabular}

5. Compra de la píldora

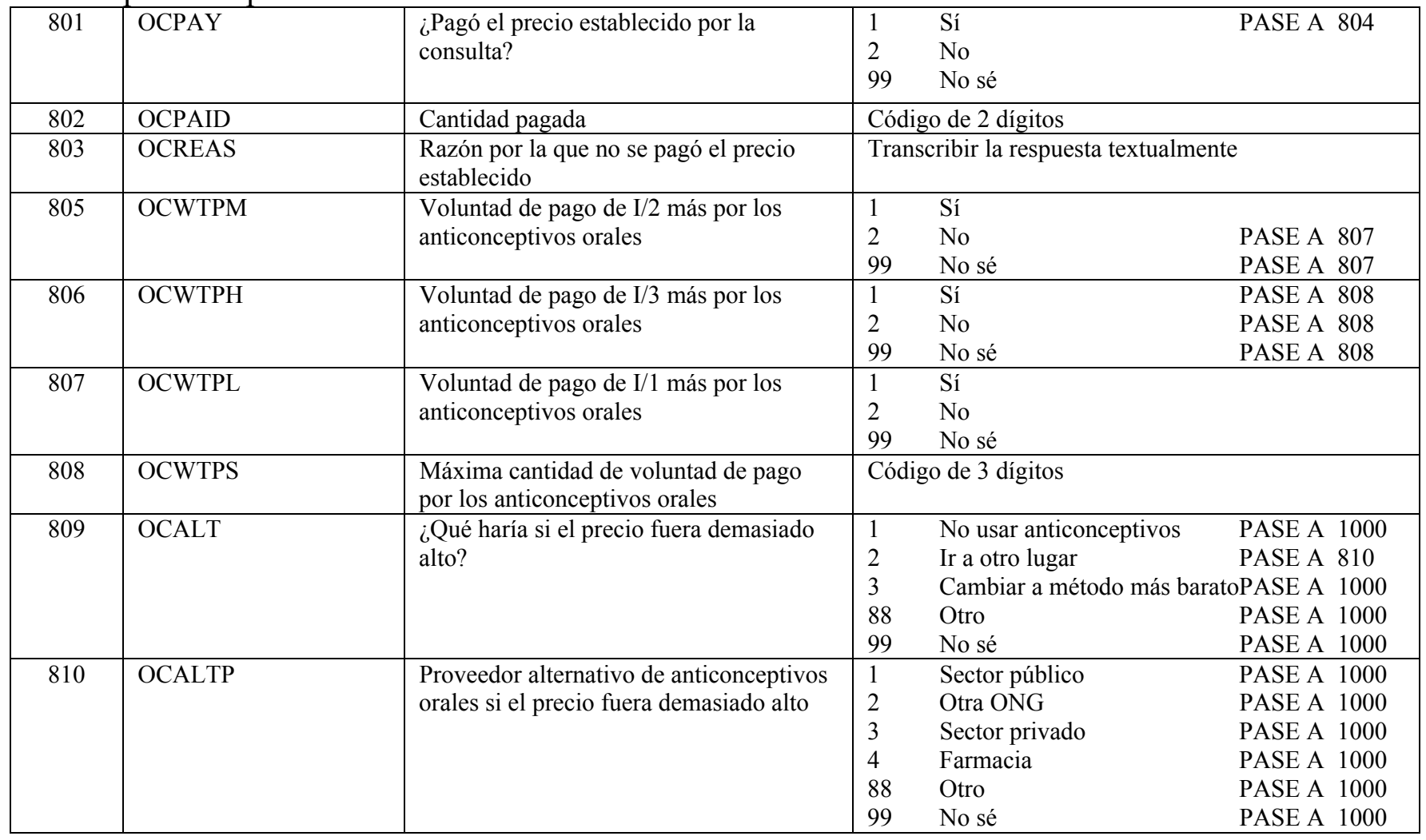


6.Cuidado prenatal

\begin{tabular}{|c|c|c|c|c|c|}
\hline 901 & PNCPAY & $\begin{array}{l}\text { ¿Pagó el precio establecido por la } \\
\text { consulta? }\end{array}$ & $\begin{array}{l}1 \\
2 \\
99\end{array}$ & $\begin{array}{l}\text { Sí } \\
\text { No } \\
\text { No sé }\end{array}$ & PASE A 905 \\
\hline 902 & PNCPAID & Cantidad pagada & \multicolumn{3}{|c|}{ Código de 3 dígitos } \\
\hline 903 & PNCREAS & $\begin{array}{l}\text { Razón por la que no se pagó el precio } \\
\text { establecido }\end{array}$ & \multicolumn{3}{|c|}{ Transcribir la respuesta textualmente } \\
\hline 905 & PNCWTPM & $\begin{array}{l}\text { Voluntad de pago de I/5 más por una } \\
\text { consulta de cuidado prenatal }\end{array}$ & $\begin{array}{l}1 \\
2 \\
99 \\
\end{array}$ & $\begin{array}{l}\text { Sí } \\
\text { No } \\
\text { No sé }\end{array}$ & $\begin{array}{l}\text { PASE A } 907 \\
\text { PASE A } 907\end{array}$ \\
\hline 906 & PNCWTPH & $\begin{array}{l}\text { Voluntad de pago de I/10 más por una } \\
\text { consulta de cuidado prenatal }\end{array}$ & $\begin{array}{l}1 \\
2 \\
99\end{array}$ & $\begin{array}{l}\text { Sí } \\
\text { No } \\
\text { No sé }\end{array}$ & $\begin{array}{l}\text { PASE A } 908 \\
\text { PASE A } 908 \\
\text { PASE A } 908 \\
\end{array}$ \\
\hline 907 & PNCWTPL & $\begin{array}{l}\text { Voluntad de pago de } \mathrm{I} / 2 \text { más por una } \\
\text { consulta de cuidado prenatal }\end{array}$ & & $\begin{array}{l}\text { Sí } \\
\text { No } \\
\text { No sé }\end{array}$ & \\
\hline 908 & PNCWTPS & $\begin{array}{l}\text { Cantidad máxima de voluntad de pago } \\
\text { por una consulta de cuidado prenatal. }\end{array}$ & \multicolumn{3}{|c|}{ Código de 3 dígitos } \\
\hline 909 & PNCALT & $\begin{array}{l}\text { ¿Qué haría si el precio fuera demasiado } \\
\text { alto? }\end{array}$ & $\begin{array}{l}1 \\
2 \\
88 \\
99 \\
\end{array}$ & $\begin{array}{l}\text { Quedarme sin el servicio } \\
\text { Ir a otro lugar } \\
\text { Otro } \\
\text { No sé }\end{array}$ & $\begin{array}{ll}\text { PASE A } 1000 \\
\text { PASE A } 910 \\
\text { PASE A } 1000 \\
\text { PASE A } 1000 \\
\end{array}$ \\
\hline 910 & PNCALTP & $\begin{array}{l}\text { Proveedor alternativo de consulta de } \\
\text { cuidado prenatal si el precio fuera } \\
\text { demasiado alto }\end{array}$ & $\begin{array}{l}1 \\
2 \\
3 \\
4 \\
88 \\
99 \\
\end{array}$ & $\begin{array}{l}\text { Sector público } \\
\text { Otra ONG } \\
\text { Sector privado } \\
\text { Farmacia } \\
\text { Otro } \\
\text { No sé }\end{array}$ & $\begin{array}{ll}\text { PASE A } & 1000 \\
\text { PASE A } & 1000 \\
\text { PASE A } & 1000 \\
\text { PASE A } & 1000 \\
\text { PASE A } & 1000 \\
\text { PASE A } & 1000\end{array}$ \\
\hline
\end{tabular}

\section{E. Preguntas VDP: usuarios potenciales}

1. Esterilización femenina

\begin{tabular}{|c|c|c|c|c|c|}
\hline 1000 & VSCKNOW & $\begin{array}{l}\text { ¿Ha oído hablar de la cirugía } \\
\text { anticonceptiva voluntaria? }\end{array}$ & $\begin{array}{l}1 \\
2 \\
99\end{array}$ & $\begin{array}{l}\text { Sí } \\
\text { No } \\
\text { No sé }\end{array}$ & $\begin{array}{l}\text { PASE A } 1100 \\
\text { PASE A } 1100 \\
\end{array}$ \\
\hline 1001 & VSCINT & $\begin{array}{l}\text { Interés futuro en CAV (en los próximos } \\
\text { dos años) }\end{array}$ & $\begin{array}{l}1 \\
2 \\
3 \\
99 \\
\end{array}$ & $\begin{array}{l}\text { Sí } \\
\text { No } \\
\text { Ya la tuve } \\
\text { No sé }\end{array}$ & $\begin{array}{ll}\text { PASE A } & 1100 \\
\text { PASE A } & 1100 \\
\text { PASE A } 1100 \\
\end{array}$ \\
\hline 1003 & VSCWTPM & $\begin{array}{l}\text { Voluntad de pago de I/200 por la } \\
\text { operación. }\end{array}$ & $\begin{array}{l}1 \\
2 \\
99 \\
\end{array}$ & $\begin{array}{l}\text { Sí } \\
\text { No } \\
\text { No sé }\end{array}$ & $\begin{array}{l}\text { PASE A } 1105 \\
\text { PASE A } 1105\end{array}$ \\
\hline 1004 & VSCWTPH & $\begin{array}{l}\text { Voluntad de pago de I/300 por la } \\
\text { operación. }\end{array}$ & $\begin{array}{l}1 \\
2 \\
99 \\
\end{array}$ & $\begin{array}{l}\text { Sí } \\
\text { No } \\
\text { No sé }\end{array}$ & $\begin{array}{ll}\text { PASE A } 1106 \\
\text { PASE A } 1106 \\
\text { PASE A } 1106 \\
\end{array}$ \\
\hline 1005 & VSCWTPL & $\begin{array}{l}\text { Voluntad de pago de } \mathrm{I} / 100 \text { por la } \\
\text { operación. }\end{array}$ & $\begin{array}{l}1 \\
2 \\
99 \\
\end{array}$ & $\begin{array}{l}\text { Sí } \\
\text { No } \\
\text { No sé } \\
\end{array}$ & \\
\hline 1006 & VSCWTPS & $\begin{array}{l}\text { Cantidad máxima de voluntad de pago } \\
\text { por la operación. }\end{array}$ & \multicolumn{3}{|c|}{ Código de 4 dígitos } \\
\hline 1007 & VSCALT & $\begin{array}{l}\text { Alternativa a la CAV si el precio fuera } \\
\text { demasiado alto }\end{array}$ & $\begin{array}{l}1 \\
2 \\
88 \\
99\end{array}$ & $\begin{array}{l}\text { Quedarme sin el servicio } \\
\text { Ir a otro lugar } \\
\text { Otro } \\
\text { No sé }\end{array}$ & $\begin{array}{ll}\text { PASE A } & 1008 \\
\text { PASE A } & 1009 \\
\text { PASE A } 1100 \\
\text { PASE A } 1100\end{array}$ \\
\hline 1008 & CONTCONT & $\begin{array}{l}\text { Si no se operara, ¿seguiría utilizando } \\
\text { anticonceptivos? }\end{array}$ & $\begin{array}{l}1 \\
2 \\
99 \\
\end{array}$ & $\begin{array}{l}\text { Sí } \\
\text { No } \\
\text { No sé }\end{array}$ & $\begin{array}{ll}\text { PASE A } & 1100 \\
\text { PASE A } & 1100 \\
\text { PASE A } 1100 \\
\end{array}$ \\
\hline
\end{tabular}




\begin{tabular}{|l|l|l|ll|}
\hline 1009 & VSCALTP & Proveedor alternativo de CAV si el & 1 & Sector público \\
& & precio fuera demasiado alto & 2 & Otra ONG \\
& & & 3 & Sector privado \\
& & & 88 & Otro \\
& & 99 & No sé \\
\hline
\end{tabular}

\section{F. VDP por mejoramiento de las instalaciones y la calidad del servicio}

A. VDP por reducciones en el tiempo de espera

\begin{tabular}{|c|c|c|c|c|c|}
\hline 1100 & WAITTIME & Cantidad de tiempo de espera antes de & \multicolumn{3}{|c|}{ Tiempo en minutos } \\
\hline 1101 & WTPERC & $\begin{array}{l}\text { ¿Qué opina de esta cantidad de tiempo de } \\
\text { espera? }\end{array}$ & & $\begin{array}{l}\text { Excesivo } \\
\text { Razonable } \\
\text { Corto }\end{array}$ & \\
\hline 1102 & WTWTPM & $\begin{array}{l}\text { Voluntad de pago de I/3 más por } \\
\text { reducciones en el tiempo de espera }\end{array}$ & $\begin{array}{l}1 \\
2 \\
99 \\
\end{array}$ & $\begin{array}{l}\text { Sí } \\
\text { No } \\
\text { No sé } \\
\end{array}$ & $\begin{array}{l}\text { PASE A } 1104 \\
\text { PASE A } 1104\end{array}$ \\
\hline 1103 & WTWTPH & $\begin{array}{l}\text { Voluntad de pago de I/6 más por } \\
\text { reducciones en el tiempo de espera }\end{array}$ & $\begin{array}{l}1 \\
2 \\
99\end{array}$ & $\begin{array}{l}\text { Sí } \\
\text { No } \\
\text { No sé }\end{array}$ & $\begin{array}{ll}\text { PASE A } & 1105 \\
\text { PASE A } & 1105 \\
\text { PASE A } & 1105\end{array}$ \\
\hline 1104 & WTWTPL & $\begin{array}{l}\text { Voluntad de pago de } \mathrm{I} / 1 \text { más por } \\
\text { reducciones en el tiempo de espera }\end{array}$ & & $\begin{array}{l}\text { Sí } \\
\text { No } \\
\text { No sé }\end{array}$ & \\
\hline 1105 & WTWTPS & $\begin{array}{l}\text { Cantidad máxima de voluntad de pago } \\
\text { por reducciones en el tiempo de espera. }\end{array}$ & & o de 2 dígitos & \\
\hline
\end{tabular}

B. VDP por consejería

\begin{tabular}{|c|c|c|c|c|c|}
\hline 1200 & CNSLTIME & $\begin{array}{l}\text { Cantidad de tiempo que el proveedor } \\
\text { pasó dando consejería al cliente }\end{array}$ & \multicolumn{3}{|c|}{ Tiempo en minutos } \\
\hline 1201 & CNSLPERC & $\begin{array}{l}\text { ¿Qué opina de la cantidad del tiempo de } \\
\text { consejería? }\end{array}$ & & $\begin{array}{l}\text { Excesivo } \\
\text { Razonable } \\
\text { Corto }\end{array}$ & PASE A 1300 \\
\hline 1202 & CNSWTPM & $\begin{array}{l}\text { Voluntad de pago de } \mathrm{I} / 3 \text { más por } \\
\text { aumentos en el tiempo de consejería }\end{array}$ & $\begin{array}{l}1 \\
2 \\
99 \\
\end{array}$ & $\begin{array}{l}\text { Sí } \\
\text { No } \\
\text { No sé }\end{array}$ & $\begin{array}{ll}\text { PASE A } 1204 \\
\text { PASE A } 1204\end{array}$ \\
\hline 1203 & CNSWTPH & $\begin{array}{l}\text { Voluntad de pago de I/6 más por } \\
\text { aumentos en el tiempo de consejería }\end{array}$ & $\begin{array}{l}1 \\
2 \\
99\end{array}$ & $\begin{array}{l}\text { Sí } \\
\text { No } \\
\text { No sé }\end{array}$ & $\begin{array}{ll}\text { PASE A } & 1205 \\
\text { PASE A } & 1205 \\
\text { PASE A } & 1205\end{array}$ \\
\hline 1204 & CNSWTPL & $\begin{array}{l}\text { Voluntad de pago de I/1 más por } \\
\text { aumentos en el tiempo de consejería }\end{array}$ & & $\begin{array}{l}\text { Sí } \\
\text { No } \\
\text { No sé }\end{array}$ & \\
\hline 1205 & CNSWTPS & $\begin{array}{l}\text { Máxima cantidad de voluntad de pago } \\
\text { por aumentos en el tiempo de consejería }\end{array}$ & & o de 2 dígito & \\
\hline
\end{tabular}

C. VDP por mejoramiento de las instalaciones de la clínica

\begin{tabular}{|c|l|l|ll|}
\hline 1301 & WRCHAIR & Importancia para el entrevistado de tener & 1 & No muy importante \\
& & sillas más cómodas en la sala de espera & 2 & \\
& & & 3 & \\
& & 4 & \\
\hline 1301 & WRAC & Importancia para el entrevistado de tener & 5 & Muy importante \\
& & aire acondicionado en la sala de espera & 2 & \\
& & & 3 & \\
& & & 4 & \\
& & & 5 & Muy importante \\
\hline
\end{tabular}




\begin{tabular}{|c|c|c|c|c|c|}
\hline 1301 & WRTV & $\begin{array}{l}\text { Importancia para el entrevistado de tener } \\
\text { televisión en la sala de espera }\end{array}$ & $\begin{array}{l}1 \\
2 \\
3 \\
4 \\
5\end{array}$ & No muy importante & \\
\hline 1302 & MOSTIMP & $\begin{array}{l}\text { Mejora más importante en la opinión del } \\
\text { entrevistado }\end{array}$ & $\begin{array}{l}1 \\
2 \\
3\end{array}$ & $\begin{array}{l}\text { Sillas más cómodas } \\
\text { Aire acondicionado } \\
\text { Televisión }\end{array}$ & $\begin{array}{ll}\text { PASE A } 1303 \\
\text { PASE A } 1307 \\
\text { PASE A } 1311 \\
\end{array}$ \\
\hline 1303 & CHWTPM & $\begin{array}{l}\text { Voluntad de pago de } \mathrm{I} / 3 \text { más por la } \\
\text { disponibilidad de sillas más cómodas en } \\
\text { la sala de espera }\end{array}$ & $\begin{array}{l}1 \\
2 \\
99\end{array}$ & $\begin{array}{l}\text { Sí } \\
\text { No } \\
\text { No sé }\end{array}$ & $\begin{array}{ll}\text { PASE A } & 1305 \\
\text { PASE A } & 1305\end{array}$ \\
\hline 1304 & CHWTPH & $\begin{array}{l}\text { Voluntad de pago de I/6 más por la } \\
\text { disponibilidad de sillas más cómodas en } \\
\text { la sala de espera }\end{array}$ & $\begin{array}{l}1 \\
2 \\
99\end{array}$ & $\begin{array}{l}\text { Sí } \\
\text { No } \\
\text { No sé }\end{array}$ & $\begin{array}{ll}\text { PASE A } 1306 \\
\text { PASE A } 1306 \\
\text { PASE A } 1306\end{array}$ \\
\hline 1305 & CHWTPL & $\begin{array}{l}\text { Voluntad de pago de } \mathrm{I} / 1 \text { más por la } \\
\text { disponibilidad de sillas más cómodas en } \\
\text { la sala de espera }\end{array}$ & $\begin{array}{l}1 \\
2 \\
99\end{array}$ & $\begin{array}{l}\text { Sí } \\
\text { No } \\
\text { No sé }\end{array}$ & \\
\hline 1306 & CHWTPS & $\begin{array}{l}\text { Máxima cantidad de voluntad de pago } \\
\text { por la disponibilidad de sillas más } \\
\text { cómodas en la sala de espera. }\end{array}$ & \multicolumn{3}{|c|}{ Código de 2 dígitos } \\
\hline 1307 & ACWTPM & $\begin{array}{l}\text { Voluntad de pago de } \mathrm{I} / 3 \text { más por la } \\
\text { disponibilidad de aire acondicionado en } \\
\text { la sala de espera }\end{array}$ & $\begin{array}{l}1 \\
2 \\
99\end{array}$ & $\begin{array}{l}\text { Sí } \\
\text { No } \\
\text { No sé }\end{array}$ & $\begin{array}{ll}\text { PASE A } 1309 \\
\text { PASE A } 1309\end{array}$ \\
\hline 1308 & ACWTPH & $\begin{array}{l}\text { Voluntad de pago de I/6 más por la } \\
\text { disponibilidad de aire acondicionado en } \\
\text { la sala de espera }\end{array}$ & $\begin{array}{l}1 \\
2 \\
99 \\
\end{array}$ & $\begin{array}{l}\text { Sí } \\
\text { No } \\
\text { No sé }\end{array}$ & $\begin{array}{ll}\text { PASE A } 1310 \\
\text { PASE A } 1310 \\
\text { PASE A } 1310 \\
\end{array}$ \\
\hline 1309 & ACWTPL & $\begin{array}{l}\text { Voluntad de pago de } \mathrm{I} / 1 \text { más por la } \\
\text { disponibilidad de aire acondicionado en } \\
\text { la sala de espera }\end{array}$ & $\begin{array}{l}1 \\
2 \\
99\end{array}$ & $\begin{array}{l}\text { Sí } \\
\text { No } \\
\text { No sé }\end{array}$ & \\
\hline 1310 & ACWTPS & $\begin{array}{l}\text { Máxima cantidad de voluntad de pago } \\
\text { por la disponibilidad de aire } \\
\text { acondicionado en la sala de espera. }\end{array}$ & \multicolumn{3}{|c|}{ Código de 2 dígitos } \\
\hline 1311 & TVWTPM & $\begin{array}{l}\text { Voluntad de pago de I/3 más por la } \\
\text { disponibilidad de aire acondicionado en } \\
\text { la sala de espera. }\end{array}$ & $\begin{array}{l}1 \\
2 \\
99\end{array}$ & $\begin{array}{l}\text { Sí } \\
\text { No } \\
\text { No sé }\end{array}$ & $\begin{array}{ll}\text { PASE A } & 1313 \\
\text { PASE A } & 1313\end{array}$ \\
\hline 1312 & TVWTPH & $\begin{array}{l}\text { Voluntad de pago de } \mathrm{I} / 6 \text { más por la } \\
\text { disponibilidad de televisión en la sala de } \\
\text { espera }\end{array}$ & $\begin{array}{l}1 \\
2 \\
99 \\
\end{array}$ & $\begin{array}{l}\text { Sí } \\
\text { No } \\
\text { No sé }\end{array}$ & $\begin{array}{ll}\text { PASE A } 1314 \\
\text { PASE A } 1314 \\
\text { PASE A } 1314 \\
\end{array}$ \\
\hline 1313 & TVWTPL & $\begin{array}{l}\text { Voluntad de pago de } \mathrm{I} / 1 \text { más por la } \\
\text { disponibilidad de televisión en la sala de } \\
\text { espera }\end{array}$ & & $\begin{array}{l}\text { Sí } \\
\text { No } \\
\text { No sé }\end{array}$ & \\
\hline 1314 & TVWTPS & $\begin{array}{l}\text { Máxima cantidad de voluntad de pago } \\
\text { por la disponibilidad de televisión en la } \\
\text { sala de espera. }\end{array}$ & \multicolumn{3}{|c|}{ Código de 2 dígitos } \\
\hline
\end{tabular}

\begin{tabular}{|l|l|l|lc} 
FIN & FIN & FIN & FIN & FIN
\end{tabular}

